Otto-Friedrich-Universität Bamberg

Fakultät Sozial- und Wirtschaftswissenschaften

Institut für Politikwissenschaft

\title{
Electoral Incentives, Critical Actors, and the Substantive Representation of Women in Parliament
}

Kumulative Dissertation zur Erlangung des Doktorgrades im Fach Politikwissenschaft (Dr. rer. Pol.).

Eingereicht an der Fakultät Sozial- und Wirtschaftswissenschaften der OttoFriedrich-Universität Bamberg.

Vorgelegt von

Daniel Höhmann, M.A.

geboren am 18.06.1989 in Gütersloh.

Bamberg, 21. Juli 2020 


\section{Mitglieder der Promotionskommission}

Erstgutachter

Zweitgutachter

Drittgutachterin
Prof. Dr. Ulrich Sieberer

Otto-Friedrich-Universität Bamberg

Prof. Dr. Thomas Saalfeld

Otto-Friedrich-Universität Bamberg

Prof. Dr. Stefanie Bailer

Universität Basel

Datum der Disputation: 08.02.2021

Ort der Disputation: Bamberg, Deutschland

Dieses Werk ist als freie Onlineversion über das Forschungsinformationssystem (FIS; https://fis.uni-bamberg.de) der Universität Bamberg erreichbar. Das

Werk steht unter der CC-Lizenz CC-BY-NC.

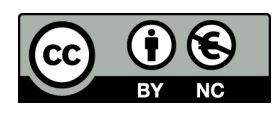

URN: urn:nbn:de:bvb:473-irb-497055

DOI: https://doi.org/10.20378/irb-49705 


\section{Inhaltsverzeichnis}

Rahmenpapier Electoral Incentives, Critical Actors, and the Substantive Representation of Women in Parliament.

Aufsatz 1

When Do Female MPs Represent Women's Interests? Electoral Systems and the Legislative Behavior of Women. Political Research Quarterly 73(4): 834-847, https://doi.org/10.1177/1065912919859437.

Aufsatz 2

When Do Men Represent Women's Interests in Parliament? How the Presence of Women in Parliament Affects the Legislative Behavior of Male Politicians. Swiss Political Science Review 26(1): 3150, https://doi.org/10.1111/spsr.12392.

Aufsatz 3

Male MPs, Electoral Vulnerability, and the Substantive

Representation of Women's Interests. Unveröffentlichtes Manuskript. 


\section{Rahmenpapier}

Electoral Incentives, Critical Actors, and the Substantive Representation of Women in Parliament. 


\section{Formal Requirements}

The following dissertation is submitted to the Faculty of Social Sciences, Economics, and Business Administration at the University of Bamberg in fulfillment of the requirements for receiving the degree of a "doctor rerum politicarum" (Dr. rer. pol.). This dissertation consists of three individual research papers and one comprehensive framework paper.

The first paper, "When Do Female MPs Represent Women's Interests? Electoral Systems and the Legislative Behavior of Women", has been accepted for publication in Political Research Quarterly, and is available as an 'OnlineFirst' article on the journal's homepage (https://doi.org/10.1177/1065912919859437). The journal is peer-reviewed and officially ranked in the 2018 Social Science Citation Index (SSCI, 5-Year Impact Factor: 2.05). The second paper, "When Do Men Represent Women's Interests in Parliament? How the Presence of Women in Parliament Affects the Legislative Behavior of Male Politicians", is published in the Swiss Political Science Review (Issue 26, Number 1, https://doi.org/10.1111/spsr.12392). The journal is also peer-reviewed and listed in the SSCI (5-Year Impact Factor: 1.71). The third paper, "Male MPs, Electoral Vulnerability, and the Substantive Representation of Women's Interests" has been under review at the British Journal of Political Science.

The first two articles are single-authored. The third paper is co-authored with Mary K. Nugent from Rutgers University. My co-author was responsible for the collection and the coding of the data that were used in the paper. I was responsible for the conception of the paper, the theoretical framework, the data analysis, and the writing of the manuscript.

The following framework paper summarizes the main results of the dissertation and situates the three papers within a broad and coherent research program.

The dissertation fulfills all formal requirements of a paper-based dissertation at the Faculty for Social Sciences, Economics, and Business Administration. Moreover, it fulfills all additional formal criteria set by the Institut für Politikwissenschaft at the University of Bamberg. 


\section{Introduction}

In a plenary debate at the German Bundestag in 1983, Petra Kelly, a Green Party Member of Parliament (MP), raised the question of whether the federal government was planning to criminalize domestic rape within marriage. The answer from MP Detlef Kleinert (Liberal Party) was a short and assertive "No", followed by laughter and visible amusement among many male MPs in the plenary. It took another 14 years until the rape of a woman by her husband was outlawed by the government in $1997 .{ }^{1}$ In the same year, MP Christine McCafferty tabled three widely supported Early Day Motions in the British House of Commons asking the government to classify women's sanitary products as essential to the family budget, and to reduce the associated Value Added Tax (VAT) to zero. In response to these motions, three years later, the Labour Government reduced VAT on sanitary products from $15 \%$ to $5 \%$ in their 2000 budget (see Childs and Withey 2006).

These examples highlight how the substantive representation of women's interests is often understood - as a job that is done by women. In other words, it is the female MPs who - once present in parliament - bring women's concerns to the political agenda, and who vigorously voice women's interests in parliament. This includes the articulation of all interests that, for either biological or social reasons, affect women more profoundly than men, as well as all areas "where policy consequences are likely to have a more immediate and direct impact on significantly larger numbers of women than of men" (Carroll 1994: 15). ${ }^{2}$

Following Hanna Pitkin's (1967) typology of political representation, and Anne Phillips' (1994; 1995) theory of a politics of presence, previous research on women in parliaments has therefore often proposed a link between the descriptive and substantive representation of women, suggesting that having a higher proportion of women in parliaments (descriptive representation) leads to a higher representation of women-specific interests (substantive representation). As female MPs share gender-specific experiences and perspectives with the female population, it is expected that they are more concerned with women's interests than their male colleagues, and that they - as the examples above demonstrate - more frequently bring topics like the gender pay gap, protection against domestic violence, or the comprehensive availability of breast cancer screenings to the legislative agenda. In this way,

\footnotetext{
${ }^{1}$ A video with a summary of the debate is published on the official Twitter account of the Tagesschau. It is available here: https://twitter.com/tagesschau/status/864177990229528576?lang=de.

${ }^{2}$ Section 3 of this paper gives a detailed definition of women's interests and presents different ways in which they can be operationalized and measured.
} 
increasing the number of women in parliament is not only a matter of democratic justice, in that the exclusion of half of the population from positions of political power is "patently and grotesquely unfair" (Phillips 1995: 63), but the presence of more female MPs is expected to also bring otherwise ignored perspectives and interests into the political process, and thereby make a difference in terms of policies (Phillips 1995; Mansbridge, 1999; Dovi 2007a).

On the one hand, these expectations are corroborated by a number of empirical studies showing that female legislators more frequently and more vigorously represent women's interests in parliament (e.g. Bäck, Debus and Müller 2014; Coffé and Reiser 2018; Volden, Wiseman and Wittmer 2018). On the other hand, many of these studies also reveal that the legislative behavior of female MPs is not always indicative of strong commitments to the representation of women's interests, and that the difference female MPs make is often very small or negligible. Hence, the empirical evidence for a link between women's descriptive and substantive representation is anything but conclusive, implying that even if the share of female MPs increases, parliaments might not become more responsive to women's demands (e.g. Towns 2003; Crowley 2004; Wängnerud 2009; Celis and Erzeel 2015; Barnes 2016; O’Brien and Piscopo 2019). These findings have led to the conclusion that the link between the descriptive and substantive representation of women is more complicated than previously assumed (Childs 2006).

More recently, scholars have therefore called for a rethink of women's substantive representation (Celis et al. 2008; Childs and Krook 2008; 2009), and a turn towards a 'thick' conception of the representation of women's interests if we wish to grasp the complexity and contingency of women's parliamentary representation (Mackay 2008). ${ }^{3}$ This new approach towards research on women and politics implies abandoning simple questions like 'Do women represent women?' or 'Do women in politics make a difference?' (Celis et al. 2008; Childs and Krook 2008; 2009; Mackay 2008). This dissertation contributes to this more thorough understanding of the occurrence and the intensity with which women's interests are represented in national parliaments. In particular, it analyzes 'when', 'why' and 'how' the substantive representation of women occurs.

\footnotetext{
${ }^{3}$ Within the women and politics literature, the term 'thick conception' of women's representation is not used synonymously with Clifford Geertz' (1973) understanding of 'thick description' as a method of interpretative and anthropological research. It instead describes the call for broader and more thorough research on women's representation (see below).
} 
Building upon Melissa Williams' statement that the "mere presence of members of marginalized groups in legislatures is not sufficient for the fair representation of citizens from those groups, even though it is often necessary" (Williams 1998: 6), this dissertation makes two main contributions. First, it analyzes when female MPs represent women's interests in parliament. Relating to the first part of Williams' statement and regarding the 'when' and 'why' of women's substantive representation, this dissertation investigates how the institutional environment affects the parliamentary behavior of female MPs and their opportunities to focus on the representation of women's interests.

Second, with regard to Williams' conclusion that the presence of women is a necessary condition for their substantive representation, this dissertation broadens our understanding of the potential actors in women's substantive representation and explicitly analyzes whether, when and why male MPs represent women's interests in parliament.

The last few decades have witnessed several examples of male politicians who have actively engaged in gender equality politics. For example, Barack Obama was among the many male supporters of the United Nation's "HeForShe" ${ }^{4}$ campaign in 2014, and Mikael Gustafsson became Chairmen of the European Parliament's Committee on Women's Rights and Gender Equality in 2011. Nevertheless, the role of male politicians in the substantive representation of women has, so far, largely been ignored, and we know hardly anything about the political and institutional conditions that affect men's likelihood of speaking on behalf of women in parliament. Contrary to the conventional assumption of a direct link between descriptive and substantive representation (Pitkin 1967), this dissertation presents one of the first empirical analyses of the role of men in representing women's interests, and explores whether male MPs can be characterized as critical actors in women's substantive representation. These critical actors are defined by a strong motivation to "act individually or collectively to bring about women-friendly policy change” (Childs and Krook 2009: 127).

In sum, the contributions of this dissertation fill a scientific, as well as socially relevant gap in the current literature. The explicit analysis of women and men and their individual incentives to participate in the representation of women's interests contributes to the important question of how and when parliaments can make steps towards gender equality in Europe and beyond (e.g. elimination of gender pay gaps, better protection against sexual violence). Moreover, it enhances our understanding of the probabilistic link between women's descriptive and

\footnotetext{
${ }^{4}$ The campaign encourages men and boys to support gender equality. See https://www.heforshe.org/en for more information.
} 


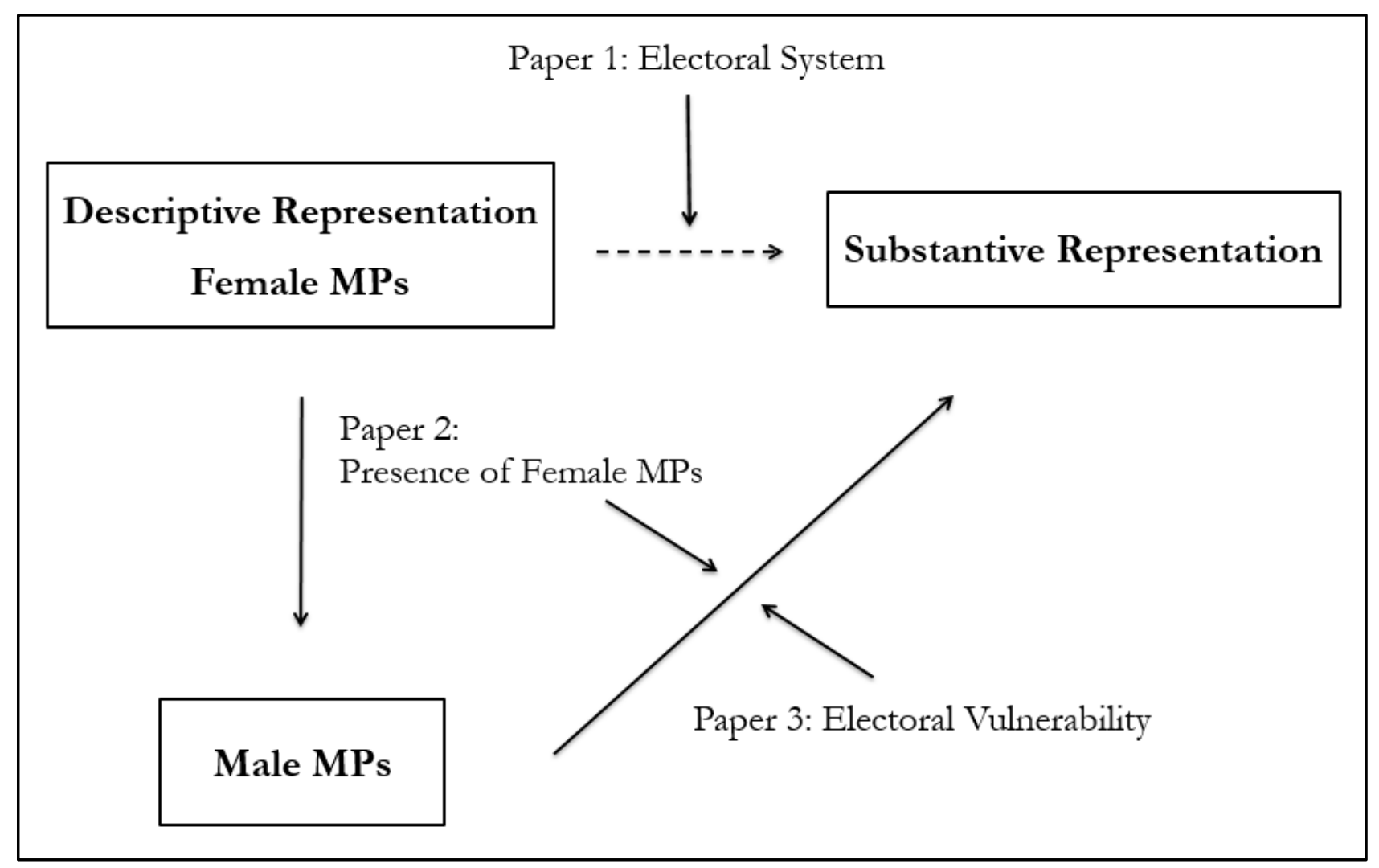

Figure 1: Overview and structure of the dissertation. How does the substantive representation of women occur?

substantive representation. The findings explicitly broaden our understanding of the potential actors, as well as of the institutional incentives that influence the willingness of female and male MPs to represent women's interests in parliament.

\subsection{Structure of the Dissertation}

Figure 1 graphically summarizes the different parts of this dissertation. It presents the general structure of the dissertation, and the individual contributions of the three papers, as well as how they are connected to each other.

Emphasizing the individual level of analysis, I examine the institutional and political conditions under which female and male MPs in the German Bundestag (1998 - 2013) and the British House of Commons (2001 - 2015) are more likely to substantively represent the interests of women in parliament. Based on this case selection, the results of the analyses present a current picture of women's representation in developed western democracies with comparably high levels of gender equality and high rates of women's participation in the 
political and public sphere. ${ }^{5}$ As explained above, the main dependent variable of all three papers is women's substantive representation.

The first paper looks at the role of female MPs in the German Bundestag, and explores the complicated and probabilistic relationship between women's descriptive and substantive representation. It investigates the causal mechanisms whereby descriptive representation is translated into more substantive representation of women, and analyzes how the institutional context affects the parliamentary behavior of female MPs. In particular, it explores the effect of the electoral system and asks whether the electoral incentive structure influences whether and to what extent female legislators represent women-specific issues more frequently than their male colleagues do. It argues that women in parliament can only engage in women's substantive representation if this does not compromise their chances of being re-elected to parliament. Female MPs are only able to focus on women's representation if they are not forced to concentrate on the representation of local issues from the constituencies in their respective electoral districts.

The second and third paper then explicitly analyze the role of male MPs in women's substantive representation, and explore the conditions under which male MPs are more likely to speak on behalf of women in parliament. The second paper asks whether the presence of women in parliament has an effect on male MPs' behavior and their decision to actively represent women's interests in the German Bundestag. Thus, as the vertical arrow in Figure 1 indicates, female MPs are no longer the main unit of analysis of the model, but their presence now constitutes the independent variable of the analysis that affects the behavior of male MPs. The paper thereby postulates that female MPs not only directly influence the substantive representation of women, but that they also indirectly affect the level of responsiveness of parliaments via the reactions of their male counterparts.

The third paper asks whether the electoral vulnerability of male MPs in the British House of Commons has an effect on their willingness to pay attention to women's concerns. Do men only speak on behalf of women if their individual re-election probability is low and if they need to win additional votes from their female constituents?

\footnotetext{
${ }^{5}$ The results, however, should not be generalized to non-democratic or less-developed countries with limited women's rights and more traditional perceptions about gender roles and women's place in the society.
} 


\subsection{New Institutionalism as a General Theoretical Framework}

Theoretically, all three papers are embedded in the new institutionalism (NI) framework and use one or more of its different variants to derive assumptions about female and male MPs' behavior and their incentives to represent women's interests in parliament. Boiled down to its fundamental premise, NI assumes that institutions 'matter' and that "the organization of political life makes a difference" (March and Olsen 1984: 747). Institutions, understood as the set of formal rules, informal rules, and ideational norms, are perceived as the central explanatory variable in political processes that affect and shape political dynamics, as well as policy outcomes (e.g. North 1990; Hall and Taylor 1996). Thus, the actions of individual MPs are embedded in the formal and informal institutional environment of the parliament, and their legislative behavior is strongly affected by their specific institutional configurations.

In my dissertation, I largely draw on the rational choice version of NI, which focuses on the behavior of individual MPs at the micro-level. According to rational choice institutionalists, MPs are understood as rational actors who act strategically in order to maximize their personal benefits. Therefore, all three papers in this dissertation perceive female and male MPs as mainly being driven by vote-seeking incentives to increase their re-election chances. Reelection is usually seen as the primary goal of legislators, given that it is the precondition for achieving other policy- and office-related objectives (Müller and Strøm 1999). Institutions, which are mainly created to overcome collective action problems or to reduce uncertainty (Ostrom 1990; North 1990; Weingast 2002), therefore provide incentives for MPs to behave in certain ways in order to advance these goals and to continue their political careers.

Additionally, this dissertation combines the assumptions of the neo-institutional framework with more recent research in feminist political science. Gender scholars have mainly critiqued NI for ignoring gender in its core assumptions, and have therefore developed a feminist variant of NI (Mackay, Kenny and Chappell 2010; Krook and Mackay 2011; Chappell and Waylen 2013). This feminist institutionalism also assumes that institutions profoundly shape the behavior of MPs, but additionally highlights how these "rules of the game" can affect men and women differently and, consequently, how power in political systems can be unevenly distributed between the two sexes. All papers in this dissertation adopt this 'gendered' view of institutions and highlight how institutional configurations provide different incentives for male and female MPs to act in the interest of women during the legislative process. It is expected that MPs adapt their parliamentary activity to the institutional environment and that 
they engage more in women's substantive representation if this benefits them personally and increases their chances of being re-elected.

The first and the third paper are entirely embedded in the rational choice and feminist variants of NI. More specifically, the two papers show how the institutional configuration of the electoral system differently affects the incentives of female and male MPs to act in the interest of women.

The second paper, while also assuming that male MPs behave as rational actors, additionally incorporates arguments of the sociological variant of NI. In general, sociological institutionalism perceives individual MPs as social actors who largely behave in habitual ways. Institutions reflect a shared understanding of "the way the world works" (Thelen 1999: 386). The behavior of MPs therefore follows a "logic of appropriateness" which pre- and proscribes certain types of behavior (March and Olsen 1989). Accordingly, the second paper uses the concept of a "gendered logic of appropriateness" (Chappell and Waylen 2013), expecting that informal rules about appropriate and acceptable gendered behavior, produce distinct roles for male and female MPs. One of these "appropriate" roles for female legislators is to be a representative of women's interests. It follows that if there are enough women in parliament, male MPs feel that they no longer have to be responsive to women's interests because female MPs can represent these issues more credibly.

All theoretical assumptions about the behavior of MPs are explained in more depth later when the individual papers are presented in more detail.

The remainder of this framework paper is structured as follows. The next section reviews the literature on women's legislative representation to situate the dissertation within a broader research program and to identify the research gaps and scholarly debates this dissertation contributes to. In the following, the definitions of women's interests and women's substantive representation are presented. Next, the individual papers are presented in more detail. Section 4 highlights the constraining effects of political institutions and then demonstrates how the electoral system affects the parliamentary behavior of female MPs (Paper 1). Section 5 presents the theoretical debates about whether or not men can legitimately represent women's interests and whether or not male MPs are potential critical actors in women's substantive representation. It then shows how the presence of female MPs (Paper 2) and levels of electoral vulnerability (Paper 3) affect the decision of male MPs to act on behalf of women. The final 
section summarizes the central results of the dissertation relating to the overarching questions of when, why, and how women's substantive representation occurs.

First, it shows that female MPs act more in the interests of women if the electoral system permits it. When the electoral incentive structure does not force them to represent the local issues of their districts, female legislators use this opportunity to more vigorously advocate for women's interests. Second, male MPs are generally willing to represent women's concerns in parliament. However, they only do so if there are not enough women in parliament who could take on the responsibility of representing women's concerns, or if their re-election is uncertain and they are forced to cater to additional voters. Thus, instead of being a critical actor, the results show that men's role is best described as that of a secondary actor.

\section{Previous Research on Women's Representation in Parliaments}

Although almost everyone seems to have an intuitive understanding of what political representation means, the concept can have many different meanings, and an extensive literature offers a variety of definitions of what political representation actually is (e.g. Eulau et al. 1959; Alcoff 1991; Manin 1997; Mansbridge 2003; 2011; Urbinati 2008; Rehfeld 2009; 2011; Saward 2010; Disch 2011; Fossen 2019).

Research on women's representation usually uses Hanna Pitkin's (1967) seminal contribution The Concept of Representation as a starting point. Pitkin offers the straightforward definition that representation simply means to "make present again". In a nutshell, this means that although citizens are not physically present in parliament, their voices, interests, concerns, and opinions are made present by an authorized legislator. In The Concept of Representation, Pitkin outlines the multiple and multifaceted character of how this 'making present again' can occur, and describes four different forms of political representation: (1) formal, (2) symbolic, (3) descriptive, and (4) substantive.

Formal representation refers to the institutional arrangements regulating the selection and deselection of political representatives. Representation takes place if the representative is legally authorized by the represented, and if the representative can be held accountable if she fails to act in the interests of the represented. In practice, free and fair elections are usually considered as a necessary condition to guarantee formal representation. Symbolic representation concerns affective beliefs about whether or not people feel represented, and how they perceive and evaluate their political representatives (Schwindt-Bayer and Mishler 2005). 
Descriptive representation, also called mirror representation or representativeness, is mainly concerned with the composition of the legislature, and describes the extent to which representatives resemble the represented in terms of shared characteristics such as gender, race or class. Lastly, substantive representation is defined as "acting in the interests of the represented in a manner responsive to them" (Pitkin 1967: 209). This dimension mainly refers to the actions of the representatives, and asks to what extent legislators are responsive to the needs and demands of their constituencies, and whether or not they act in the interest of the represented (Childs and Lovenduski 2013).

While there are only a handful of studies on the symbolic ${ }^{6}$ and formalistic representation of women, previous research on gender and politics has mainly focused on the descriptive and substantive representation of women in parliament. In the early phases of women and politics research, scholars particularly focused on descriptive representation, examining the political, institutional and social determinants that explain the low number of female MPs in parliaments around the world. ${ }^{7}$

With an increasing number of women now present in parliaments, however, research on gender and politics has started to focus on the actual behavior of female legislators and has investigated the question of whether women 'make a difference' once elected to the legislative arena. The focus has shifted from an explanation of the factors that affect the descriptive representation of women towards an interest in the substantive representation of women and the extent to which female politicians represent women-specific interests (Schwindt-Bayer and Mishler 2005).

Whereas Pitkin (1967) describes her four types of representation as being (mostly) independent of each other, the central question within the field of women's representation in parliament moved on to whether there is a link between women's descriptive and substantive

\footnotetext{
${ }^{6}$ An exception are several studies investigating whether female MPs are perceived as role models that encourage more women to run for political offices (e.g. Campbell and Wolbrecht 2006; Gilardi 2015; Foos and Gilardi 2019).

${ }^{7}$ Several studies have shown that the electoral system is among the factors with the strongest influence on women's descriptive representation. In particular, parliaments with proportional electoral systems - compared to single member district systems - have significantly higher shares of female MPs (e.g. Duverger 1955; Kenworthy and Malami 1999; Reynolds 1999; Fortin-Rittberger and Eder 2013). Given that this dissertation is mainly interested in the substantive representation of women, research on women's descriptive representation is not reviewed in detail. See Wängnerud (2009), Krook and Schwindt-Bayer (2013), and Taylor-Robinson (2014) for comprehensive overviews.
} 
representation, or in other words, whether a higher number of women in parliament leads to a stronger articulation of women's interests in the legislative arena. ${ }^{8}$

To a large extent, this shift goes back to Anne Phillips' theory of a politics of presence (1994; 1995). Phillips' main argument for the connection between women's descriptive and substantive representation are so called "overlooked interests". She explains that "[w]omen occupy a distinct position within society: they are typically concentrated, for example, in lower paid jobs; and they carry the primary responsibility for the unpaid work of caring for others. There are particular needs, interests, and concerns that arise from women's experience, and these will be inadequately addressed in a politics that is dominated by men" (Phillips 1994: 71f.). Phillips assumes that the divergent life experiences of women and men result in distinct policy priorities and preferences. Since female MPs share these experiences with women in the society, it is expected that they develop a sense of solidarity and linked fate with women in the general population. This group identification and the shared gendered life experiences then not only provide the necessary knowledge to credibly represent these perspectives, but also positively impact on the motivation of female MPs to make women's interests heard in the legislative arena (Tamerius 1995; Celis 2008b; Sobolewska, McKee and Campbell 2018). Thus, female legislators are expected to vigorously address the social perspective of women, and to represent women's interests more frequently in parliament compared with their male colleagues. Since male MPs are often unaware of the priorities and interests of women, or to what extent certain policies affect women and men differently, women's interests would be "overlooked" if women were not present in parliament. It is therefore crucial that women are actually present in the legislature in order to make their interests heard and to introduce new perspectives into the political process (Jones 1997; Mansbridge 1999; Young 2000).

On the one hand, the findings of a number of empirical studies confirm this assumed link between women's descriptive and substantive representation. They show that female legislators have different priorities than male MPs and that they see themselves as representatives of the female electorate (Reingold 1992; Carroll 2002, Childs 2002; Swers 2002; Gerrity, Osborn and Morehouse-Mendez 2007; Schwindt-Bayer 2010; Brunsbach 2011; Smooth 2011; Xydias 2007; 2014; Coffé and Reiser 2018; Reher 2018; Funk and Phillips 2019), that they increasingly engage in plenary and committee debates on women-specific interests (Swers 2002; Taylor-Robinson and Heath 2003; Childs 2004; Bäck, Debus and Müller 2014;

\footnotetext{
${ }^{8}$ See Section 3 for a detailed definition of women's interests.
} 
Debus and Hansen 2014), and they introduce more law initiatives on women-specific interests (Thomas 1994; Vega and Firestone 1995; Bratton 2002; Swers 2002; Devlin and Elgie 2008; Franceschet and Piscopo 2008, MacDonald and O'Brien 2011; Volden, Wiseman and Wittmer 2018).

On the other hand, however, scholars have begun to question how strong the postulated connection between women's descriptive and substantive representation actually is (e.g. Childs and Krook 2006; 2009). This skepticism is fueled by empirical findings as well as theoretical considerations.

First, many political theorists question the connection between descriptive and substantive representation and argue that not every member of a historically disadvantaged group is wholeheartedly committed to addressing the interests, opinions, and concerns of their own social group (Dovi 2007a: 34ff.). First and foremost, Hanna Pitkin herself was very suspicious about focus being placed on the social composition of parliaments and the conclusion that the descriptive make-up of a parliament would have any effect on its responsiveness towards the interests and needs of any particular social group. For Pitkin (1967: 142), the "fact that a man [sic] or an assembly is a very good descriptive representation does not automatically guarantee that they will be good representatives in the sense of acting for [...] Thus, for the activity of representing, the ideal of a perfect copy or likeness is chimerical".

Furthermore, although many scholars use Phillips' politics of presence theory to argue in favor of a connection between Pitkin's forms of representation and to justify why female MPs guarantee a better representation of women's concerns, Phillips was rather skeptical about the existence of a deterministic connection between women's descriptive and substantive representation. She states that "[h]owever plausible it is to say that male-dominated assemblies will not adequately address the needs and interests of women, it cannot be claimed with equal confidence that a more balanced legislature will fill this gap (Phillips 1995: 71). She continues by arguing that

the shared experience of women as women can only ever figure as a promise of shared concerns, and there is no obvious way of establishing strict accountability to women as a group. Changing the gender composition of elected assemblies is largely an enabling condition but it cannot present itself as a guarantee. It is, in some sense, a shot in the dark: far more likely to reach its target than when those shooting are predominantly male, but still open to all kinds of accident (Phillips 1995: 83). 
Thus, rather than ensuring that women will represent women's interests, a higher number of women in parliament instead tends to increase the probability of proper substantive representation of women's concerns occuring (Phillips 2012). This notion is echoed by Melissa Williams (1998). She concludes that "it would be absurd to claim that a representative, simply because she is a woman, therefore represents the interests or perspectives of women generally [...]" (Williams 1998: 6).

Second, there are numerous empirical studies revealing that the legislative actions of female MPs do not always indicate strong commitments to the representation of women-specific interests.

In her comprehensive review, Wängnerud (2009) concludes that the empirical evidence for the link between the descriptive and substantive representation of women is "mixed" at best. Several case studies of one or a few countries show that the found differences in attitudes and parliamentary behavior between men and women are often very small or, in some cases, even non-existent (e.g. Tremblay 1998; Htun and Jones 2002; Taylor-Robinson 2014; also see the overview in Celis 2019). In her large-scale comparative analysis of the behavior of female MPs in several European national parliaments, Mateo Diaz (2005) shows that many women do indeed act in the interest of women, these conclusion are, however, not applicable to all women. More recently, Dingler, Kroeber and Fortin-Rittberger (2019) studied the preference congruence between MPs and mass publics in 21 European countries by gender. They found that women's preferences are more accurately represented in parliament than those of men, even though the proportion of female MPs is much lower than that of male MPs, suggesting that male MPs are equally willing to represent the interests of women.

Due to these inconclusive findings and expectations about whether or not women 'make a difference' in parliament, many scholars have drawn on earlier works by Kanter (1977) and Dahlerup (1988) and used the theory of critical mass to explain why female MPs are not always in a situation to vigorously act in the interest of women once elected to parliament.

Accordingly, if the share of women in parliament is relatively low, female MPs will be reduced to a token status, which often forced them to play by the rules of the dominant group in parliament (i.e. men), and to reduce their visibility in parliament (Childs and Krook 2006; 2008). However, once women constitute a large enough group in parliament (the often cited magic number is $30 \%$ ), they are able to effectively work together to transform the way politics is done in the legislature. This will then enable them to influence the agenda of parliament, to speak on behalf of women in parliament, and, ultimately, reach women-friendly outcomes. 
Offering support for the critical mass theory, Mendelberg, Karpowitz and Goedert (2014) show in a series of experiments with differing group compositions that women did indeed speak less often when they were in the minority. If their numbers increased, however, they became more likely to speak and to represent women's distinct positions in group discussions. Moreover, Bratton and Ray (2002), as well as Kittilson (2008) were able to show that parliaments with a higher share of female MPs are associated with more women-friendly policies (e.g. higher spending on day-care provisions for young children).

The majority of empirical studies, however, have not found any evidence for the existence of a critical mass, showing that even if the share of female MPs increases above $30 \%$, parliaments do not become more responsive to women's demands (e.g. Studlar and McAllister 2002; Towns 2003; Crowley 2004; Grey 2006; Homola 2019; Dingler, Kroeber and Fortin-Rittberger 2019).

Taken together, the theoretical and empirical evidence of these studies suggests that the mere presence of women in parliaments does not automatically translate into a more vigorous representation of women's interests. The - admittedly appealing - connection between women's descriptive and substantive representation should therefore be "better understood as complicated rather than straightforward" (Childs 2006: 8) and is rather probabilistic than deterministic (Dodson 2006; Erzeel 2015). This dissertation contributes to this debate and analyzes the complexity and contingency of women's substantive representation.

First, it is fully acknowledged that it is not enough to simply look at the agency of individual female MPs, but that the parliamentary behavior of women is conditional on, and mediated by, the broader institutional context in which they operate. Specific institutional regulations can either limit or enhance the incentives and opportunities for female MPs to represent women's interests in parliament (Childs 2006; Childs and Krook 2009; Celis and Wauters 2010; Erzeel, Caluwaerts and Celis 2014).

Second, this dissertation explicitly broadens the range of potential actors that might claim to represent women in parliament. In other words, it examines whether male MPs represent women's interests in parliament, and it analyzes the conditions that make men more likely to engage in women's substantive representation. In line with the call for a 'thicker' (Mackay 2008) and more thorough conception of women's substantive representation, several authors have therefore suggested that we should move beyond analyzing only female MPs' behavior and the questions of how and when women represent the interests and preferences of their 
female constituents (Celis and Erzeel 2015; Celis et al. 2008; Childs and Krook 2008; 2009; Grey 2006; Mackay 2008).

If we want to paint a complete picture of the substantive representation of women as such, Childs and Krook $(2008,2009)$ recommend moving the "analytical focus from the macro to the micro level, replacing attempts to discern 'what women do' to study 'what specific actors do'” (Childs and Krook 2008: 734). This idea departs from the notion that female MPs are the only actors in the substantive representation of women, and emphasizes that men can also be important actors expressing women's interests in parliament. Based on Dahlerup's (1988) observations that sometimes critical acts of a minority of highly motivated individuals are more beneficial for a women-friendly policy change than having large numbers of women in parliament, Childs and Krook (2006; 2008; 2009) reject the assumptions of critical mass theory and instead suggest using the concept of critical actors to analyze how the substantive representation of women occurs.

According to Childs and Krook (2009: 138) critical actors are defined as

legislators who initiate policy proposals on their own and/or embolden others to take steps to promote policies for women [...]. The common feature of critical actors [...] is their relatively low threshold for political action: they may hold attitudes similar to those of other representatives, but they are much more motivated than others to initiate women-friendly policy reforms. Although critical actors may operate alone, they may also stimulate others to act, setting in motion momentum for policy change.

The contributions of this dissertation adopt this approach and present one of the first empirical analyses of the institutional and political conditions under which male MPs decide to represent women's interests in parliament. Using Childs and Krook's definition as a benchmark, the results will show whether men are able to legitimately speak on behalf of women, and to what extent male MPs in Germany and the UK can be characterized as critical actors in women's substantive representation. 


\section{What are Women's Interests and how is Women's Substantive Representation Measured?}

\subsection{The Definition of Women's Interests}

Analyzing when, why and how women's substantive representation occurs requires a definition of "women's interests" to determine which topics female and male MPs should represent in order to act in the interest of women. This is not an easy task given that the concept of women's interests is a controversial and hotly debated topic.

Scholarship on women's representation usually defines “interests" as fundamental substantive values affecting women's life chances and their options for action (Jónasdóttir 1988; Beckwith 2011; 2014). Thus, most studies on women's substantive representation generally start from the premise that women in society have specific experiences and share comparable circumstances that are different from those of men, and that give rise to a common political interest. Among the first scholars who tried to define women's interests are Sapiro (1981), as well as Diamond and Hartsock (1981). For Sapiro (1981), women's interests originate due to the private division of labor between men and women in the household. Since women give birth to children, and take on the main burden of childcare, their socio-economic position differs from that of men. Consequently, they develop distinct interests that should be represented in the political process. Diamond and Hartsock (1981) add that it is not only the private division of labor, but also the gendered division of productive labor, namely that women stay at home while men work in the public sphere, that contributes to diverging social and economic positions of women and men that require a distinct representation in the political process.

However, attempts to find a general definition of women's interests have often been criticized for being essentialist and for assuming that women are a monolithic and homogenous group. It is argued that the vast diversity of experiences and identities of women, who represent half of the world's population, makes it hard to see how there might be a coherent set of interests that could be labelled “women's interests”. According to Dovi (2007b: 311) “women differ when they have children or do not, are divorced or not, have been raped or not, are straight or gay, obese or thin, Muslim or Christian, menopausal or prepubescent”. Moreover, women's diversity with regard to their social class and their ethnic identities presents a plethora of different perspectives and needs. This multiplicity of women's experiences demonstrates that women are a diverse group without a uniform set of common interests. Whereas, for example, 
white and middle-class women in Europe might have an interest in reducing the gender pay gap between women and men, women in many states of the Middle East (e.g. Saudi Arabia) are still fighting for equal political rights and equal participation in public life.

Another frequent criticism concerns the feminist conception of women's interests. Dahlerup (2014), for example, claims that women's interests should be understood as only those topics that empower and expand the opportunities of women, because it is women's position in relation to male dominance that creates the shared condition of women upon which women's substantive representation is based (Dahlerup 2014). Celis and Childs (2012) on the other hand argue that women's interests should not be reduced to feminist demands because there are also many women who are not feminists and who hold more traditional views about women's role in society. The representation of feminist issues is therefore only one part of women's substantive representation, and women's interests should not be equated with feminist interests (Celis 2009). This perspective would largely exclude the action of MPs who promote socially conservative policies (e.g. anti-abortion policies), but nevertheless claim to act in the interests of women (Reingold et al. 2020; Campbell and Childs 2015).

More recently, scholars of women's representation have therefore refrained from painting an essentialists image of women, and have accepted that there is no fixed set of interests that is shared by all women across time and space. Nevertheless, this approach does not deny that women in society experience gendered constraints and exclusions that differ from men's opportunities and give rise to women-specific interests. These gendered experiences, however, are diversified, and not all women are faced with the same constraints or disadvantages. According to Beckwith (2014: 20), only "within specific contexts, similar shaping forces exist and have similar consequences for women”. Thus, women's interests are not homogenous or uniform, but are instead context-specific, changing over time and often only shared by a subset of women (Celis 2006; Reingold and Swers 2011; Severs 2019). As Phillips (1995: 68) summarizes it:

[T] he variety of women's interests does not refute the claim that interests are gendered. That some women do not bear children does not make pregnancy a gender-neutral event; that women disagree so profoundly on abortion does not make its availability a matter of equal concern to both women and men; that women occupy such different positions in the occupational hierarchy does not mean they have the same interests as men in their class.

Based on these considerations, scholars have proposed different empirical approaches to defining women's interests and their substantive representation in parliament. One 
possibility is to define women's interests as those policy areas where there is a gender gap between men and women in public opinion (e.g. Dingler, Kroeber and Fortin-Rittberger 2019). However, the feasibility of this approach depends on the availability of high-quality survey data over time, and potential topics might be missed, since surveys do not include items on every possible policy area.

A second approach draws on internationally agreed-upon standards of women's rights. ReyesHouseholder (2016), for example, uses the rights laid out in the UN's Convention on the Elimination of all forms of Discrimination Against Women (CEDAW) as her conception of women's interests. In a similar vein, Baldez (2011) argues for the adoption of the current demands of the Women's Rights movement as a definition of women's interests. However, both CEDAW and the Women's Rights Movement, privilege feminist and Western conceptions of women's interests and often prioritize the preferences and interests of white and middle-class women. Therefore, they do not provide a broad and inclusive definition of women's interests.

To acknowledge that women's interests are context-specific, and to avoid the critique of essentialism, this dissertation does not apply a pre-defined list of women-specific interests, which is very subjective and can easily be manipulated by the researcher. Instead, women's interests are defined as those topics that explicitly have women or some subset of women, "as their primary subject matter" (Reingold 2000, 166-167). It thereby follows the often-cited definitions by Susan Carroll (1994) and Karen Celis (2006; 2008a). According to Carroll, women's interests are those "where policy consequences are likely to have a more immediate and direct impact on significantly larger numbers of women than of men" (1994: 15). Building on Celis (2008a), this means that women's interests are those topics that - for either biological or social reasons - disproportionally affect women more strongly than men, or those that address a social condition in which women are disadvantaged compared to men. Furthermore, topics are considered as women-specific if they propose provisions to mitigate or completely eliminate inequalities between men and women.

More concretely, this means that the majority of topics that were coded as women-specific address issues such as gender pay gaps, legal protection for working mothers, domestic and sexual violence against women, medical care for women with breast or ovarian cancer, as well as legal provisions concerning abortions and prenatal examinations. In addition, concerns about professions that are more frequently pursued by women than men (e.g. midwifery) are defined as women-specific. Topics that have traditionally been described as soft or female, such 
as youth policies, education, or health, are only perceived as women's interests if they explicitly refer to discrimination against women.

This definition of women's interests is very broad, not limited to a specific context, and includes feminist as well as more traditional conceptions of women's role in society. ${ }^{9}$ On the one hand, women's substantive representation therefore includes advocacy for the expansion of women's opportunities, and the mitigation of inequalities between men and women. On the other hand, it also includes the actions of MPs who stress traditional gender roles, or asked the government to restrict equal rights for women.

\subsection{The Measurement of Women's Substantive Representation}

How can we measure women's substantive representation in parliament and how, and at what stages of the legislative process does the substantive representation of women take place? Franceschet and Piscopo (2008) draw a distinction between influencing the process of lawmaking and influencing the final policy output and outcome.

Women's substantive representation during the process of parliamentary procedures has been conceptualized in various ways (Kroeber 2018). First, scholars frequently look at MPs' personal attitudes, problem perceptions and priorities. These are usually assessed using surveys or interviews with MPs to see whether they perceive women as a distinct social group, and whether and how strongly they feel responsible for representing women's needs in parliament (e.g. Reingold 1992; Childs 2004; Brunsbach 2011).

Second, many studies go one step further and look at the actual behavior of MPs. Measured behavior include the introduction and co-sponsorship of bills relating to women's interests (e.g. Celis 2006; Swers 2009), speech-making and participation in debates on policy matters related to women (e.g. Catalano 2009; Bäck and Debus 2019), membership in parliamentary committees responsible for women and/or gender equality (women's committees) (e.g. Barnes 2016; Mahoney 2018; Coffé, Bolzendahl and Schnellecke 2019), as well as roll-call votes regarding bills on women-specific topics (e.g. Swers 2002).

\footnotetext{
${ }^{9}$ Due to this very broad definition, this dissertation does not further distinguish between women's interests, issues, and preferences. According to Beckwith $(2011 ; 2014)$ interests are, as explained above, fundamental, and relate to major gender cleavages between men and women. Issues present specific components derived from these general interests that are more specific, immediate, and limited. Preferences then constitute a range of different opinions and positions that one could have in relation to a specific issue.
} 
The third stage considers the policy outputs achieved (Thomas 1994; Franceschet and Piscopo 2008; Brunsbach 2011). Studies interested in actual policy outputs and outcomes analyze whether parliaments actually pass women-friendly bills, and whether these newly enacted laws are able to improve the situation of women in society (e.g. Bratton and Ray 2002).

Tamerius (1995) demonstrates that the advocacy of individual MPs on behalf of women can be expected to be the most pronounced during the earlier stages of the legislative process. The final policy output, by contrast, is largely determined by political parties as a whole, as well as the majority constellation in parliament, and is therefore not necessarily indicative about the preferences and the behavior of individual MPs. However, due to strong party unity in European parliaments (Sieberer 2006), many of the other indicators of women's substantive representation mentioned above (e.g. bill sponsorship, speeches, committee membership) are also highly influenced by political parties and therefore tend to measure the ideological position of the political party rather than the preferences and behavior of individual legislators. Given that the analyses of this dissertation focus on the actions of individual MPs, these indicators are not suitable as valid measurements of women's substantive representation.

In order to measure how strongly individual MPs represent women's interests in parliament, indicators are needed that are not strongly affected by party discipline or party leadership. In line with more recent approaches to measuring parliamentary behavior, I therefore use the following two indicators: Parliamentary questions (PQs) for the German case and Early Day Motions (EDMs) for the UK.

Each individual MP in the Bundestag can ask up to four written questions per month which will then be answered by the government. Additionally, he or she can submit two oral questions for the weekly question hour of the Bundestag. EDMs in the House of Commons are short and non-binding formal notices of motions submitted by individual MPs for debate in the House of Commons for which no date has been fixed. They can be introduced by any MP, and then be signed by other MPs to indicate their support for a motion. Since the party leadership usually does not officially control PQs and EDMs, they provide researchers with one of the very few direct and quantitative indicators of individual parliamentary activities (Childs and Withey 2004; Bird 2005; Martin 2011; Saalfeld 2011; Saalfeld and Bischof 2013; Kellerman 2013; Keh 2015).

Despite their advantage of constituting a direct indication of the priorities of individual MPs, the usefulness of PQs and EDMs as a measure of parliamentary behavior has been 
questioned. Since they have no formal policy implications and a comparably low visibility in parliament, it might be argued on the one hand that they constitute a form of cheap talk rather than an integral part of the legislative process. On the other hand, however, there are several arguments supporting that the importance of PQs and EDMs should not be underestimated and that they have several characteristics that make them suitable indicators for the analyses of the present dissertation.

First, the introductory examples of the VAT-reduction on sanitary products and the question on the legal status of rape within the marriage demonstrate that asking PQs and submitting EDMs can initiate debates in parliament that ultimately lead to substantial policy changes. Christine McCafferty's EDMs stimulated a lively debate about the tax-related classification of women's sanitary products that eventually led to a noticeable reduction in VAT rates for sanitary products from $15 \%$ to $5 \%$ (see Childs and Withey 2006). Petra Kelley's question contributed to a public debate about domestic violence that ultimately led to the criminalization of rape within the marriage.

Second, PQs and EDMs represent one of MPs few opportunities to generate publicity in their constituencies, to raise issues that are important to them, and to differentiate themselves from the official party agenda. In this way, PQs and EDMs serve as a signaling device which individual MPs can use to demonstrate their responsiveness to their constituencies, and to cultivate personal reputations in their local districts. EDMs, for example, go on official record, allowing MPs to say that they have 'tabled a motion in Parliament', thus demonstrating that they care about their local constituencies' needs. It is also quite common for MPs to publicize tabled PQs and EDMs on their personal webpages and social media channels. ${ }^{10}$

Third, with respect to EDMs, previous research has demonstrated that voters are aware of their respective MP's EDM activities and that these activities are also rewarded electorally. Kellermann (2013) found that EDMs attract a considerable amount of media attention from national and local newspapers, and that the number of EDMs tabled has a positive effect on the media coverage received by individual MPs. In addition, his study demonstrated that MPs from competitive constituencies introduced more EMDs than those from less competitive districts, and that higher rates of EDM introduction are associated with larger winning margins in subsequent elections. EDMs' effectiveness as a political tool for building an electoral connection with local voters has been corroborated in a recent study by David Parker

10 See e.g. http://tommysheppardmp.scot/index.php/blog/tommys-blog/entry/prevention-ofincitement-to-sexual-crime-and-violence. 
(2019). Using data from the 2015 British Election study, he found that the number of constituency-related EDMs positively affected the likelihood that the respondent would perceive the MP to be a constituency servant who cares about local concerns, and who brings the district's issues to parliament.

Moreover, Childs (2002) and Childs and Withey (2004) have shown that EDMs are a viable way for MPs to substantially represent the interests of women. By interviewing several female Labour MPs, Childs (2002) found that EDMs were frequently mentioned as an important tool for raising and promoting issues important to women.

Finally, submitting PQs and EDMs on a specific topic requires the allocation of scarce resources and is by no means a cheap activity in terms of time and opportunity costs. MPs must identify the information they want to obtain with the question, write it, format and submit it appropriately and wait for a reply (Martin 2011).

These arguments, together with the fact that PQs and EDMs are usually not officially controlled by the party leadership, show that they are a direct indication of MPs' priorities. The content of the question or the motion therefore provides an appropriate measure of how strongly individual legislators substantially represent the interests of certain social groups. Although PQs and EDMs are rarely publicly debated on the floor, they are still valid acts of representation on behalf of women. Remembering Pitkin's (1967) definition that representation is about "making present" a person or viewpoint, an MP who represents women's perspectives even in early or more peripheral stages of lawmaking is making the substantive interests of women present (Lowande, Ritchie and Lauterbach 2019). Womenspecific PQs or EDMs indicate efforts to publicly voice interests in the legislative arena that are important for (at least parts of) women.

Measuring to what extent individual legislators engage in women's substantive representation requires all PQs and EDMs that have been submitted during the period of investigation to be coded to identify whether they deal with a women-specific topic. This classification was then used to create a dataset that includes information on the number of PQs and EDMs with a women-specific concern that each MP in the Bundestag and the House of Commons has submitted or signed. The simple logic is that the more strongly a legislator is committed to the substantive representation of women, the more PQs or EDMs concerning women's interests she or he should submit or sign. 
For the British case, all EDMs have been hand-coded by the authors. ${ }^{11}$ Regarding the coding of PQs in Germany, this dissertation is one of the first studies that explicitly applies quantitative text analysis techniques to analyze the substantive representation of women in parliaments. To handle the huge amount of data (70,438 PQs in total), automated content analysis was applied to code each PQ as either referring to a women's interest or not. In recent years, text-as-data approaches have become increasingly popular in political science, and researchers in this field have developed a quite sophisticated toolkit for automated contend analyses of large-scale collections of political texts (see e.g. Monroe and Schrodt 2008; Grimmer and Stewart 2013; Lucas et al. 2015; Wilkerson and Casas 2017 for good overviews). However, these methodological advances have - so far - not been used to assess how strongly women's interests are represented in the parliamentary arena.

The applied coding procedure combines a supervised machine learning algorithm (Naïve Bayes classifier) and a dictionary-based approach (e.g. Grimmer and Stewart 2013; Lucas et al. 2015). ${ }^{12}$ For the supervised machine learning algorithm, all PQs from the $16^{\text {th }}$ and $17^{\text {th }}$ Bundestag (2005-2013) were hand-coded by the author to identify women-specific questions. After the required pre-processing of the data ${ }^{13}$, this set of hand-coded questions was used to train a Naïve Bayes classifier (Grimmer and Stewart 2013) which then automatically classified all PQs tabled during the $14^{\text {th }}$ and $15^{\text {th }}$ Bundestag. To identify obviously women-specific questions that the Naïve Bayes classifier had missed, a dictionary-based approach was applied independently of the supervised machine learning algorithm. A dictionary of women-specific keywords was created and all the questions were then searched for these keywords and classified as women-specific if they contained at least one keyword. A detailed description of the coding procedure can be found in the Online Appendix of Paper 2.

The empirical analysis of Paper 2 also takes into account whether the PQs advocate for equal rights and promote the status and well-being of women, or whether they rather restrict gender equality and stress traditional perceptions of the role of women in the society. Therefore, all women-specific PQs were additionally hand-coded for direction, and classified according to whether they were feminist, anti-feminist or neutral. Following the example of Childs and

\footnotetext{
${ }^{11}$ Mary Nugent was mainly responsible for the data collection and coding of the EDMs. Ambiguous cases were discussed between the two authors.

${ }^{12}$ All quantitative text analyses are estimated using the quanteda-package in $R$.

13 This includes the tokenization of PQs, the removal of stop words, very rare or very frequent words, the transformation of words to lowercase, and the reduction of words to their stem form (Grimmer and Stewart 2013; Lucas et al. 2015).
} 
Withey (2004) and Reingold (2000), PQs were coded as feminist if their aim was the expansion of women's opportunities or the mitigation of inequalities between men and women. If MPs stressed traditional gender roles or asked the government to restrict equal rights for women, the PQs concerned were coded as anti-feminist. In most instances these were questions about the provision of contraceptive pills or women's access to abortion. Issues which could not be clearly identified as being either feminist or anti-feminist were coded as neutral. Most of these neutral PQs were about women's health (e.g. regulations concerning the treatment of breast cancer). ${ }^{14}$

Besides contributing to a more thorough understanding of how the substantive representation of women occurs, this dissertation additionally makes two modest methodological contributions. First, it has compiled a comprehensive and publicly available dataset of all oral and written parliamentary questions tabled in the German Bundestag between 1998 and 2013. For each PQ, the dataset includes the full text of the question, as well as the name and party affiliation of the MP responsible for the question. Further variables indicate the type of the question (oral or written), the date on which it was submitted, as well as the ministry that provided an answer to the question. The dataset also includes several ID variables which make it possible to link the information on PQs to other datasets on the behavior of individual MPs in the German Bundestag. ${ }^{15}$ The dataset is freely available to the academic community and will hopefully be useful for researchers interested in legislative studies and the representational behavior of individual MPs. ${ }^{16}$

Second, the quantitative text analysis of PQs demonstrate that the combination of different automated text classifications is a useful tool to identify women's substantive representation when dealing with extremely large amount of textual data.

\footnotetext{
${ }^{14}$ In total, 62\% of the women-specific PQs were coded as feminist, 36\% were deemed neutral, and 2\% have an anti-feminist direction. However, there are significant gender differences. Among the PQs submitted by female MPs, $67 \%$ are feminist, $32 \%$ are neutral and $1 \%$ are coded as anti-feminist. By contrast, only $52 \%$ of the women-specific PQs from male MPs have a feminist direction, $44 \%$ are neutral, and $4 \%$ are classified as anti-feminist.

15 These include the Bundestag Roll Call Vote Data Set (BTVote, Sieberer et al. 2018), Phillip Manow's database of individual German MPs (Manow 2015), as well as the Jenaer Parlamentarierbefragung (Best et al. 2010).

16 The data set is available on the Harvard Dataverse at https://doi.org/10.7910/DVN/WIE8L4.
} 


\section{The Effect of Institutions on the Link Between Women's Descriptive and Substantive Representation}

As Melissa Williams (1998) noted, the mere presence of women in parliament is not a sufficient condition to guarantee a more intense substantive representation of women's interests. Even if female MPs would like to advocate equal payment for women and men, or stricter laws against sexual harassment, they might not always be able to do so because they are constrained by the institutional environment in which they operate.

More recently, scholars have thus begun to investigate the causal mechanisms of how descriptive representation is translated into more substantive representation of women. Previous studies on the mediating influence of the legislative context have analyzed a wide range of political institutions that help to explain why female MPs are not always able to engage in women's substantive representation. Taken together, these studies identify three main institutional factors that affect the behavior of female MPs and constrain their capacity to enact a women-friendly parliamentary agenda: (1) party affiliation and ideology, (2) unequal distribution of leadership positions among men and women, and (3) male-dominated informal rules about appropriate behavior ('gendered parliaments').

Due to their central role in most European national parliaments, political parties constrain the legislative influence of individual MPs. Political parties and their programmatic orientations primarily determine the legislative agenda as well as the enacted policy outputs. Moreover, given that the majority of parliaments are characterized by strong party discipline, most parliamentary activities (e.g. speech making, bill introduction, voting) are controlled by the party leadership, and the opportunities for individual MPs to bring new topics or policies to the parliamentary floor are severely limited (Cowley and Childs 2003; Sieberer 2006; Saalfeld and Strøm 2014). Whether or not female MPs are able to advocate women's interests therefore largely depends on the ideological orientation of their party (e.g. Beckwith and Cowell-Meyers 2007; Childs and Krook 2009; Xydias 2013; Espírito-Santo, Freire and Serra-Silva 2020). Several studies have demonstrated that left-wing parties generally show stronger commitment to gender equality and that they are more open to including the needs of marginalized groups in their policy programs (e.g. Norris 1985; Caul 1999; Beckwith and Cowell-Meyers 2007; Kittilson 2011; Annesley, Engeli and Gains 2015) Thus, left-wing parties - in contrast to conservative right-wing parties - provide conditions that are more conducive for individual female MPs to express women's interests in the legislative arena. 
The second constraining institutional factor is the limited positional power of women in governments and parliaments. Men still disproportionally occupy leadership positions in powerful committees or within the parliamentary party group. Female MPs are often excluded from these prominent positions, and are instead relegated to less prestigious committees or policy areas (Heath, Schwindt-Bayer and Taylor-Robinson 2005; Höhmann 2017; Coffé, Bolzendahl and Schnellecke 2019) As a consequence, female MPs lack the necessary influence on the parliamentary agenda, and are therefore not able to push for more women-friendly policies.

Lastly, research on gendered institutions points towards informal rules in parliaments that privilege typically masculine forms of behavior (Acker 1990). Debates and meetings in parliament are usually loud, conflictual and aggressive, thereby giving men an advantage that allows them to dominate important discourses. Moreover, parliamentary sessions and meetings of party groups often take place in the evening, and quite frequently go on until late into the night. This poses a serious obstacle for female politicians to reach powerful positions in the party or parliament, since women still disproportionally carry the main responsibility for the housework and childcare (O’Brien and Piscopo 2019).

However, our knowledge about how institutional variables affect the parliamentary behavior of female MPs and the substantive representation of women is still limited. As Krook (2018: 187) points out, it is particularly striking that the effect of the incentive structures from different electoral systems on female legislators and the substantive representation of women has thus far only very rarely been studied. Although mainstream parliamentary research has repeatedly shown that politicians adapt their parliamentary behavior to the incentives of different electoral systems to increase their re-election chances (Carey and Shugart 1995), an explicit application of these findings to the legislative behavior of women is still missing.

The first paper of this dissertation contributes to this debate by analyzing how the electoral incentive structure affects the substantive representation of women by female legislators. Explicitly, it intends to answer the research question of whether the electoral incentive structure has an effect on whether, and to what extent female legislators represent womenspecific issues compared with their male colleagues.

Paper 1 is theoretically embedded in a rational choice institutionalist framework, and perceives female MPs as rational actors driven by the intention of advancing their chances of being re-elected (Müller and Strøm 1999). Different electoral systems can create a more or less favorable context for women's substantive representation, and offer incentives as well as 
disincentives for female MPs to act in the interest of women. This means that although many female MPs might have the intrinsic motivation to act on behalf of women's concerns, they will only represent these issues more strongly in the legislative arena if it does not compromise their individual re-election prospects. Thus, having more women in parliament is only a sufficient condition for more substantive representation of women if the electoral incentive structure does not constrain female MPs from speaking on behalf of women's concerns.

The theoretical part of the paper explicitly links the assumptions of mainstream parliamentary research about the incentives and constraints of different electoral systems to the study of the substantive representation of women. I theoretically expect that the electoral incentive structure of single-member district systems (SMD) constrains female MPs from representing women's interests, and that the substantive representation of women should be higher in proportional electoral systems (PR).

Drawing on the assumptions of the Competing Principals Theory (Carey 2007), the electoral incentive structure of SMD systems forces female legislators to represent the local interests of the majority of the people in a geographic district to increase their chances of being re-elected. Exclusively representing women's interests and simultaneously disregarding the interests of the male constituency or other local issues could thus be a risky strategy. If a legislator spends most of her time dealing with women's issues, she will not be able to bring other problems in her district to the legislative arena, and many of her constituents would not feel sufficiently represented. This necessity to develop a representational style that is sensitive to all local problems of the district constrains female MPs from exclusively concentrating on womenspecific interests.

However, in proportional systems, electoral districts are usually state- or nationwide and reelection probability mainly depends on the vote share of the state- or national party. Hence, female MPs are not bound by any severe local responsibilities. This opens up the possibility for MPs to concentrate on the representation of broader interests, and thus gives female MPs the chance to focus on the substantive representation of women-specific interests, without having to fear any electoral disadvantage (Taylor-Robinson 2014: 258; Tremblay 2006).

Consequently, the link between the descriptive and substantive representation of women should be stronger if the re-election of female MPs does not depend on the representation of interests from the constituencies in their local districts. Female MPs elected in PR systems with closed-party lists should more strongly represent women's issues compared with their male colleagues. 
To test these expectations empirically, I use the German mixed electoral system, since it offers the advantage of observing the behavior of MPs that are elected under different electoral rules within the same country (half of the MPs are elected via SMD, the other half via PR). However, given that most MPs in Germany run as dual candidates in both electoral tiers, I use the reelection safety of a legislator in the two different tiers to operationalize the overlapping electoral incentive structures, and to take potential contamination effects into account (Stoffel and Sieberer 2018). In a nutshell, if the re-election probability of female MPs is high (either through a promising list slot or candidacy in a stronghold district), I assume that they are not depended on additional local votes from their districts to be re-elected, and are able to more strongly concentrate on the exclusive representation of women's interests. If their chances of being re-elected are low, then they are expected to need to devote a large proportion of their scarce resources to district-related tasks to fight for additional votes from their local voters.

As presented above, I use a content coding of written and oral PQs as an indicator for the behavior of individual MPs and their efforts to engage in women's substantive representation. Since most MPs do not table any women-specific PQ, the data are extremely right-skewed. In order to address this problem, I estimate a hurdle regression model consisting of a logit and a beta regression that are estimated as separate processes (Mullahy 1986; Hardin and Hilbe 2012).

The results generally support the idea that female MPs engage more strongly in women's substantive representation. In the time-period studied, $32 \%$ of all female MPs actively represented women's issues in the parliamentary arena and have tabled at least one womenspecific PQ. In contrast, only $12 \%$ of the male MPs acted on the behalf of women. Among all women-specific PQs, 73\% were issued by female MPs. However, the results also strongly support the argument that the behavior of female MPs is moderated by the electoral system, and that the electoral incentive structure affects how many women-specific PQs they submit. The hurdle regression model shows a significant interaction effect between gender and the electoral incentive structure. In particular, the beta regression provides evidence that female legislators only act more frequently on behalf of women compared with male MPs if their reelection is safe, which means that they do not depend on the representation of local interests from the constituencies in their districts. Across the full range of the electoral security scale, the predicted proportion for the share of women-specific PQs that MPs submit when they are not dependent on the representation of local interests increases from slightly above 6 percent 
to almost 9 percent for women, and decreases from 8.5 to slightly under 6 percent for male MPs.

The results confirm the theoretical expectations and show that female legislators act more frequently on behalf of women if their re-election is secured and if they do not have to fight for additional local votes from their district. Indeed, women do represent women's interests in parliament, but they pursue these goals more actively if their electoral incentive structure permits it! When the electoral incentive structure does not force MPs to represent local district issues, female legislators use this opportunity and act more in the interest of women. Thus, the theoretical link between descriptive and substantive representation requires qualification, and should take the effect of different electoral systems into account.

\section{Can Male MPs be Critical Actors in Women's Substantive Representation?}

\subsection{Theoretical and Normative Debates about Men's Role in Women's Substantive Representation}

Intuitively, it is assumed that the representation of women's interests is a duty of female MPs, and that the presence of women in parliament is a necessary condition for women's substantive representation to occur. But is this really the case? Or is it also possible that men legitimately speak on behalf of women? In order to present a thorough discussion on men's role in women's substantive representation, the following section synthetizes the main theoretical arguments in favor and against the legitimate participation of male MPs in women's representation. In what follows, the empirical evidence of the second and third paper of this dissertation will be summarized. Together with the theoretical arguments about men's involvement in women's representation, the empirical findings are then used to assess to what extent male MPs in Germany and the UK can be characterized as critical actors in women's substantive representation.

On a theoretical level, some authors are optimistic that male MPs can legitimately engage in advocacy for women-specific concerns. As mentioned earlier, Pitkin herself does not assume any strong connections between descriptive and substantive representation, and recommends focusing on the activities of parliaments rather than their descriptive composition: "Think of the legislature as a pictorial representation or a representative sample of the nation, and you will almost certainly concentrate on its composition rather than its activities" (Pitkin 1967: 
226). In a chapter of her book that has so far received only scant attention from representation scholars, Pitkin (1967: 168ff.) further elaborates on this thought. She points out that - aside from the common conception that political interests are attached to the identity of specific people or a specific group (e.g. interests of women) - representatives can also act in favor of interests that are unattached to their own personal identity (Pitkin 1967: 168-189; Staehr Harder 2019). Pitkin relates this idea to Edmund Burke who argued for the benefits of a 'virtual representation' of interest, and famously stated that it is not necessary for the people of Birmingham to send a representative to parliament, because their general interests are already represented by the representative elected in Bristol (Pitkin 1967: 168ff.).

Applied to men's role in women's substantive representation, Staehr Harder (2019) argues that if we understood women's substantive representation in terms of gender equality - rather than as an interest exclusively attached to women - female MPs would not be the a priori actors who are responsible for its representation in parliament. Acting in the interests of gender equality would be more likely to be perceived as something that does not belong to a particular group, but something that men could also actively participate in (Staehr Harder 2019; Palmieri 2013).

In a similar vein, Welzel and Inglehart (2014) argue that compared to shared gender or socioeconomic status, empathy for the situation of others has become the more important factor in creating feelings of solidarity between people. Analogous to the previous point that not all female MPs vigorously act on behalf of women, there might be several male MPs motivated to advocate gender equality and to work on the mitigation of gendered differences between men and women.

This reflects Childs and Krook's (2009) notion that it is not enough to look for a critical mass of women in parliament, but that it is necessary to identify the 'critical actors' who act in the interests of women. And these critical actors, as Childs and Krook explicitly state - can be women or men.

The large majority of scholars, however, deny that male MPs can legitimately speak on behalf of women. For various reasons that will be summarized below, they are skeptical about the possibility that men can become critical actors in women's substantive representation acting individually or collectively to bring about women-friendly policy change.

One of the first critics of non-descriptive group representatives was John Stuart Mill, who claimed already more than a century ago that "in the absence of its natural defenders, the interest of the omitted is always in danger of being overlooked; and when looked at, is seen 
with very different eyes from those of the persons whom it directly concerns" (Mill 1967 [1861]: 22). Anne Phillips doubts that men can play an active role in women's representation, since even "with the best will in the world (and all too often we cannot rely on this), people are not good at imagining themselves in somebody else's shoes" (Phillips 1995: 53). She then quotes a group of Frenchwomen who expressed that "a man, no matter how honest he may be, cannot represent a woman (Phillips 1995: 53). Why do these scholars so vehemently reject the possibility that men can act in the interest of women?

Most scholars agree that not all social groups (e.g. left-handers, redheads) require proportional representation in parliament, but that the actual need for descriptive representatives is always contextual and that this need depends on historical, as well as the current conditions of exclusion (Mansbridge 1999; 2015; Phillips 1995; Young 1990; Dovi 2002; 2007b). In the case of women's substantive representation, several contextual factors speak against the notion that men could take on the representation of women's interests.

First, women's participation in public life has been suppressed for centuries, and access to political positions of power has been consistently denied them only on the basis of their gender. Mansbridge (1999) argues that this structural discrimination against women creates a context of mistrust between women and men, and prevents adequate communication between members of the two groups. She notes that this "history of dominance and subordination typically breeds inattention, even arrogance, on the part of the dominant group" (Mansbridge 1999: 641), and that therefore men - as the main actors in women's discrimination - cannot legitimately stand in for the interests of those persons that they have systematically excluded.

Even Burke, who otherwise argues for the possibility that interests can be 'virtually' represented by non-group members, accepts the general idea that the substantive representation of the concerns of historically disadvantaged or discriminated groups requires the presence of descriptive representatives in parliament. For him, all social groups with serious substantive grievances have to be personally present in parliament to protect their group concerns. It follows that right-handers might legitimately represent left-handers, whereas men are unlikely to protect the gender-based interests of women.

Regarding Childs and Celis' (2009) definition of a critical actor, it is additionally disputable whether men can be highly motivated to act in the interests of women, and whether they have a low threshold for taking action and for initiating women-specific policies. This essential element of a critical actor is questioned in the case of male MPs, because it is assumed that a 
person is more likely to take individual actions if they are personally affected by a specific policy decision. This is all the more true if the situation or decision at hand entails any personal disadvantages or detriments for the individual in question or the whole social group they belong to.

In the case of advocacy for women's interests, this is often referred to as a linked fate. Dovi (2002) argues that a person's motivation to act on behalf of a specific social group is higher if they believe that their personal interests are affected, and if their self-interests are connected to the interests of the whole group. This notion of a linked fate also entails that individuals believe that what happens to their social group as a whole also has direct consequences for their own personal lives. Regarding male MPs' role in women's substantive representation, it thus follows that it is implausible to expect men to become critical actors because they do not share any linked fate with women in society. Quite the contrary, male MPs engaging in gender equality would be actively work against their own advantages and their dominant position compared to women. For example, it is not possible to achieve equal pay for women and men without lessening the financial privileges of men compared to women, or to increase the number of women in powerful political positions without men losing parts of their dominant status in the legislature or executive (Phillips 1995: 69). Drawing on Mansbridge's (2009) selection model of political representation, it can therefore be concluded that many male MPs have little intrinsic motivation to act on behalf of women because they are either not directly affected, or, as is the case in most instances, because advocacy on behalf of women would have negative repercussions for the group of men as a whole. Regarding the definition of a critical actor, it thus becomes clear that most male MPs have rather high thresholds for engaging in women's substantive representation, due to a lack of intrinsic motivation or a linked fate with women in society. Consequently, men's "potentiality" (Uhlaner 2012) to become a critical actor and to work on behalf of women is rather low.

Another consequence of the missing linked fate of male MPs and their low intrinsic motivation is a reduced legitimacy to speak on behalf of women. Dovi (2002) develops the concept of "preferable descriptive representatives", and forcefully argues that representatives and members of historically disadvantaged groups must mutually recognize each other. This entails that representatives and the represented accept each other as belonging to the same disadvantaged group, and that the MP who speaks on behalf of a particular group is recognized by the members of this group as "being one of us" (Dovi 2002: 736). Only in such mutual relationship cases is it possible for a representative to legitimately make claims on behalf of a 
historically disadvantaged group. In light of the past discriminations against, and limitations of female citizens' self-determination by male elites, however, it is rather unlikely that women will trust male MPs to adequately represent their concerns and needs. Accordingly, it is unthinkable for Dovi (2002; 2007b) that male MPs can be accepted as the legitimate representatives of women's interests.

This missing legitimacy of male MPs to act in the interests of women is also supported by Linda Alcoff (1995: 98) stating that "where an individual speaks from affects both the meaning and truth of what she says. Having certain experiences can lend authority to one's questioning or advocating for certain policies." In other words, being a member of a disadvantaged group, and sharing distinctive experiences with that group serves as source of authority for MPs to legitimately make claims on behalf of this group (Dovi 2007b). ${ }^{17}$

Mansbridge (2009) identifies another contextual factor that makes male MPs' participation in women's substantive representation unlikely: the presence of uncrystallized interests. If women's interests were - as Burke's concept of virtual representation assumes - static, objective, clearly defined, and few in number, then women's substantive representation could be boiled down to a representation of a 'laundry list' of pre-agreed detailed policies that all women would want to see enacted. If this were the case, it would not really matter who is responsible for the actual representation and implementation of these clearly demarcated interests or policy programs and, consequently, female as well as male MPs could become critical actors representing women's interests (Phillips 1995; Mansbridge 1999). However, as has been shown above, there is no such thing as a universal laundry list of women's interests. For Mansbridge (1999), women-specific concerns are uncrystallized, meaning that they are not clearly delineated and that they can change over time. This also implies that new topics affecting these concerns might surface unpredictably on the political agenda.

For example, after the exposure of the sexual-abuse allegations against Hollywood producer Harvey Weinstein in 2017, the \#MeToo debate circulated rapidly and was the target of

\footnotetext{
17 This higher legitimacy of women to represent women's issues is also corroborated by several more recent empirical studies. Coffé and Reiser (2018), for example, analyze data from the 2009 German Candidate Survey and find that female candidates in Germany - compared to their male counterparts - are more likely to believe that women are the better representatives of women's interests in parliament. Relatedly, Celis and Wauters (2010) conducted interviews with MPs in Belgium and report that many female MPs are expected to take over the role of a group representative of women's interests. Using experimental methods, Arnesen and Petersen (2017) as well as Clayton, O'Brien and Piscopo (2019) show that the perceived legitimacy of a decision that affects women as a group increases if women are included in the decision making body.
} 
discussion in almost all social and political spheres. This then forced MPs to take action and to position themselves without the scaffold of pre-defined party programs or policy proposals. In these situations, Mansbridge (1999) argues, descriptive representatives are necessary to ensure an adequate substantive representation of those groups for whom these uncrystallized interests and newly emerging topics are important. Regarding women's representation, she states "the many issues relating to gender [...] where views are changing and policies developing in a relatively ad hoc way to meet a rapidly evolving situation, descriptive representatives are, other things equal, more likely than non-descriptive representatives to act as their descriptive constituents would like them to act” (Mansbridge 1999: 646). Related to the ideas of a politics of presence (Phillips 1995), descriptively similar MPs are able to draw on shared experiences to recognize aspects of the evolving issues that others would not see, and are therefore able to imagine what is in the best interest of their constituents.

In her conceptualization of different forms of representation, Mansbridge (2003) refers to this type of behavior as "gyroscopic representation". To act in the interest of their constituents, MPs are expected to follow their 'internal gyroscope', which is derived from their own social backgrounds. "The representative looks within, for guidance in taking action, to a contextually derived understanding of interests, interpretive schemes ("common sense"), conscience, and principles" (Mansbridge 2003: 520f.) Regarding the representation of women, this 'gyroscope' is a virtue that male MPs cannot possess, and therefore renders them incapable of becoming critical actors in women's substantive representation.

\subsection{Empirical Studies on Men's Role in Women's Substantive Representation}

Apart from this skepticism about men's role in women's substantive representation, some initial empirical studies have started to analyze whether, and to what extent, male MPs can be characterized as critical actors advocating for women's interests in their parliamentary work. On a descriptive level, Celis and Erzeel (2015) and Erzeel (2015) analyzed PartiRep survey data from 10 European countries and found that an almost equal number of male and female legislators indicated that they promoted women's interests in parliamentary party group (PPG) meetings. Dingler, Kroeber and Fortin-Rittberger (2019) studied the preference congruence between MPs and mass publics in 21 European countries by gender. They found that women's preferences are more accurately represented in parliament than those of men, even though the proportion of female MPs is much lower than that of male MPs, suggesting that male MPs are equally competent to represent the interests of women. In a study of British 
MPs' voting behavior and debate contributions, Evans (2012) showed that a few male MPs represented women's concerns in their debate contributions. However, they were in the minority and spoke less if women's interests had already been expressed by many female MPs in these debates.

Going beyond a mere description of the activity levels of male MPs, Olofsdotter Stensota (2020) shows that male MPs' personal backgrounds and socializations affect their legislative priorities and their inclination to represent women-specific issues. In a study of Swedish MPs, she found that men were more likely to express an interest in social policy if they had been on parental leave during their time in office. Relatedly, Washington (2008) finds that having a daughter affects the voting behavior of male politicians. Analyzing male members of the US Congress, his findings indicate that their probability of voting liberally on reproductive rights increased as their number of daughters increased. The effect size, however, is relatively small and a more recent analysis shows that it completely disappears after adequately controlling for the influence of party ideology (Costa et al. 2019).

Kokkonen and Wängnerud (2017) conducted a survey of locally elected politicians in 290 municipalities in Sweden to analyze the effect of female councilors on male MPs' attitudes towards the representation of women's interests. They found that the proportion of women has a significant negative effect on male MPs' willingness to act for women in the council. The more women are present in the council, the less likely it is that male MPs feel responsible for representing women's issues. However, given that Kokkonen and Wängneruds' analysis is based on survey data, it is questionable whether the self-reported claims of male MPs of engaging in women's substantive representation are translated into actual behavior.

Taken together however, this scarce evidence about the role of male MPs in women's substantive representation and - more importantly - about the factors that might transform them into critical actors in this regard, vindicates Celis and Erzeel's (2015: 60) call that it is essential to "examine under what institutional, political and discursive conditions [men] can both participate and contribute to a responsive process in representing women's interests". In response to Celis and Erzeel (2015), and in light of the above presented theoretical skepticism about whether male MPs can legitimately act in the interest of women, the second and third paper of this dissertation analyze the conditions affecting male MPs' proclivity for representing women's interests. 


\subsection{The Effect of Women on Male MPs' Political Behavior}

Paper 2 looks at one important factor in this regard, and explores whether the presence of female MPs has an effect on men's parliamentary behavior, and whether male MPs are more or less likely to act in women's interests if the proportion of female MPs is high. Contrary to the expectations of critical mass theory, an increasing number of female MPs does not always result in a more intense substantive representation of women's issues. This suggests that a greater proportion of women in parliament not only affects the opportunities of female MPs working together on issues related to women, but will also affect the behavior of male MPs (Childs and Krook 2008; Yoder 1991).

On a theoretical level, I propose three contrasting hypotheses. On the one hand, one could expect a positive spillover effect which postulates that men are more likely to become critical actors who act on behalf of women if the number of female MPs increases. According to this argument, male MPs develop an awareness of women's interests if they come into contact with an increasing number of female MPs and their gender-specific experiences. Exposure to women's specific interests might either occur through discussions with female MPs or through direct observation if female MPs are able to introduce women's issues to the parliamentary agenda. If these experiences cause a positive spillover effect, male MPs will not only change their attitudes towards gender equality, but also express these issues in their actual parliamentary behavior and become more responsive to women's interests.

On the other hand, a group-threat effect could occur which creates a negative backlash among male MPs (Blalock 1967; Yoder 1991). This effect implies that male MPs become hostile towards female MPs and their legislative agenda if they fear losing their majority status in parliament. Regarding the legislative arena, which has always been dominated by men, this means that male MPs perceive women as intruders and therefore react negatively towards a more intense representation of women's interests.

The third hypothesis postulates a specialization effect between male and female MPs. Drawing on the theories of sociological and feminist institutionalism (Chappell and Waylen 2013), it expects that according to appropriate gendered behavior, the representation of women's interests is typically seen as a function that should be fulfilled by female MPs. With its roots in the skepticism presented above, the specialization argument assumes that female MPs share gendered experiences and a linked fate with other women. Thus, compared to their male colleagues, they are in a position to legitimately speak about women's issues in parliament. Even though male MPs are not hostile towards women's interests, gender norms prescribe 
that female MPs are mainly responsible for the representation of women's issues. If there are enough women in parliament, male MPs feel that they no longer have to be responsive to women's interests because female MPs can represent these issues more credibly. If more women enter parliament, male MPs will not show hostile resentments towards female MPs, but they will no longer feel responsible for the representation of women's issues, and will thus decrease the intensity with which they represent women's interests in parliament.

For all three hypothesis, I expect that it is not the number of women in the whole parliament that is decisive, but the number of women in the respective parliamentary party group (PPG) of male MPs. The literature on legislative organization and parliamentary behavior shows that PPGs are the most relevant actors in the parliamentary process, and that the parliamentary work of individual MPs is mainly organized by and around the PPG (e.g. Sieberer 2006).

Similar to the first paper, the responsiveness of MPs to the concerns of women is examined through an analysis of PQs tabled by individual MPs in the German Bundestag. To model the effect of women's presence in parliament on the behavior of male MPs, I again estimate a hurdle regression model.

The descriptive results of the analysis show that in total 2,012 PQs referring to a women's interest were tabled by the MPs of the German Bundestag between 1998 and 2013. Among these, 726 (36\%) were tabled by male MPs, showing that - although female legislators generally focus more strongly on the substantive representation of women's interests - men are by no means totally uninterested in the representation of women's interests.

Regarding the effect of the presence of women on the proclivity of male MPs to act in the interest of women, the results of the hurdle regression model demonstrate that the proportion of women in the PPG has a significant negative effect on the proportion of women-specific questions submitted by male MPs. This supports the theoretical expectations that female MPs make men less likely to represent women's interests. In line with the idea of a specializationmechanism, male MPs do not completely refuse to represent women in parliament if the proportion of female MPs is high, but they significantly reduce the intensity with which they speak on behalf of women.

The specialization hypothesis is also corroborated by the distribution of feminist, antifeminist and neutral PQs. Of the 726 women-specific PQs submitted by male MPs 374 (51.5\%) were classified as feminist and 320 (44.1\%) fell into the neutral category. The distribution for female MPs appears similar, however, they submitted significantly more feminist PQs (67.4\%). In situations where only a few women were present, male MPs did not 
represent traditional or anti-feminist standpoints, but instead represented women's interests in a more neutral way. When the proportion of women increases, male MPs ask fewer women-specific PQs and female MPs take over the responsibility for representing women's interests.

Thus, male MPs might engage in "virtual representation", showing responsiveness to women's interests as long as women suffer from weak descriptive representation. Although male MPs do not have an inherent personal source of responsiveness, a certain number of male MPs are generally willing to represent women's issues in parliament. However, if women are highly represented in the PPG, it is expected that female MPs will cover the "gender angle" more competently (Evans 2012), and that they should be left to represent their gender-specific interests on their own. Indeed, compared to their male colleagues, female MPs indeed represent women's interests in a more specialized way and more often push for an expansion of women's opportunities and rights.

The results of the second paper also highlight why having a critical mass of women in parliament is not always enough to produce more women-friendly outcomes. Even if a greater proportion of women in parliament allows female MPs to work together effectively to push for the representation of women's interests, this influx of women simultaneously provokes a negative effect among male MPs, making them less willing to act on women's behalf. In this way, female MPs not only have a direct effect on the substantive representation of women, but they also indirectly affect the level of responsiveness of parliaments via the reactions of their male counterparts. If we were to ignore women's influence on men, we would paint an incomplete and biased picture of female MPs' impact on the representation of women's interests in the parliamentary process.

\subsection{The Effect of Electoral Vulnerability on Male MPs' Political Behavior}

Paper 3 of this dissertation investigates the motivation of male MPs to represent women's interests. If male MPs are to be perceived as critical actors, they should be highly and intrinsically motivated to advocate on behalf of women, and should have a low threshold for taking action to initiate women-friendly policies in parliament. The third paper therefore analyzes whether male MPs' electoral situation affects their decision to act on behalf of women. In particular, it explores the role of electoral vulnerability in this regard and analyzes whether male MPs' re-election prospects affect their likelihood of paying attention to women's concerns. Are male MPs indeed intrinsically motivated to take action on behalf of 
women, or are they instead rational and vote-seeking actors who represent women's interests only in situations of high electoral vulnerability, and if they need to win additional votes to be re-elected?

In order to hypothesize about the conditions under which it is electorally beneficial for male MPs to represent women's issues, the paper draws on the concept of a gendered leeway which was recently introduced by Bergqvist, Bjarnegård and Zetterberg (2018). According to this gendered leeway, male MPs - in contrast to their female colleagues - are not expected to be active on women's issues and will not be held accountable if they do not actively promote these issues in parliament. Similar to the specialization hypothesis of the second paper, it is argued that female MPs share gender-specific experiences with women in the population, and will therefore address women-specific issues more strongly than their male colleagues. In contrast, since male MPs are not directly (at least not negatively) affected by genderinequalities, and because they do not share any linked fate with women in society, they perceive no strong obligation to substantively represent women. However, if they do act in women's interest, they can gain additional credit because it is not generally perceived as a duty that male politicians should fulfil. In other words, "[f]emale politicians are blamed if they do not pursue 'women's issues' while male politicians get credit if they do" (Bergqvist, Bjarnegård and Zetterberg 2018: 581).

Thus, if male MPs are rational, vote-seeking actors, they should be more likely to speak on behalf of women if their electoral security is low and they are forced to fight for additional votes to be re-elected. If their re-election to parliament is hanging in the balance and they are faced with a competitive race in the district, male MPs discover women as an additional source of votes which might ensure their return to parliament in the upcoming legislative term. In contrast, there is no need for male MPs who are electorally secure to become active in the substantive representation of women. They can leave this area to their female colleagues and focus on other issues instead. Hence, it is hypothesized that the higher their individual electoral vulnerability, the more vigorously male MPs will represent women's interests in parliament.

Analyzing EDM submissions and signatures of male MPs in the British House of Commons (2001-2015), the results of a hurdle regression model corroborate the expectation that male MPs make use of a gendered leeway regarding women's substantive representation. The analysis shows a significant positive effect of electoral vulnerability, measured as the vote 
margin between the winner and the second-best competitor in the district, on male MPs' general decision to represent women's interests in parliament.

The results provide evidence that male MPs are more likely to either sign or propose a womenspecific EDM, if their re-election is at risk. No such effect is found for female MPs. Hence, it is interpreted as a rational strategy used by male politicians to cater to female voters in order to win additional votes from the women in their constituencies.

Moreover, the empirical analysis indicates qualitative differences in the representation of women's interests by male and female MPs. Whereas women in the House of Commons are more likely to introduce their own EDMs on topics of women's interest, men instead engage in low-cost activities and merely sign women's EDMs, rather than writing their own motions. Regarding the motivations of male MPs to play an active role in women's substantive representation, it can therefore be concluded that one of the key drivers of this behavior is a rational calculation of how they can enhance their Election Day prospects, rather than an intrinsic motivation to stand up for women's rights and gender equality. It appears that male MPs are mainly extrinsically motivated, and primarily speak on behalf of women in order to win elections.

\section{Summary of Results}

When, why and how does the substantive representation of women in parliament occur? Building upon Melissa Williams' (1998) notion that the presence of women is necessary but not sufficient, the papers of this dissertation try to contribute to a more thorough understanding of women's representation. The main results of this analysis are summarized below.

Concerning the questions of 'when' and 'why' descriptive representation leads to more substantive representation of women, the findings demonstrate that institutions mediate the complicated relationship between women's presence in parliament and the representation of women's interests. In particular, the results show that incentives from different electoral systems may create a more or less favorable context for women's substantive representation, and the decision of individual female MPs to act in the interests of women. It can be shown that the incentives of SMD elections constrain re-election oriented female MPs from engaging in women's substantive representation, and that women in parliament are more likely to act on behalf of women if they do not depend on the representation of local interests from the 
constituencies in their districts. This finding demonstrates that - although women might have a higher motivation to speak on behalf of women's concerns - this intrinsic motivation is often trumped by the extrinsic motivations created by the electoral incentive structure and the desire to be re-elected to parliament. Although female MPs share a linked fate with other women, they do not vigorously act in the interests of women under all circumstances. However, when the electoral incentive structure does not force MPs to represent the local issues of their districts, female legislators use this opportunity to more strongly engage in women's substantive representation compared to their male colleagues.

The link between women's descriptive and substantive representation is conditional on the electoral system, and the greater presence of female MPs is only a sufficient condition for more substantive representation of women if the electoral incentive structure does not provide strong disincentives for female legislators to advocate women's interests. This contributes to a better understanding of the institutional settings under which female legislators more strongly represent women-specific interests, and demonstrates that attitudes and intrinsic motivations do not always and directly translate into actual behavior.

The second part of the dissertation dealt with the question of whether the presence of female MPs is indeed a necessary condition for the representation of women's interests. Looking at 'how' advocacy for women's interests occurs, this dissertation presents one of the first studies that explicitly develops an understanding of male MPs' roles in the substantive representation of women. It analyzes whether and under what institutional and political conditions male MPs speak on behalf of women, and asks whether male MPs can be characterized as 'critical actors' who credibly and legitimately engage in the representation of women's interests in parliament.

To recapitulate, according to Childs and Krook (2009), critical actors are characterized by the following three qualities: (1) they are highly motivated and have a low threshold for political action, (2) they take action to represent women on their own, and (3) they stimulate others to promote women's interests in parliament. Using these characteristics as a benchmark, the results of the second and third paper do not support the notion of male MPs as critical actors. Although male MPs participate in women's substantive representation, their role is best described as that of a secondary actor.

First, the actions taken by male MPs on behalf of women are strongly affected by an increasing presence of female MPs in their PPGs. Men significantly reduce the intensity with which they speak on behalf of women if the proportion of female MPs is high. Instead of stimulating 
others to advocate for women's concerns, they rather withdraw from women's substantive representation as soon as the circumstances allow and let the women do the job.

This supports some of the theoretical arguments against the active participation of men in women's substantive representation that have been presented above. Related to Dovi's (2002) concept of a "preferable descriptive representative" who shares a linked fate with the represented group, female MPs are perceived as the legitimate representatives of women due to a shared social perspective. If there are enough women in parliament, male MPs feel that they no longer have to be responsive to women's interests because female MPs can represent these issues more credibly and more competently. This also supports Mansbridge's (2003) notion of a gyroscopic representation in a sense that men believe that female MPs are better able to use their 'internal gyroscope' to represent the crystallized and uncrystallized interests of women.

Second, the results from the third paper show that - in accordance with the theoretical skepticism about men's involvement in women's representation - many male MPs are not highly or even intrinsically motivated to represent women's interests. Given that the majority of men are not negatively affected by gender differences in the private, political, or economic sphere, they have no intrinsic motivation to stand up for gender equality. The behavior of male MPs in the British House of Commons demonstrates that men are mainly extrinsically motivated and only act in the interest of women if they need additional votes to secure their re-election to parliament.

In comparison with the results from the first paper, this finding demonstrates how the electoral incentive structure differently affects the behavior of female and male MPs. In cases of high electoral vulnerability, the representation of women's interests does not seem to be a promising strategy for women to win additional votes. Female MPs who substantively represent women seem to be fulfilling a generally accepted expectation and as a result, do not receive particular praise for it - quite the contrary. If their re-election is uncertain, since they fear to lose votes in their districts, they refrain from talking about women's interests and instead try to cater to the local interests of their constituency.

For male MPs, however, speaking about women's interests is a viable electoral strategy to cater to additional voters, since the representation of women is not a duty automatically expected of male politicians. This reflects the assumptions of the feminist institutionalism in showing how the same institutional "rules of the game" can affect men and women differently and, as a consequence, how the constraints on the political behavior of MPs can be unevenly 
distributed between the two sexes. Male MPs enjoy "the privilege of a larger maneuvering room that enables them to speak within the gender-equality discourse without being delegitimized when they prioritize other issues" (Bergqvist, Bjarnegård and Zetterberg 2018: 581). In contrast to female MPs, male politicians can freely choose whether or not they want to represent women's issues in parliament. And the higher their electoral vulnerability is, the more often they do this.

Third, the results from the British case also indicate that male MPs often do not take action on their own, but instead only support the work that female MPs do on behalf of women. When engaging in women's substantive representation, British male MPs mainly engage in low-cost parliamentary activities, merely signing women's EDMs that were initiated by other MPs, rather than writing their own motions on behalf of women.

In sum, male MPs do play a distinct role in women's substantive representation, and many of them are willing to represent women's interest in parliament. However, male legislators have rather high thresholds to take political action, they are mostly externally motivated, they do not motivate others to promote women's concerns, and they mostly engage in parliamentary activities that are less labor-intense than that of many female MPs. Hence, the results of this dissertation indicate that male MPs' role in women's substantive representation is best described as that of a secondary actor. Anne Phillips' (1995: 69) seems to be right when she claims that female MPs "can expect to find a few powerful allies among the men. What they cannot really expect is the degree of vigorous advocacy that people bring to their own concerns."

\section{Directions for Future Research}

Taken together, the results of this dissertation show that the analysis of women's substantive representation requires more than simply measuring how vigorously female MPs act for women. The relationship between women's descriptive and substantive representation is everything but straightforward, and it is therefore crucial to analyze the institutional mechanisms and the multiple actors who affect 'when', 'why', and 'how' the interests of women are represented in the parliamentary process.

Where do we go from here? Regarding the role of female MPs, a promising avenue for future research would be to take a closer look at the diversity of the group of female legislators. As the definition of women's interests has emphasized, women are not a homogenous or 
uniform group. In particular, not all women are feminists who support the extension of women's rights and gender equality. More recently, scholars have begun to analyze the behavior of these conservative women more closely, and have started to examine why some female MPs promote rather traditional gender roles in their parliamentary activities (Celis and Childs 2012; 2018; Wineinger and Nugent 2020; Reingold et al. 2020). In line with the finding that female MPs act as rational, vote-seeking actors, further studies should therefore examine the political and institutional conditions under which female politicians explicitly decide to represent anti-feminists standpoints. In light of the arguments made in the first and third paper, making claims about traditional gender roles could be a promising strategy for female MPs or candidates in very rural and conservative electoral districts to win additional votes from conservative (male) voters. Reingold et al. (2020) take a first step in this direction and find that conservative Republican women in the US Congress are more likely to initiate and support anti-abortion policies in contexts of highly polarized and competitive partisan environments. Concerning male MPs' behavior, the analyses have shown that men have distinct reasons for engaging in women's substantive representation that often differ from those of female MPs. However, these findings about the role of male MPs in women's substantive representation only constitute a first step, and further analyses are necessary to enhance our knowledge about how and why male MPs decide to take action on behalf of women.

Beyond the rational choice and sociological institutionalist approaches that have been used in this dissertation, the 'constructivist turn' (e.g. Saward 2006; 2010; Squires 2008; Severs 2012) within scholarship on representation presents a promising perspective on the role that male MPs can play in women's substantive representation. Scholars in this tradition perceive representation as a 'claims-making' process in which the representative claims to speak for the represented and thereby constitutes the substantive interests of that group (Saward 2006; 2010).

One crucial aspect regarding men's participation in women's representation is therefore the question of whether male MPs can legitimately claim to speak on behalf of women without sharing a linked fate or gendered experiences with the group of women. To assess whether or not an MP is a legitimate representative of a specific group, Rehfeld (2006; 2017) suggests one crucial criterion: "[I]n order to actually serve as a representative, [...] an individual must be recognized by the appropriate people - those whose recognition will impart to the individual the power to be a 'stand-in-for another group, 'in-order-to-do' some particular action” (Rehfeld 2017: 63). This means that men can only legitimately speak on behalf of women if women, as 
the represented, accept male MPs as their representative who legitimately make claims on their behalf. Or, in other words, the likelihood of male MPs' successful engagement in women's substantive representation hinges on the potential linkages between descriptive, substantive, and symbolic representation. According to Pitkin (1967), symbolic representation concerns affective beliefs about whether or not people feel that their interests and views are represented in parliament. Future research should therefore go beyond merely analyzing the extent of male MP's engagement in women's substantive representation, and should explore the question of whether or not women in the population feel represented if men speak on their behalf, or if they instead believe that their views and interests are more thoroughly represented by female MPs (English, Pearson and Strolovitch 2019).

This question could be analyzed in several experiments in which respondents could be presented with a vignette including, for example, a report on a newly enacted women-specific policy in parliament. Randomizing the gender of the responsible MP, female respondents could then be asked how well they feel represented to estimate whether the gender of a MP affects the perceived symbolic representation of women.

Methodologically, the presented quantitative studies should be supplemented by qualitative and more in-depth studies of individual MPs and their motivations to engage in women's substantive representation. Interviews with female, as well as male MPs, could help to grasp a deeper understanding of the policy priorities of individual MPs, and their reasons for acting (or not) in the interests of women.

A broader understanding of the potential actors and their incentives and opportunities to participate in the representation of women's interests in parliament not only contributes to the literature on women's representation, but also adds to a more general discussion about how a specific group's identity shapes the role that non-group members can play in its substantive representation. Many aspects of the role of male MPs in women's substantive representation also apply to other marginalized and underrepresented groups, including the representation of minority ethnic interests by members of the majority ethnic group, or the representation of LGBTQ interests by straight MPs. Future research in this field can therefore help to explore whether Burkes' idea of a virtual representation of group interests is possible and acceptable today, and to what extent the presence of descriptive representatives is indeed a necessary condition for the successful substantive representation of group interests.

The results of this dissertation demonstrate that the parliamentary representation of women's interests is still perceived as a primary duty of female MPs, and that male MPs only play the 
role of a secondary or ancillary actor in this regard. Perceptions about a gendered logic of appropriateness seem to be deeply entrenched in present-day parliaments. And as the new institutionalism reminds us, institutions are sticky and hard to change. However, it also tells us that in the long-run, perceptions about appropriate gender roles can be changed and the notion of female MPs as the only actors responsible for the representation of women's interests might be modified (Chappell 2006). As Pitkin (1967) and Phillips (1995) have both observed, representation is a long process. "Fair representation is not something that can be achieved in one moment, nor is it something that can be guaranteed in advance. Representation depends on the continuing relationship between representatives and the represented [...]" (Philips 1995: 82).

Future analyses of women's substantive representation will uncover whether we are able to break with traditional gender roles and accept that the representation of women's interests is not only a responsibility of female MPs, that not all female MPs are feminists advocating an extension of women's rights, and that both male and female MPs can become critical actors in women's substantive representation. 


\section{Literature}

Acker, Joan. 1990. “Hierarchies, Jobs, Bodies: A Theory of Gendered Organizations.” Gender and Society 4(2): 139-58.

Alcoff, Linda. 1991. “The Problem of Speaking for Others.” Cultural Critique 20: 5-32.

Alcoff, Linda. 1995. “The Problem of Speaking for Others.” In Who Can Speak, eds. Judith Roof and Robyn Wiegman. Chicago: University of Illinois Press, 97-119.

Annesley, Claire, Isabelle Engeli, and Francesca Gains. 2015. “The Profile of Gender Equality Issue Attention in Western Europe.” European Journal of Political Research 54(3): 525-42.

Arnesen, Sveinung, and Yvette Peters. 2017. "The Legitimacy of Representation: How Descriptive, Formal, and Responsiveness Representation Affect the Acceptability of Political Decisions." Comparative Political Studies 51(7): 868-99.

Bäck, Hanna, and Marc Debus. 2019. "When Do Women Speak? A Comparative Analysis of the Role of Gender in Legislative Debates.” Political Studies 67(3): 576-96.

Bäck, Hanna, Marc Debus, and Jochen Müller. 2014. "Who Takes the Parliamentary Floor? The Role of Gender in Speech-making in the Swedish Riksdag.” Political Research Quarterly 67(3): 504-18.

Baldez, Lisa. 2011. “The UN Convention to Eliminate All Forms of Discrimination Against Women (CEDAW): A New Way to Measure Women's Interests.” Politics Q Gender 7(3): 41923.

Barnes, Tiffany D. 2016. Gendering Legislative Behavior: Institutional Constraints and Collaboration. New York: Cambridge University Press.

Beckwith, Karen. 2011. "Interests, Issues, and Preferences: Women's Interests and Epiphenomena of Activism.” Politics \& Gender 7(3): 424-29

Beckwith, Karen. 2014. "Plotting the Path from One to the Other - Women's Interests and Political Representation." In Representation. The Case of Women, eds. Maria C. EscobarLemmon and Michelle M. Taylor-Robinson. Oxford: Oxford University Press, 19-40.

Beckwith, Karen, and Kimberly Cowell-Meyers. 2007. "Sheer Numbers: Critical Representation Thresholds and Women's Political Representation.” Perspectives on Politics 5(3): 553-65. 
Bergqvist, Christina, Elin Bjarnegård, and Per Zetterberg. 2018. “The Gendered Leeway: Male Privilege, Internal and External Mandates, and Gender-Equality Policy Change.” Politics, Groups, and Identities 6(4): 576-92.

Best, Heinrich, Michael Edinger, Daniel Gerstenhauer, and Lars Vogel. 2010. Jenaer Parlamentarierbefragung 2010. Dokumentation zum Deutschen Bundestag. Jena.

Bird, Karen. 2005. "Gendering Parliamentary Questions." British Journal of Politics and International Relations 7(3): 353-70.

Blalock, Hubert M. 1967. Toward a Theory of Minority-Group Relations. New York: Wiley.

Bratton, Kathleen A. 2002. "The Effect of Legislative Diversity on Agenda Setting: Evidence from Six State Legislatures." American Politics Research 30(2): 115-42.

Bratton, Kathleen A., and Leonard P. Ray. 2002. "Descriptive Representation, Policy Outcomes, and Municipal Day-Care Coverage in Norway." American Journal of Political Science 46(2): 428-37.

Brunsbach, Sandra. 2011. "Machen Frauen den Unterschied? Parlamentarierinnen als Repräsentantinnen frauenspezifischer Interessen im Deutschen Bundestag." Zeitschrift für Parlamentsfragen 42(1): 3-24.

Campbell, David E., and Christina Wolbrecht. 2006. "See Jane Run: Women Politicians as Role Models for Adolescents." The Journal of Politics 68(2): 233-47.

Campbell, Rosie, and Sarah Childs. 2015. "Conservatism, Feminisation and the Representation of Women in UK Politics.” British Politics 10(2): 148-68.

Carey, John M. 2007. “Competing Principals, Political Institutions, and Party Unity in Legislative Voting." American Journal of Political Science 51(1): 92-107.

Carey, John M., and Matthew S. Shugart. 1995. "Incentives to Cultivate a Personal Vote: A Rank Ordering of Electoral Formulas.” Electoral Studies 14(4): 417-39.

Carroll, Susan. 1994. Women as Candidates in American Politics. Bloomington: Indiana University Press.

Carroll, Susan J. 2002. “Representing Women: Congresswomen's Perceptions of Their Representational Roles." In Women Transforming Congress, eds. Cindy S. Rosenthal and Richard F. Fenno. Oklahoma: University of Oklahoma Press, 50-68. 
Catalano, Ana. 2009. "Women Acting for Women? An Analysis of Gender and Debate Participation in the British House of Commons 2005-2007.” Politics \& Gender 5(1): 45-68.

Caul, Miki. 1999. “Women's Representation in Parliament: The Role of Political Parties." Party Politics 5(1): 79-98.

Celis, Karen. 2006. “Substantive Representation of Women: The Representation of Women's Interests and the Impact of Descriptive Representation in the Belgian Parliament (19001979)." Journal of Women, Politics \& Policy 28(2): 85-114.

Celis, Karen. 2008a. “Studying Women's Substantive Representation in Legislatures: When Representative Acts, Contexts and Women's Interests Become Important.” Representation 44(2): 111-23.

Celis, Karen. 2008b. “Gendering Representation.” In Politics, Gender, and Concepts, eds. Gary Goertz and Amy Mazur. Cambridge: Cambridge University Press, 71-93.

Celis, Karen. 2009. “Substantive Representation of Women (and Improving it): What it is and Should be About?" Comparative European Politics 7(1): 95-113.

Celis, Karen. 2019. “Exclusion and Representation: Women's Struggle for Inclusion.” In The Edges of Political Representation - Mapping, Critiquing and Pushing the Boundaries, eds. Mihnea Tanasescu and Claire Dupont. London: Rowman \& Littlefield, 27-46.

Celis, Karen, and Sarah Childs. 2012. "The Substantive Representation of Women: What to Do with Conservative Claims?” Political Studies 60(1): 213-25.

Celis, Karen, Sarah Childs, Johanna Kantola, and Mona L. Krook. 2008. "Rethinking Women's Substantive Representation.” Representation 44(2): 99-110.

Celis, Karen, and Silvia Erzeel. 2015. "Beyond the Usual Suspects: Non-Left, Male and NonFeminist MPs and the Substantive Representation of Women." Government and Opposition 50(1): 45-64.

Celis, Karen, and Bram Wauters. 2010. "Pinning the Butterfly: Women, Blue-Collar and Ethnic Minority MPs vis-à-vis Parliamentary Norms and the Parliamentary Role of the Group Representative.” The Journal of Legislative Studies 16(3): 380-93.

Chappel, Louise. 2006. "Comparing Political Institutions: Revealing the Gendered Logic of Appropriateness.” Politics Q Gender 2(2): 223-35. 
Chappel, Louise, and Georgina Waylen. 2013. "Gender and the Hidden Life of Institutions." Public Administration 91(3): 599-615.

Childs, Sarah. 2002. "Hitting the Target: Are Labour Women MPs 'Acting for' Women?” Parliamentary Affairs 55(1): 143-53.

Childs, Sarah. 2004. New Labour's Women MPs: Women Representing Women. London: Routledge.

Childs, Sarah. 2006. “The Complicated Relationship between Sex, Gender and the Substantive Representation of Women.” European Journal of Women's Studies 13(1): 7-21.

Childs, Sarah, and Mona L. Krook. 2006. "Should Feminists Give Up on Critical Mass? A Contingent Yes." Politics a Gender 2(4): 522-30.

Childs, Sarah, and Mona L. Krook. 2008. "Critical Mass Theory and Women's Political Representation." Political Studies 56(3): 725-36.

Childs, Sarah, and Mona L. Krook. 2009. “Analysing Women's Substantive Representation: From Critical Mass to Critical Actors." Government and Opposition 44(2): 125-45.

Childs, Sarah, and Joni Lovenduski. 2013. "Political Representation.” In The Oxford Handbook of Gender and Politics, eds. Georgina Waylen, Karen Celis, Johanna Kantola and S. Laurel Weldon. Oxford: Oxford University Press, 489-514.

Childs, Sarah, and Julie Withey. 2004. "Women Representatives Acting for Women: Sex and the Signing of Early Day Motions in the 1997 British Parliament.” Political Studies 52(3): $552-64$.

Childs, Sarah, and Julie Withey. 2006. “The Substantive Representation of Women: The Case of the Reduction of VAT on Sanitary Products." Parliamentary Affairs 59(1): 10-23.

Clayton, Amanda, Diana Z. O'Brien, and Jennifer M. Piscopo. 2019. “All Male Panels? Representation and Democratic Legitimacy." American Journal of Political Science 63(1): $113-29$.

Coffé, Hilde, Catherine Bolzendahl, and Katia Schnellecke. 2019. “Parties, Issues, and Power: Women's Partisan Representation on German Parliamentary Committees." European Journal of Politics and Gender 2(2): 257-81. 
Coffé, Hilde, Reiser, Marion. 2018. “Political Candidates' Attitudes Towards Group Representation." Journal of Legislative Studies 24(3): 272-97.

Costa, Mia, Jill S. Greenlee, Tatishe Nteta, Jesse H. Rhodes, and Elizabeth A. Sharrow. 2019. "Family Ties? The Limits of Fathering Daughters on Congressional Behavior." American Politics Research 47(3): 471-93.

Cowley, Philip, and Sarah Childs. 2003. “Too Spineless to Rebel? New Labour's Women MPs.” British Journal of Political Science 33(3): 345-65.

Crowley, Jocelyn E. 2004. “When Tokens Matter.” Legislative Studies Quarterly 29(1): 109-36.

Dahlerup, Drude. 1988. "From a Small to a Large Minority: Women in Scandinavian Politics.” Scandinavian Political Studies 11(4): 275-98.

Dahlerup, Drude. 2014. "Representing Women - Defining Substantive Representation of Women.” In Representation. The Case of Women, eds. Maria C. Escobar-Lemmon and Michelle M. Taylor-Robinson. Oxford: Oxford University Press, 58-75.

Debus, Marc, and Martin E. Hansen. 2014. "Representation of Women in the Parliament of the Weimar Republic: Evidence from Roll Call Votes.” Politics Q Gender 10(3): 341-64.

Devlin, Claire, and Robert Elgie. 2008. “The Effect of Increased Women's Representation in Parliament: The Case of Rwanda." Parliamentary Affairs 61(2): 237-54.

Diamond, Irene, and Nancy Hartsock. 1981. "Beyond Interests in Politics: A Comment on Virginia Sapiro's "When Are Interests Interesting? The Problem of Political Representation of Women"." American Political Science Review 75(3): 717-21.

Dingler, Sarah C., Corinna Kroeber, and Jessica Fortin-Rittberger. 2019. "Do Parliaments Underrepresent Women's Policy Preferences? Exploring Gender Equality in Policy Congruence in 21 European Democracies." Journal of European Public Policy 26(2): 302-21.

Disch, Lisa. 2011. “Toward a Mobilization Conception of Democratic Representation." American Political Science Review 105(1): 100-14.

Dodson, Debra L. 2006. The Impact of Women in Congress. Oxford: Oxford University Press.

Dovi, Suzanne. 2002. "Preferable Descriptive Representatives: Will Just Any Woman, Black, or Latino Do?” American Political Science Review 96(4): 729-43.

Dovi, Suzanne. 2007a. The Good Representative. Malden: Blackwell Publishing. 
Dovi, Suzanne. 2007b. “Theorizing Women's Representation in the United States.” Politics \& Gender 3(3): 297-319.

Duverger, Maurice. 1955. The Political Role of Women. Paris: UNESCO.

English, Ashley, Kathryn Pearson, and Dara Z. Strolovitch. 2019. "Who Represents Me? Race, Gender, Partisan Congruence, and Representational Alternatives in a Polarized America.” Political Research Quarterly 72(4): 785-804.

Erzeel, Silvia. 2015. "Explaining Legislators' Actions on Behalf of Women in the Parliamentary Party Group: The Role of Attitudes, Resources, and Opportunities." Journal of Women, Politics Q Policy 36(4): 440-63.

Erzeel, Silvia, Didier Caluwaerts, and Karen Celis. 2015. "From Agency to Institutions and Back: Comparing Legislators' Acting on Behalf of Women in Parliamentary Democracies.” In Representing the People - A Survey among Members of Statewide and Sub-State Parliaments, eds. Kris Deschouwer and Sam Depauw. Oxford: Oxford University Press, 66-86.

Espírito-Santo, Ana, André Freire, and Sofia Serra-Silva. 2020. "Does Women's Descriptive Representation Matter for Policy Preferences? The Role of Political Parties.” Party Politics 26(2): 227-37.

Eulau, Heinz, John C. Wahlke, William Buchanan, and Leroy C. Ferguson. 1959. "The Role of the Representative: Some Empirical Observations on the Theory of Edmund Burke." American Political Science Review 53(3): 742-56.

Evans, Elizabeth. 2012. "From Finance to Equality: The Substantive Representation of Women's Interests by Men and Women MPs in the House of Commons." Representation 48(2): 183-96.

Foos, Florian, and Fabrizio Gilardi. 2019. “Does Exposure to Gender Role Models Increase Women's Political Ambition? A Field Experiment with Politicians.” Journal of Experimental Political Science. Online First. https://doi.org/10.1017/XPS.2019.21.

Fortin-Rittberger, Jessica, and Christina Eder. 2013. “Towards a Gender-Equal Bundestag? The Impact of Electoral Rules on Women's Representation.” West European Politics 36(5): 969-85.

Fossen, Thomas. 2019. "Constructivism and the Logic of Political Representation." The American Political Science Review 113(3): 824-37. 
Franceschet, Susan, and Jennifer M. Piscopo. 2008. “Gender Quotas and Women's Substantive Representation: Lessons from Argentina.” Politics Q Q Gender 4(3): 393-425.

Funk, Kendall D., and Andrew Q. Philips. 2019. “Representative Budgeting: Women Mayors and the Composition of Spending in Local Governments." Political Research Quarterly 72(1): $19-33$.

Geertz, Clifford. 1973. The Interpretation of Cultures: Selected Essays. New York: Basic Books.

Gerrity, Jessica C., Tracy Osborn, and Jeanette M. Mendez. 2007. "Women and Representation: A Different View of the District?” Politics \& Gender 3(2): 179-200.

Gilardi, Fabrizio. 2015. “The Temporary Importance of Role Models for Women's Political Representation.” American Journal of Political Science 59(4): 957-70.

Grey, Sandra. 2006. "Numbers and Beyond: The Relevance of Critical Mass in Gender Research.” Politics Q Gender 2(4): 492-502.

Grimmer, Justin, and Brandon M. Stewart. 2013. “Text as Data: The Promise and Pitfalls of Automatic Content Analysis Methods for Political Texts.” Political Analysis 21(3): 267-97.

Hall, Peter A., and Rosemary C. R. Taylor. 1996. "Political Science and the Three New Institutionalisms." Political Studies 44(5): 936-57.

Hardin, James W., and Joseph Hilbe. 2007. Generalized Linear Models and Extensions. College Station: Stata Press.

Heath, Roseanna M., Leslie A. Schwindt-Bayer, and Michelle M. Taylor-Robinson. 2005. “Women on the Sidelines: Women's Representation on Committees in Latin American Legislatures." American Journal of Political Science 49(2): 420-36.

Höhmann, Daniel. 2017. "Frauen in politischen Spitzenämtern: Die Ernennung von weiblichen Ministern in die Landeskabinette der deutschen Bundesländer.” Zeitschrift für Vergleichende Politikwissenschaft 11(3): 391-416.

Homola, Jonathan. 2019. “Are Parties Equally Responsive to Women and Men?” British Journal for Political Science 49(3): 957-75.

Htun, Mala, and Mark P. Jones. 2002. "Engendering the Right to Participate in DecisionMaking: Electoral Quotas and Women's Leadership in Latin America.” In Gender, the 
Politics of Rights and Democracy in Latin America, eds. Maxine Molyneux and Nikki Craske. Basingstoke: Palgrave, 432-56.

Jónasdóttir, Anna G. 1988. “On the Concept of Interests, Women's Interests, and the Limitation of Interest Theory." In The Political Interests of Gender, eds. Kathleen B. Jones and Anna G. Jónasdóttir. London: Sage, 33-65.

Jones, Mark P. 1997. "Legislator Gender and Legislator Policy Priorities in the Argentine Chamber of Deputies and the United States House of Representatives." Policy Studies Journal 25(4): 613-29.

Kanter, Rosabeth M. 1977. "Some Effects of Proportions on Group Life: Skewed Sex Ratios and Responses to Token Women.” American Journal of Sociology 82(5): 965-90.

Keh, Julia F. 2015. “The Centralisation of Parliamentary Policy Statements in Western European Parliaments.” West European Politics 38(5): 1086-1105.

Kellermann, Michael. 2013. "Sponsoring Early Day Motions in the British House of Commons as a Response to Electoral Vulnerability." Political Science Research and Methods 1(2): 263-80.

Kenworthy, Lane, and Melissa Malami. 1999. "Gender Inequality in Political Representation: A Worldwide Comparative Analysis." Social Forces 78(1): 235-68.

Kittilson, Miki C. 2008. "Representing Women: The Adoption of Family Leave in Comparative Perspective." The Journal of Politics 70(2): 323-34.

Kittilson, Miki C. 2011. "Women, Parties and Platforms in Post-Industrial Democracies." Party Politics 17(1): 66-92.

Kokkonen, Andrej, and Lena Wängnerud. 2017. “Women's Presence in Politics and Male Politicians Commitment to Gender Equality in Politics: Evidence from 290 Swedish Local Councils." Journal of Women, Politics Q Policy 38(2): 199-220.

Kroeber, Corinna. 2018. "How to Measure the Substantive Representation of Traditionally Excluded Groups in Comparative Research: A Literature Review and New Data." Representation 54(3): 241-59.

Krook, Mona L. 2018. “Electoral Systems and Women's Representation.” In Oxford Handbook of Electoral Systems, eds. Erik Herron, Robert Pekkanen and Matthew Shugart. Oxford: Oxford University Press, 175-93. 
Krook, Mona L., and Fiona Mackay, eds. 2011. Gender, Politics and Institutions: Towards a Feminists Institutionalism. Basingstoke: Palgrave Macmillan.

Krook, Mona L., and Leslie Schwindt-Bayer. 2013. “Electoral Institutions.” In The Oxford Handbook of Gender and Politics, eds. Georgina Waylen, Karen Celis, Johanna Kantola and S. Laurel Weldon. Oxford: Oxford University Press, 554-78.

Lowande, Kenneth, Melinda Ritchie, and Erinn Lauterbach. 2019. "Descriptive and Substantive Representation in Congress: Evidence from 80,000 Congressional Inquiries." American Journal of Political Science 63(3): 644-59.

Lucas, Christopher, Richard Nielsen, Margaret Roberts, Brandon Stewart, Alex Storer, and Dustin Tingley. 2015. “Computer-Assisted Text Analysis for Comparative Politics.” Political Analysis 23(2): 254-77.

MacDonald, Jason A., and Erin E. O’Brien. 2011. "Quasi-Experimental Design, Constituency, and Advancing Women's Interests: Reexamining the Influence of Gender on Substantive Representation." Political Research Quarterly 64(2): 472-86.

Mackay, Fiona. 2008. “'Thick' Conceptions of Substantive Representation: Women, Gender and Political Institutions." Representation 44(2): 125-39.

Mackay, Fiona, Meryl Kenny, and Louise Chappell. 2010. “New Institutionalism Through a Gender Lens: Towards a Feminist Institutionalism?” International Political Science Review 31(5): 573-88.

Manin, Bernard. 1997. The Principles of Representative Government. Cambridge: Cambridge University Press.

Manow, Philip. 2015. Mixed Rules, Mixed Strategies. Candidates and Parties in Germany's Electoral System. Colchester: ECPR Press.

Mansbridge, Jane. 1999. "Should Blacks Represent Blacks and Women Represent Women? A Contingent "Yes"." The Journal of Politics 61(3): 628-57.

Mansbridge, Jane. 2003. “Rethinking Representation.” American Political Science Review 97(4): 515-28.

Mansbridge, Jane. 2009. “A “Selection Model” of Political Representation.” Journal of Political Philosophy 17(4): 369-98. 
Mansbridge, Jane. 2011. "Clarifying the Concept of Representation.” American Political Science Review 105(3): 621-30.

Mansbridge, Jane. 2015. “Should Workers Represent Workers?” Swiss Political Science Review 21(2): 261-70.

March, James G., and Johan P. Olsen. 1984. “The New Institutionalism: Organizational Factors in Political Life." American Political Science Review 78(3): 734-49.

Martin, Shane. 2011. "Using Parliamentary Questions to Measure Constituency Focus: An Application to the Irish Case." Political Studies 59(2): 472-88.

Mateo Diaz, Mercedes. 2005. Representing Women? Female Legislators in West European Parliaments. Colchester: ECPR Press.

Mendelberg, Tali, Christopher F. Karpowitz, and Nicholas Goedert. 2014. “Does Descriptive Representation Facilitate Women's Distinctive Voice? How Gender Composition and Decision Rules Affect Deliberation.” American Journal of Political Science 58(2): 291-306.

Mill, John S. 1967[1861]. Considerations on Representative Government. London: Longmans, Green and Co.

Monroe, Burt, and Philip Schrodt. 2008. “Introduction to the Special Issue: The Statistical Analysis of Political Text." Political Analysis 16(4): 351-55.

Mullahy, John. 1986. "Specification and Testing of Some Modified Count Data Models." Journal of Econometrics 33(3): 341-65.

Müller, Wolfgang C., and Kaare Strøm. 1999. Policy, Office, or Votes? How Political Parties in Western Europe Make Hard Decisions. Cambridge: Cambridge University Press.

Norris, Pippa. 1985. “Women’s Legislative Participation in Western Europe.” West European Politics 8(4): 90-101.

North, Douglass C. 1990. Institutions, Institutional Change and Economic Performance. Cambridge: Cambridge University Press.

O'Brien, Diana Z., and Jennifer M. Piscopo. 2019. “The Impact of Women in Parliament.” In The Palgrave Handbook of Women's Political Rights, eds. Susan Franceschet, Mona L. Krook and Netina Tan. London: Palgrave Macmillan, 53-72. 
Olofsdotter Stensota, Helena. 2020. "Does Care Experience Affect Policy Interests? Male Legislators, Parental Leave, and Political Priorities in Sweden.” Politics Q Gender 16(1): 123 44.

Ostrom, Elinor. 1990. Governing the Commons: The Evolution of Institutions for Collective Action. Cambridge: Cambridge University Press.

Palmieri, Sonia. 2013. "Sympathetic Advocates: Male Parliamentarians Sharing Responsibility for Gender Equality." Gender \& Development 21(1): 67-80.

Parker, David. 2019. “Looking after Constituency Interests: The Utilisation of MP Expenses and Early Day Motions to Craft Constituency Service Home Styles.” Parliamentary Affairs. Online First. https://doi.org/10.1093/pa/gsz042.

Phillips, Anne. 1994. “Democracy and Representation: Or, Why Should It Matter Who Our Representatives Are?” SVPW-Jahrbuch 34(1): 63-76.

Phillips, Anne. 1995. The Politics of Presence. Oxford: Clarendon Press.

Phillips, Anne. 2012. “Representation and Inclusion.” Politics Q G Gender 8(4): 512-18.

Pitkin, Hanna F. 1967. The Concept of Representation. Berkeley: University of California.

Reher, Stefanie. 2018. "Gender and Opinion-Policy Congruence in Europe." European Political Science Review 10(4): 613-35.

Rehfeld, Andrew. 2006. “Towards a General Theory of Political Representation.” The Journal of Politics 68(1): 1-21.

Rehfeld, Andrew. 2009. “Representation Rethought: On Trustees, Delegates, and Gyroscopes in the Study of Political Representation and Democracy." American Political Science Review 103(2): 214-30.

Rehfeld, Andrew. 2011. “The Concepts of Representation.” American Political Science Review 105(3): 631-41.

Rehfeld, Andrew. 2017. "What is Representation? On Being and Becoming a Representative." In Reclaiming Representation - Contemporary Advances in the Theory of Political Representation, ed. Mónica Brito Vieira. London: Routledge, 50-74.

Reingold, Beth. 1992. "Concepts of Representation among Female and Male State Legislators." Legislative Studies Quarterly 17(4): 509-37. 
Reingold, Beth. 2000. Representing Women: Sex, Gender, and Legislative Behavior in Arizona and California. Chapel Hill: University of North Carolina Press.

Reingold, Beth, Rebecca J. Kreitzer, Tracy Osborn, and Michele L. Swers. 2020. “Anti-abortion Policymaking and Women's Representation.” Political Research Quarterly. Online First. https://doi.org/10.1177/1065912920903381.

Reingold, Beth, and Michele Swers. 2011. “An Endogenous Approach to Women's Interests: When Interests Are Interesting in and of Themselves.” Politics Q Gender 7(3): 429-35.

Reyes-Householder, Catherine. 2016. "Presidential Power, Partisan Continuity and ProWomen Change in Chile: 2000-10." In The Gendered Executive: A Comparative Analysis of Presidents, Prime Ministers, and Chief Executives, eds. Janet M. Martin and Maryanne Borrelli. Philadelphia: Temple University Press, 229-49.

Reynolds, Andrew. 1999. "Women in the Legislatures and Executives of the World: Knocking at the Highest Glass Ceiling." World Politics 51(4): 547-72.

Saalfeld, Thomas. 2011. "Parliamentary Questions as Instruments of Substantive Representation: Visible Minorities in the UK House of Commons, 2005-10.” The Journal of Legislative Studies 17(3): 271-89.

Saalfeld, Thomas, and Daniel Bischof. 2013. "Minority-Ethnic MPs and the Substantive Representation of Minority Interests in the House of Commons, 2005-2011." Parliamentary Affairs 66(2): 305-28.

Saalfeld, Thomas, and Kaare Strøm. 2014. "Political Parties and Legislators.” In The Oxford Handbook of Legislative Studies, eds. Shane Martin, Thomas Saalfeld and Kaare Strøm. Oxford: Oxford University Press, 371-98.

Sapiro, Virginia. 1981. "When Are Interests Interesting? The Problem of Political Representation of Women.” American Political Science Review 75(3): 701-16.

Saward, Michael. 2006. “The Representative Claim.” Contemporary Political Theory 5(3): 297318.

Saward, Michael. 2010. The Representative Claim. Oxford: Oxford University Press.

Schwindt-Bayer, Leslie A. 2010. Political Power and Women's Representation in Latin America. Oxford: Oxford University Press. 
Schwindt-Bayer, Leslie A., and William Mishler. 2005. “An Integrated Model of Women's Representation." The Journal of Politics 67(2): 407-28.

Severs, Eline. 2012. “Substantive Representation Through a Claims-Making Lens: A Strategy for the Identification and Analysis of Substantive Claims." Representation 48(2): 169-81.

Severs, Eline. 2019. “Theorizing Representation Fairness: Why We Need to Account for Social Groups." In The Edges of Political Representation - Mapping, Critiquing and Pushing the Boundaries, eds. Mihnea Tanasescu and Claire Dupont. London: Rowman \& Littlefield, 81102.

Sieberer, Ulrich. 2006. "Party Unity in Parliamentary Democracies: A Comparative Analysis." The Journal of Legislative Studies 12(2): 150-78.

Sieberer, Ulrich, Thomas Saalfeld, Tamaki Ohmura, Henning Bergmann, and Stefanie Bailer. 2018. "Roll-Call Votes in the German Bundestag: A New Dataset, 1949-2013." British Journal of Political Science. Online First. https://doi.org/10.1017/S0007123418000406.

Smooth, Wendy. 2011. "Standing for Women? Which Women? The Substantive Representation of Women's Interests and the Research Imperative of Intersectionality." Politics Q Gender 7(3): 436-41.

Sobolewska, Maria, Rebecca McKee, and Rosie Campbell. 2018. “Explaining Motivation to Represent: How Does Descriptive Representation Lead to Substantive Representation of Racial and Ethnic Minorities?” West European Politics 41(6): 1237-61.

Squires, Judith. 2008. “The Constitutive Representation of Gender: Extra-Parliamentary RePresentation of Gender Relations.” Representation 44(2): 187-204.

Staehr Harder, Mette M. 2019. “Pitkin's Second Way: Freeing Representation Theory from Identity." Representation: Online First. https://doi.org/10.1080/00344893.2019.1636853.

Stoffel, Michael F., and Ulrich Sieberer. 2018. "Measuring Re-Election Prospects Across Electoral Systems: A General Approach Applied to Germany.” West European Politics 41(5): 1191-1207.

Studlar, Donley T., and Ian McAllister. 2002. “Does a Critical Mass Exist? A Comparative Analysis of Women's Legislative Representation since 1950.” European Journal of Political Research 41(2): 233-53. 
Swers, Michele L. 2002. The Difference Women Make: The Policy Impact of Women in Congress. Chicago: University of Chicago Press.

Swers, Michele L. 2005. "Connecting Descriptive and Substantive Representation: An Analysis of Sex Differences in Cosponsorship Activity.” Legislative Studies Quarterly 30(3): 407-33.

Tamerius, Karin L. 1995. “Sex, Gender, and Leadership in the Representation of Women.” In Gender Power, Leadership, and Governance, eds. Georgia Duerst-Lahti and Rita M. Kelly. Ann Arbor: Michigan University Press, 243-49.

Taylor-Robinson, Michelle M. 2014. "Gender and Legislatures.” In The Oxford Handbook of Legislative Studies, eds. Shane Martin, Thomas Saalfeld and Kaare Strøm. Oxford: Oxford Univ. Press, 250-66.

Taylor-Robinson, Michelle M., and Roseanna M. Heath. 2003. "Do Women Legislators Have Different Policy Priorities than Their Male Colleagues? A Critical Cast Test.” Women \& Politics 24(4): 77-101.

Thelen, Kathleen. 1999. "Historical Institutionalism in Comparative Politics.” Annual Review of Political Science 2(1): 369-404.

Thomas, Sue. 1994. How Women Legislate. Oxford: Oxford University Press.

Towns, Ann. 2003. "Understanding the Effects of Larger Ratios of Women in National Legislatures: Proportions and Gender Differentiation in Sweden and Norway.” Women \& Politics 25(1-2): 1-29.

Tremblay, Manon. 1998. "Do Female MPs Substantively Represent Women? A Study of Legislative Behaviour in Canada's 35th Parliament." Canadian Journal of Political Science 31(3): 435-65.

Tremblay, Manon. 2006. “The Substantive Representation of Women and PR: Some Reflections on the Role of Surrogate Representation and Critical Mass." Politics \& Gender 2(4): 502-11.

Uhlaner, Carole J. 2012. “Potentiality and Representation: The Link between Descriptive Representation and Participation in the United States.” Politics Q Gender 8(4): 535-41.

Urbinati, Nadia. 2008. Representative Democracy: Principles and Genealogy. Chicago: University of Chicago Press. 
Vega, Arturo, and Juanita M. Firestone. 1995. "The Effects of Gender on Congressional Behavior and the Substantive Representation of Women." Legislative Studies Quarterly 20(2): 213-22.

Volden, Craig, Alan E. Wiseman, and Dana E. Wittmer. 2018. "Women's Issues and Their Fates in the US Congress." Political Science Research and Methods 6(4): 679-96.

Wängnerud, Lena. 2009. "Women in Parliaments: Descriptive and Substantive Representation." Annual Review of Political Science 12: 51-69.

Washington, Ebonya L. 2008. "Female Socialization: How Daughters Affect Their Legislator Fathers' Voting on Women's Issues." American Economic Review 98(1): 311-32.

Weingast, Barry. 2002. "Rational-Choice Institutionalism." In Political Science: The State of the Discipline, eds. Ira Katznelson and Milner Helen. New York: Norton, 660-92.

Welzel, Christian, and Ronald Inglehart. 2014. "Political Culture.” In Comparative Politics, ed. Daniele Caramani. Oxford: Oxford University Press, 284-301.

Wilkerson, John, and Andreu Casas. 2017. "Large-Scale Computerized Text Analysis in Political Science: Opportunities and Challenges." Annual Review of Political Science 20: 52944.

Williams, Melissa S. 1998. Voice, Trust, and Memory: Marginalized Groups and the Failings of Liberal Representation. Princeton: Princeton University Press.

Wineinger, Catherine, and Mary K. Nugent. 2020. “Framing Identity Politics: Right-Wing Women as Strategic Party Actors in the UK and US." Journal of Women, Politics Q Policy 41(1): 91-118.

Xydias, Christina. 2007. “Inviting More Women to the Party: Gender Quotas and Women's Substantive Representation in Germany." International Journal of Sociology 37(4): 52-66.

Xydias, Christina. 2013. “Mapping the Language of Women's Interests: Sex and Party Affiliation in the Bundestag." Political Studies 61(2): 319-40.

Xydias, Christina. 2014. "Women's Rights in Germany: Generations and Gender Quotas." Politics Q Gender 10(1): 4-32.

Yoder, Janice D. 1991. "Rethinking Tokenism: Looking beyond Numbers.” Gender \& Society 5(2): 178-92. 
Young, Iris M. 1990. Justice and the Politics of Difference. Princeton: Princeton University Press. Young, Iris M. 2000. Inclusion and Democracy. Oxford: Oxford University Press. 
Aufsatz 1

When Do Female MPs Represent Women's Interests? Electoral Systems and the Legislative Behavior of Women.

Daniel Höhmann

Publiziert im Jahr 2020 in Political Research Quarterly 73(4): 834-847, https://doi.org/10.1177/1065912919859437. 


\title{
When Do Female MPs Represent Women's Interests? Electoral Systems and the Legislative Behavior of Women 2020, Vol. 73(4) 834-847 (C) 2019 University of Utah Article reuse guidelines: \\ sagepub.com/journals-permissions DOI: I0.1।77/10659|2919859437 journals.sagepub.com/home/prq (SAGE
}

Political Research Quarterly

\author{
Daniel Höhmann' (iD
}

\begin{abstract}
Research on women's political representation has repeatedly shown that female legislators represent women's interest more strongly than their male colleagues. However, a growing body of literature shows that the parliamentary behavior of female members of parliament (MPs) and the relationship between descriptive and substantive representation of women is affected by a number of institutional variables. This paper contributes to this debate by analyzing the effect of the electoral incentive structure on the substantive representation of women. Drawing on the Competing Principals Theory, it is expected that female legislators more frequently act on behalf of women if their re-election does not depend on the representation of local interests in electoral districts. The empirical analysis uses the German mixed electoral system and analyzes the representation of women's issues in oral and written parliamentary questions tabled in the German Bundestag between 2005 and 2013. The results of a hurdle regression model show that female MPs are more likely to concentrate on the representation of women's interests if their re-election is secured and if they do not have to fight for additional local votes from their district.
\end{abstract}

\section{Keywords}

electoral systems, gender, substantive representation, women's interests, parliamentary questions

\section{Introduction}

Research on women in parliaments often proposes a link between the descriptive and substantive representation of women and suggests that having a higher proportion of female legislators leads to a higher representation of women-specific interests (Wängnerud 2009). Because female members of parliament (MPs) share gender-specific experiences and problems with the female population-so the argument goes-it is expected that they are more concerned with women-specific topics and that they also represent these issues more frequently in the parliamentary process compared with their male colleagues (e.g., Mansbridge 1999; Phillips 1995). Numerous empirical studies regarding the behavior of female MPs confirm this hypothesis (e.g., Gerrity, Osborn, and Mendez 2007; Swers 2002; Volden, Wiseman, and Wittmer 2018). More recently, scholars have begun to investigate the causal mechanisms of how descriptive representation is translated into more substantive representation of women. They have shown that the political and institutional conditions in the legislature (e.g., partisanship, quotas) moderate the parliamentary behavior of female MPs and significantly affect their possibilities to focus on the representation of women's interests (e.g., Barnes 2016; Dodson
2006; Xydias 2013, 2014). However, our knowledge about the effect of institutional variables on the parliamentary behavior of female MPs and the substantive representation of women is still limited. As Krook (2018: 187) points out, it is particularly striking that the effect of the incentive structures from different electoral systems on female legislators and the substantive representation of women has only been studied very rarely to date. Although mainstream parliamentary research has repeatedly shown that politicians adapt their parliamentary behavior to the incentives of different electoral systems to increase their re-election probability (Carey and Shugart 1995), an explicit application of these findings to the legislative behavior of women is still missing.

In order to contribute to this debate, this article analyzes the effect of the electoral incentive structure on the substantive representation of women by female legislators. Explicitly, the analysis intends to answer the research

\footnotetext{
'University of Bamberg, Germany
}

\section{Corresponding Author:}

Daniel Höhmann, Professorship for Empirical Political Science, University of Bamberg, Feldkirchenstrasse 21, 96052 Bamberg, Germany.

Email: daniel.hoehmann@uni-bamberg.de 
question of whether the electoral incentive structure has an effect on whether and to what extent female legislators more strongly represent women-specific issues compared with their male colleagues.

On a theoretical level, this article explicitly links the assumptions of mainstream parliamentary research about the incentives and constraints of different electoral systems to the study of the substantive representation of women. Assuming that female MPs generally have stronger intrinsic motivations to act on behalf of women compared with male MPs (Phillips 1995), I theoretically expect that the electoral incentive structure of singlemember district systems (SMD) constrains female MPs from representing women's issues and that the substantive representation of women should be higher in proportional electoral systems (PR). Drawing on the assumptions of the Competing Principals Theory (CPT; Carey 2007), the electoral incentive structure of SMD systems forces female legislators to represent the local interests of the majority of the people in a geographic district to increase their chances of being re-elected. An exclusive representation of women's interests and a simultaneous disregard of the male constituency or other local issues could thus be a risky strategy. However, in proportional systems, electoral districts are state- or nationwide and the re-election probability mainly depends on the vote share of the national party. This opens up the possibility to concentrate on the representation of broader interests and thus gives female MPs the chance to focus on the substantive representation of women-specific issues (Taylor-Robinson 2014: 258; Tremblay 2006).

On the empirical level, the paper provides the first analysis of the effect of different electoral incentives on the behavior of female MPs in a European national parliament. The empirical analysis uses the German mixed electoral system and analyzes the substantive representation of women between 2005 and 2013. ${ }^{1}$ In general, mixed electoral systems offer a promising research design, given that the behavior of legislators that are elected in different electoral systems can be observed within the same country. However, most MPs simultaneously run as dual candidates in both electoral tiers and thus simultaneously face electoral incentives from the PR and the SMD tier. In order to take these "contamination effects" (Ferrara, Herron, and Nishikawa 2005) into consideration, I use the re-election safety of a legislator in the two different tiers to operationalize the overlapping electoral incentive structure of MPs (Stoffel 2014b; Stoffel and Sieberer 2018). Theoretically, it is expected that female legislators are more likely to represent women's interests if their re-election does not depend on the representation of local interests of the constituencies in their electoral districts.
In contrast to a growing number of studies that either use parliamentary speeches (e.g., Bäck, Debus, and Müller 2014) or bill sponsorship (e.g., Volden, Wiseman, and Wittmer 2018) to study the parliamentary behavior of female MPs, this study uses written and oral parliamentary questions (PQs) as a measure of women's substantive representation. Since the Bundestag is a party-centered parliament that is characterized by strong party unity (Sieberer 2006), speeches and bill proposals are significantly influenced by the party leadership and rather reflect the ideological position of the party as a whole. Since the present analysis is primarily interested in the behavior of individual MPs, these indicators are not appropriate in this case. PQs, by contrast, are usually not directly controlled by the party leadership and therefore provide a better and more valid measure of the individual preferences of MPs (Martin 2011b).

Based on an original dataset, the results of a hurdle regression model show a significant interaction effect between gender and the electoral incentive structure. Female legislators are more likely to act on behalf of women if their re-election is secured and if they do not depend on the representation of local interests from the constituencies in their districts. Thus, the theoretical link between descriptive and substantive representation has to be qualified and should take the effect of different electoral systems into account.

\section{Previous Research on Electoral Systems and the Substantive Representation of Women}

With an increasing number of women in parliaments, research on gender and politics has started to analyze the behavior of female legislators and investigated the question of whether women make a difference once elected to the legislative arena. On a theoretical level, it is expected that female legislators represent women's interests in parliament more frequently compared with their male colleagues because they share genderspecific experiences and problems with the female population. Drawing on the works of Pitkin (1967) and Phillips (1995), a causal link between descriptive and substantive representation is postulated, that is, having a higher proportion of women in parliaments leads to an increased representation of women's issues (Dovi 2002; Mansbridge 1999).

The empirical findings of a number of empirical studies suggest that female legislators have different priorities than male MPs and that they see themselves as representatives of the female electorate (Coffé and Reiser 2018; Funk and Philips 2019; Gerrity, Osborn, and Mendez 2007; Reher 2018; Schwindt-Bayer 2010), they increasingly engage in plenary and committee 
debates on women-specific interests (Bäck, Debus, and Müller 2014; Swers 2002) and they introduce more law initiatives on women-specific interests (Swers 2002; Volden, Wiseman, and Wittmer 2018). For the case of the German Bundestag, Brunsbach (2011) and Xydias $(2007,2014)$ show that women are more likely to see themselves as representatives of the female population and that they also articulate women's interests more frequently in committee debates and plenary speeches. These results are corroborated by a more recent study by Coffé and Reiser (2018). Analyzing data from the 2009 German Candidate Survey, the authors find that female candidates in Germany are more likely to believe that women are the better representatives of women's interests in parliament.

However, many of these studies also reveal that the legislative actions of female MPs do not always indicate strong commitments to the representation of womenspecific interests. The differences in attitudes and parliamentary behavior between men and women are often very small or even completely non-existent (TaylorRobinson 2014: 253). Based on the finding that the link between descriptive and substantive representation seems to be more complicated than previously assumed (Dodson 2006), researchers more recently have begun to analyze the political and institutional mechanisms that influence the legislative behavior of female politicians. The central endeavor is to identify the conditions and institutional settings under which female legislators actually represent women's interests more strongly than their male colleagues (Childs and Krook 2009; Krook 2018).

Whereas several studies show that partisanship and ideology are often more important than gender in terms of explaining the legislative behavior of female MPs (e.g., Xydias 2013), the effect of the electoral incentive structure on the substantive representation of women by female MPs has not gained much scholarly attention to date (Krook 2018). For national and subnational parliaments in Latin America, Schwindt-Bayer (2010) and Barnes (2016) find that under party-centered electoral systems (e.g., PR systems or SMD systems with high district magnitudes), female MPs tend to be marginalized by the male-dominated party elite. This gives women fewer opportunities to collaborate and bring women's issues to the parliamentary agenda.

Similar to Barnes (2016) and Schwindt-Bayer (2010), Clark and Caro (2013) examine the effect of district magnitude on the substantive representation of women in the House of Representatives and the Senate of the U.S. state of Arizona. They compare legislative co-sponsorship networks in the Arizona House, which relies upon multi-member districts, and the Arizona Senate, which uses SMDs. The results show that female politi- cians more often co-sponsor laws on female specific topics if the district magnitude increases.

Manon Tremblay (2003) examines the influence of electoral systems on the perceptions of female legislators in Australia and Canada regarding the substantive representation of women. In contrast to the aforementioned studies, Tremblay finds that female MPs elected under proportional electoral systems generally more often perceive themselves as representatives of women in the population. This effect is much weaker in SMD systems. However, Tremblay does not develop any theoretical foundation from which differences in the behavior of female MPs in different electoral systems could be derived.

This paper adds to these studies and analyzes the effect of the electoral incentive structure on the legislative behavior of female MPs in a European national parliament. It develops a new theoretical framework that stresses the individual decision calculus of re-electionoriented female MPs and provides empirical evidence from the intriguing setting offered by the German mixed electoral system.

\section{Different Electoral Incentives and the Substantive Representation of Women}

Scholars in parliamentary research have repeatedly shown that institutional arrangements - and the electoral system in particular - have a strong influence on legislative behavior because politicians adapt their parliamentary activities to the incentives of different electoral system to increase their chances of being re-elected (Bawn and Thies 2003; Carey and Shugart 1995; Crisp et al. 2004; Hug and Martin 2012; Olivella and Tavits 2014). The present analysis perceives female MPs as rational actors driven by the intention to advance their personal goals and careers. Generally, I assume that being re-elected is the primary goal of legislators, given that this is usually the precondition for achieving other policy- and office-related objectives (Müller and Strøm 1999). From this follows the underlying argument that the substantive representation of women's interests by female MPs is dependent on the electoral incentive structure. Although all female MPs might have the intrinsic motivation to act for women's concerns, they will represent these issues more strongly in the legislative arena if it does not compromise their individual re-election prospects. In the following theoretical section, I first derive how pure PR and SMD systems might affect the substantive representation of women. These assumptions are then adapted to the simultaneous electoral incentive structures of the mixed electoral system of the German Bundestag. 
This is the first paper that explicitly draws on the CPT (Carey 2007) to develop a theoretical framework explaining the conditions under which the representation of women's issues does not produce electoral disadvantages for female MPs. According to the CPT, a legislator can be accountable to different principals that decisively influence the prospects of her re-election. Politicians in closed-list PR systems have to adhere to the demands of their political party because voters can only cast votes for the entire list of a party and the party controls the position of candidates on that list (Carey 2007; Crisp et al. 2004; Olivella and Tavits 2014). By contrast, legislators elected in SMD systems should mainly adhere to the preferences and needs of the local constituency in their electoral districts. Since voters can cast their votes for individual candidates, politicians have to develop an "electoral connection" with the local citizens in their districts to secure re-election (André and Depauw 2013; Cain, Ferejohn, and Fiorina 1987; Crisp et al. 2004; Fenno 1978). ${ }^{2}$

Contrary to Barnes (2016) and Schwindt-Bayer (2010), who assume that party-centered PR systems have a negative effect on the substantive representation of women because male party elites can actively sideline female MPs in parliament, I draw on previous work from Bawn and Thies (2003), Crisp et al. (2004), TaylorRobinson (2014) and Hennl (2014) and will show that PR systems offer favorable conditions for the representation of women's issues, whereas the electoral incentive structure of SMD precludes female MPs from exclusively representing women's interests.

In SMD systems, a female legislator has to win the majority of votes of the constituency in her district to be re-elected to parliament. From a rational perspective, an exclusive representation of women's interests and a simultaneous disregard of the male constituency could thus be a risky strategy. If a legislator spends most of her time dealing with women's issues, many other potential problems of the district could not be brought to the legislative arena and many of the local voters (especially most of the male constituency) would not feel sufficiently represented by their deputy. As a result, the re-election chance of the female MP would decrease. Of course, this does not imply that female MPs in SMD systems cannot engage in the substantive representation of women at all. In some cases, the representation of the demands of a local women's group might even be a rewarding form of constituency service. ${ }^{3}$ In general, however, the necessity to develop a representational style that is sensitive to all local problems of the district prevents female MPs from exclusively concentrating on women-specific interests. This effect is supported in a recent study by Coffé (2018: 376) who conducted interviews with MPs elected under the mixed electoral systems in New Zealand and
Germany. Her results show that the majority of district MPs express a strong representational focus on their district and that only very few of them felt responsible for the concerns of particular social groups.

However, in proportional systems - where districts are state- or nationwide and re-election mainly depends on the vote share of the party at the national level-female MPs are not bounded by any local responsibilities. This offers the opportunity to engage in the representation of broader interests spread among the whole population (Tremblay 2006). Hence, the electoral incentive structure of PR systems gives female MPs the opportunity to concentrate on the substantive representation of women, without having to fear any electoral disadvantage. Quite the contrary, being the representative of women's interests even helps to increase the vote share of the party among women in the whole population and thereby increases the re-election prospects of the female MPs. Moreover, because other politicians from the same party can concentrate on the representation of other interests, the party does not neglect large parts of the electorate if female MPs more strongly represent topics that disproportionally affect women. In line with this assumption, Coffé (2018) shows that legislators elected under proportional electoral rules are more likely to mention a certain social group (e.g., women, ethnic groups) when asked about their representational focus. Coffé (2018: 378) furthermore reports that

one MP from an ethnic minority stated that they and their party considered standing them in a district, but eventually decided against it. Standing in a district would have meant they would also have had to focus on district issues, whereas only standing as a list MP allowed them to focus exclusively on their ethnic community.

Consequently, the link between descriptive and substantive representation of women should be stronger if the re-election of female MPs does not depend on the representation of interests from the constituencies in their local districts. Thus, female MPs elected in PR systems with closed-party lists should more strongly represent women's issues compared with their male colleagues. By contrast, in SMD systems, no gender-specific differences should occur.

\section{CPT and the Mixed Electoral System of the German Bundestag}

In Germany's mixed electoral system, half of the MPs are elected in the 299 SMD) using the first-past-the-post system, while the other half is elected via proportional representation (PR) with closed-party lists in the sixteen federal states (Klingemann and Wessels 2001). Whereas 
candidates for the SMD tier are nominated from the local party organizations, party lists are centrally chosen at the state level.

However, given that most candidates for the Bundestag simultaneously run in both electoral tiers (Manow 2013), a simple distinction between MPs elected in the districts and those elected via the party list might not sufficiently reflect the actual electoral incentive structure of the legislators. This problem is often referred to as the "contamination hypothesis," which states that the different tiers of mixed electoral system do not operate independently because candidates running on both tickets are simultaneously confronted with the incentives from the PR and the SMD tier (Bernauer and Munzert 2014; Ferrara, Herron, and Nishikawa 2005; Ohmura 2014; Olivella and Tavits 2014; Stoffel 2014a).

In order to take this possible contamination into account, I adapt the theoretical expectations for pure PR and SMD systems to the simultaneous electoral incentive structures in the mixed electoral system of the German Bundestag and theoretically derive when dual candidates can represent broad interests and when they have to follow the demands of the constituency in their district (which theoretically hinders female MPs from representing women's issues).

Ceteris paribus, I assume that dual candidates compare the chances of being re-elected in the PR and SMD tier and then follow the demands of the principal that offers them a higher re-election probability as well as stronger prospects for the advancement of their personal careers (Stoffel 2014a).

As shown in the previous section, female MPs can more easily concentrate on the representation of women's issues if their re-election does not depend on the interests of the constituencies in local districts. Following Stoffel (2014a), the German mixed electoral system essentially offers two scenarios in which female MPs are freed from the necessity to invest a significant amount of their resources in district-related activities, thereby giving them the chance to focus on the representation of womenspecific interests. In the first scenario, female MPs are independent from the support of their local constituencies if their re-election probability in the PR tier is high. If female politicians have a safe spot on the party list, their re-election to the Bundestag is virtually certain and they do not have to care about the demands of their local constituency. Second, female MPs do not have to devote many of their scarce resources to district-related tasks if they run as candidates in so-called "stronghold" districts. Based on the ideological orientation of the local electorate, these strongholds always favor the candidate of a specific party. If a female MP is the candidate of the ideologically preferred party, her re-election probability in the SMD tier is very high regardless of the amount of time that she has invested in district service (Stoffel 2014a: 80 ). Thus, if the re-election probability of a female MP is high (through either a promising list slot or candidacy in a stronghold district), female politicians do not depend on additional local votes from their districts and they are able to more strongly concentrate on the exclusive representation of women's interests. Under these scenarios, working for the district does not pay off because the party not only guarantees re-election to parliament but also decides over the personal advancement within parliament (through the distribution of offices and money). However, which electoral incentive structures force female MPs to invest much work into their district and thus prevent them from exclusively working in the interests of women?

In general, female MPs who face a narrow race in their district (several candidates have realistic chances to win the district mandate) should more strongly respond to the demands of their local constituency because gaining a few more votes could guarantee their re-election to parliament (Bernauer and Munzert 2014). ${ }^{4}$ However, at the same time, it has to be given that the candidate is not backed up with a promising slot on the party list, which would otherwise serve as a "safety net" (Stratmann and Baur 2002) if the race in the district would be lost.

In sum, the German mixed electoral system provides a promising setting to compare the behavior of MPs that have to respond to different electoral incentives. However, it is not the actual seat type held during the legislative period, but the joint re-election probability that ultimately affects whether MPs conform to the incentives of SMD or PR systems. If the re-election to parliament is not certain, dual candidates have strong incentives to adhere to the demands of their local district and behave like candidates in pure SMD systems, that is, the exclusive representation of women-specific interests becomes a risky strategy (Bernauer and Munzert 2014; Stoffel 2014a; Zittel and Gschwend 2008). If the district race is lopsided or the candidate has a safe position on the party list, she can behave according to the assumptions of pure PR systems. Accordingly, she can focus on the demands of her party and represent broad interests among the electorate. In this case, the substantive representation of women becomes more likely.

Hypothesis: Female MPs represent women's issues more strongly compared with male MPs if their re-election is secured and the electoral incentive structure does not force them to represent the local interests of the constituency in their districts.

\section{Methods and Data}

The empirical part of the paper analyzes the substantive representation of women-specific interests during the 16th and 17th Bundestag (2005-2013). The analysis uses 
the German mixed electoral system which offers the promising opportunity to observe the legislative behavior of MPs who have to respond to the demands of different principals (Carey 2007), while all unobserved countryspecific characteristics can be held constant. As pointed out above, I take into account the criticism of the contamination literature and explicitly model the simultaneous and overlapping incentive structures for candidates who run in both tiers.

The central dependent variable of the analysis is the substantive representation of women by individual legislators. The measurement and operationalization of the individual behavior of female legislators and their substantive representation of women issues is a complex endeavor. Due to strong party unity-especially in European parliaments - previous measurements (e.g., bill sponsorship, speeches, committee membership of legislators) measure the ideological position of the political party rather than the preferences and behavior of individual legislators. In order to reduce the impact of party discipline, I use written and oral PQs to measure how strongly MPs focus on the representation of women-specific interests (Bird 2005; Martin 2011b). Since PQs are usually not officially controlled by the party leadership, they provide one of the very few direct and quantitative indicators of parliamentary activities and offer an attractive tool to operationalize the representative roles of individual MPs (Bailer and Ohmura 2018; Martin 2011b). As Martin (2011b: 475) points out, asking PQs on a specific topic requires the allocation of scarce resources and is by no means a costless activity in terms of time and opportunity costs (MPs must identify the information they want to obtain with the question, write it, format and submit it appropriately and wait for a reply). Moreover, the number of PQs that can be asked is limited. Individual MPs in the German Bundestag have the right to ask up to four written questions per month as well as two oral questions for the weekly question hour of the Bundestag. Therefore, PQs are a direct indication of the priorities of legislators and the content of the question provides an excellent way to measure the extent to which individual legislators substantially represent the interests of certain social groups (Bailer 2011; Martin 2011a, 2011b; Saalfeld 2011; Saalfeld and Bischof 2013). The simple logic is that the more strongly that a legislator is committed to the substantive representation of women, the more questions about women-specific issues that she should submit.

This study analyzes all written and oral questions tabled by members of the Bundestag between 2005 and 2013 (41,690 questions in total). In order to quantify the substantive representation of women, each question was hand-coded to identify whether it deals with a womanspecific topic. ${ }^{5}$ This classification is then used to create a dataset that includes information on the number of questions with a women-specific concern that each member of the Bundestag has submitted.

At this point, the definition of women's issues needs further clarification. Generally, the concept of women's issues is a widely debated topic that is often criticized for assuming that women are a homogenous group with a common set of interests (Mansbridge 1999). In order to avoid this critique of essentialism, the analysis does not apply a pre-defined list of women-specific interests, which is very subjective and can easily be manipulated by the researcher; instead, it uses the often-cited definitions from Susan Carroll (1994) and Karen Celis (2008). According to Carroll (1994: 15), women's issues are those "where policy consequences are likely to have a more immediate and direct impact on significantly larger numbers of women than of men." Building on Celis (2008), this means that a question is classified as womanspecific if it refers to a topic that - for either biological or social reasons - disproportionally affects women more strongly than men, or if it addresses a social condition in which women are disadvantaged compared with men. Furthermore, questions are coded as women-specific if they propose provisions to mitigate or completely eliminate inequalities between men and women. The majority of questions coded as women-specific addresses issues such as gender pay gaps, legal protection of working mothers, sexual violence against women as well as legal provisions concerning prenatal examinations and abortion. In addition, questions about professions that are more frequently pursued by women than men (e.g., midwives) are coded as women-specific. Questions about youth policies, education and rights for lesbian, gay, bisexual, and transgender (LGBT) are only coded as women-specific if they explicitly refer to discrimination against women or girls.

Below are a few examples of PQs coded as womenspecific that were tabled to the government during the 16th and 17th legislative term of the Bundestag:

What is the federal government planning to do to achieve their stated goal of doubling the proportion of women in science within the next 10 years? (Krista Sager, Greens)

When is the federal government expected to have completed the evaluation of the establishment of a nationwide emergency telephone number for victims of all forms of violence against women? (Ina Lenke, Liberals)

How does the federal government react to the fact thataccording to the Women's Data Report of the Institute of Economic and Social Research-the average income of women with full-time employment is far lower than that of men? (Inge Höger-Neuling, Left Party) 
The independent variables in this study are (1) the sex of a legislator and (2) the electoral incentive structure, which is measured through the re-election probabilities in both electoral tiers. The sex of MPs is coded based on biographical information of the legislators in Kürschner's Handbook of the German Bundestag (Kürschners Volkshandbuch 2009-2010) and receives the value zero for male and one for female MPs. The most straightforward solution to measure electoral incentives would be a dummy variable indicating whether a MP is elected in the SMD or PR tier. However, as outlined above, a simple dichotomous distinction between list and PR candidates is not sufficient in the German case due to the huge number of dual candidates and the resulting contamination effects between the two electoral tiers. ${ }^{6}$ Following Stoffel $(2014 a, 2014 b)$ and Bernauer and Munzert (2014), I thus use the re-election probability of MPs in both tiers to measure their actual electoral incentive structure. This variable replaces the simple dichotomous distinction between district and list candidates with a continuous measurement, accounts for possible contaminations of the electoral tiers and indicates whether MPs should rather adhere to the incentives of the SMD or PR electoral system. The Online Appendix A5 includes a model with a dummy variable for list candidates instead of the electoral security as the main independent variable.

Re-election probabilities are calculated in a threestep process as described in Stoffel (2014b) and Stoffel and Sieberer (2018). ${ }^{7}$ First, in order to determine the reelection safety in the district $\left(p_{D}^{i}\right)$, a probit model is calculated that uses the winning/losing margin at the election at time $t-1$ to calculate the probability that an MP wins the district seat at the election at time $t$. The coefficient is then used to predict the individual re-election probability for each MP. In the second step, the electoral safety of an MP on her party list is predicted. Again, a probit model is calculated that uses the list position at time $t$ to predict the probability that a MP wins a list mandate $\left(p_{L}^{i}\right)$ (see Stoffel (2014b) and Stoffel and Sieberer (2018) for a detailed description). In the final step, the two individual probabilities are combined to obtain the total re-election probability for each member of the Bundestag. Following standard probability theory ${ }^{8}$ and assuming that $\left(p_{L}^{i}\right)$ and $\left(p_{D}^{i}\right)$ are not mutually exclusive, the overall re-election probability of a MP equals the sum of the district and list probability, minus the joint probability $\left(\left(p_{L}^{i} \cap p_{L}^{i}\right)=\left(p_{L}^{i} * p_{D}^{i}\right)\right)$ that the MP is elected in both tiers

$$
s_{i}=p_{L}^{i}+p_{D}^{i}-\left(p_{L}^{i} * p_{D}^{i}\right)
$$

Detailed information on the re-election probabilities across parties can be found in the Online Appendix A2.

\section{Statistical Model: Hurdle Regression Model}

The unit of analysis for the following empirical test is the individual MP. For each MP, the dependent variable of the analysis is expressed as the ratio of the number of women-specific questions among the total number of questions that the MP has submitted. The descriptive analysis reveals that during 2005 to 2013 many of the MPs in the Bundestag do not table any women-specific questions at all. Hence, the overwhelming majority of observations receives a score of zero on the dependent variable.

The statistical analysis of proportions with an extremely right- or left-skewed distribution poses several difficulties. Because proportions are bounded on the $[0 ; 1]$ interval and due to the skewed distribution of the data, the dependent variable cannot be modeled as a linear function of the explanatory variables. In order to address these problems, I estimate a hurdle regression model comprising two different equations that are estimated as separate processes (Hardin and Hilbe 2012; Mullahy 1986). In the first step, the hurdle component models the general decision of MPs to become active in the substantive representation of women or not. If this "hurdle" is overcome, the effect of the explanatory variable on the strength or intensity of the dependent variable is estimated in the second step. More specifically, the first step estimates the effect of the independent variable on the likelihood that the dependent variable does not equal zero. The dependent variable is expressed as a dummy variable that receives a score of one if the proportion of submitted questions with a women-specific concern is greater than zero and a logistic regression model is fitted to determine the effect of the electoral incentive structure on the general decision of an MP to represent women's issues in parliament or not. In the second step, a beta regression model is estimated. This model contains only those observations that have tabled at least one question dealing with a women-specific interest and calculates the effect of the electoral incentive structure on the proportion of women-specific questions (i.e., the intensity of substantive representation).

The beta regression model assumes that the data are distributed according to a beta distribution bounded between zero and one (zero and one not included). The beta distribution is very flexible and thus is very well suited to describe unimodal as well as bimodal distributions (Smithson and Verkuilen 2006). The standard errors of the beta regression are conditional on the results from the logit regression. This accounts for the fact that although the two models are estimated in two separate steps, they are dependent on one another. ${ }^{9}$

Moreover, the statistical model has to take into account the fact that the dataset contains multiple 
observations for the same MP that are not independent from each other. Therefore, all models are calculated with robust standard errors clustered at the level of MPs. Since I theoretically expect that the impact of gender is conditional on the electoral incentive structure, multiplicative interaction effects between sex and re-election probability are calculated.

\section{Control Variables}

Although many county-specific factors are controlled for by design, several control variables are introduced. First, dummies for party membership of the MPs are included in the model, because it is assumed that left parties are generally more in favor of gender equality and thus facilitate the descriptive and substantive representation of women (Caul 1999; Xydias 2013). Thus, members of the SPD, Greens and the Left Party should generally more often table questions about women-specific interests compared with MPs from the Union (CDU/CSU) or the FDP. ${ }^{10}$ Party membership also has an effect on the electoral security since members of the SPD and the CDU/ CSU generally have higher re-election probabilities compared with members of the smaller parties. Moreover, all models control for membership in the Committee on Family Affairs, Senior Citizens, Women and Youth, since these MPs - irrespective of their re-election probability - should be more inclined to submit women-specific questions. Additionally, I include dummy variables for MPs of a governing party and for legislators holding an executive or parliamentary office, because it is expected that these legislators generally submit fewer PQs than MPs from opposition parties. ${ }^{11}$ At the same time, being in government or holding an executive office oftentimes guarantees a safe spot on the party list. Bailer and Ohmura (2018) show that the use of PQs in the German Bundestag also depends on the career stages in which legislator are in. In order to control for potential intervening effects of parliamentary experience, I include the duration of parliament membership (measured in years) in the models. Moreover, all models directly control for the total number of PQs tabled by an MP in the respective legislative period to account for different activity levels of MPs over the course of their career. All models additionally include a time dummy that denotes observations from the 16th Bundestag to control for potential time trends that affect all MPs equally. Table A1 in the online appendix contains descriptive statistics of all variables.

\section{Results}

The empirical analysis uses an original data set containing information on the share of submitted questions dealing with a women-specific concern and the electoral incentive structure for each MP of the 16th and 17th Bundestag (2005-2013). This provides a total of 1,293 observations. The descriptive statistics show that according to the theoretical expectations, female legislators more strongly focus on the substantive representation of women's issues compared with their male colleagues. In all, 32 percent of all female MPs actively represent women's issues in the parliamentary arena and table at least one women-specific PQ. In contrast, only 12 percent of the male MPs become active in the substantive representation of women and table PQs that are concerned with women's issues. Of the 41,911 written and oral questions tabled by the members of the Bundestag between 2005 and 2013, 1,238 PQs (3\%) tackle a topic that disproportionally affects women. Among these, 899 PQs (73\%) were issued by female MPs, whereas male legislators tabled only $339(27 \%)$ questions on a women's issue.

Let us now turn to the question of whether the assumptions of Carey's (2007) Competing Principal Theory are also reflected in the substantive representation of women and whether female legislators act more strongly on behalf of women if their electoral incentive structure permits it. The complete results for all coefficient estimates can be found in Table 1. Estimates of the logit regression (hurdle component; effect on the decision to act on behalf of women or not) are shown on the left, while the results from the beta regression (effect on the intensity of substantive representation) are presented in the right part of the table. The central explanatory variable is the interaction effect of gender and electoral incentive structure, which tests whether female MPs are more likely to represent women's issues if their re-election is not dependent on local votes from their district constituencies. All coefficients are presented as $\log$ odds with robust standard errors clustered at the level of individual MPs.

In both parts of the model, the results in Table 1 show the theoretically expected positive interaction effect between gender and re-election security. Accepting the 5 percent significance level, the interaction effect of the beta regression is statistical significant, whereas the coefficient of the logit regression is statistically not distinguishable from zero. However, since both models are non-linear and contain an interaction effect, an assessment of the statistical significance of the interaction term for different values of electoral security as well as an interpretation of the substantive strength of the effects is difficult based on the $\log$ odds from Table 1 alone. Therefore, I calculate and plot the average marginal effects as well as the predicted probabilities of gender across the entire range of re-election probability. All other variables retain their empirically observed values, whereby re-election probability is centered around its mean value to obtain useful comparative groups for the conditional effects. The results for the logit regression are 
Table I. The Effect of Electoral Incentive Structure on the Substantive Representation of Women's Issues, Log-Odds.

\begin{tabular}{|c|c|c|}
\hline Variables & $\begin{array}{c}\text { General decision (Hurdle; } \\
\text { Logit-regression) }\end{array}$ & $\begin{array}{l}\text { Intensity of substantive } \\
\text { representation (beta-regression) }\end{array}$ \\
\hline Female & $0.91 * * *(0.2 I)$ & $0.40 * * * *(0.10)$ \\
\hline Re-election probability (centered) & $-1.60 * *(0.53)$ & $-0.57 *(0.26)$ \\
\hline Female * Re-election prob.(centered) & $0.50(0.7 I)$ & $1.06 * *(0.34)$ \\
\hline No. of submitted questions (in total) & $0.01 * * * *(0.002)$ & $-0.003 * *(0.001)$ \\
\hline Duration MP & $0.03(0.02)$ & $0.01(0.01)$ \\
\hline Member women's committee & $1.58 * * *(0.28)$ & $1.32 * * *(0.22)$ \\
\hline Leadership position & $-0.38(0.21)$ & $0.09(0.12)$ \\
\hline Member governing party & $-2.19 * * *(0.40)$ & $0.49 *(0.22)$ \\
\hline Social Democrats (SPD) & $-0.48(0.40)$ & $0.41(0.33)$ \\
\hline Greens & $-0.4 \mathrm{I}(0.53)$ & $0.42(0.32)$ \\
\hline Liberals (FDP) & $-0.22(0.49)$ & $0.56(0.34)$ \\
\hline Left & $-0.74(0.54)$ & $0.46(0.34)$ \\
\hline 16th Bundestag (Time Dummy) & $-0.12(0.18)$ & $-0.03(0.14)$ \\
\hline Constant & $-1.4 \mid * *(0.48)$ & $-3.25 * * *(0.40)$ \\
\hline$N$ & 1268 & 234 \\
\hline Log-pseudolikelihood & -397.38 & 419.95 \\
\hline$x^{2}$ & $429.80 * * *$ & $165.48 * * *$ \\
\hline
\end{tabular}

Hurdle Model. DV Model I: Dummy variable coded I if share of women-specific questions > 0. DV Model 2: Share of women-specific questions. Coefficients: Log-Odds. Standard errors (in parentheses) are clustered by MP. Reference category for parties: CDU/CSU. MP = members of parliament.

$* p<.05 . * * p<.01 . * * * p<.001$.

A

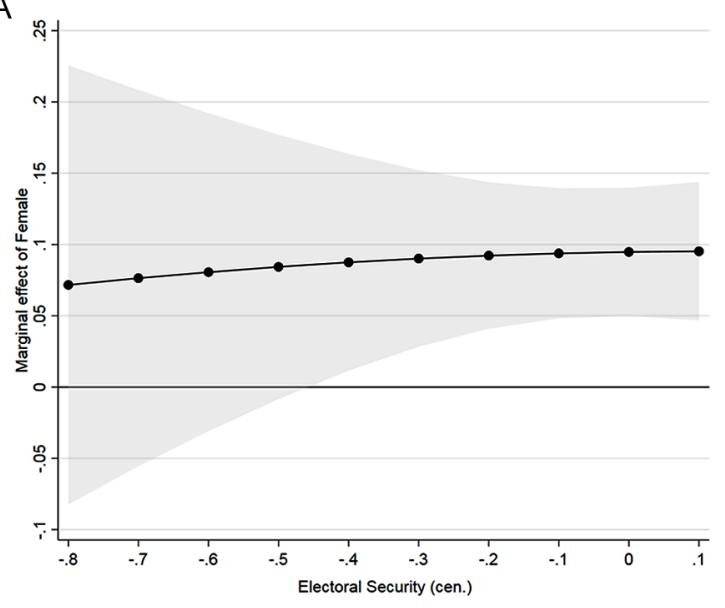

B

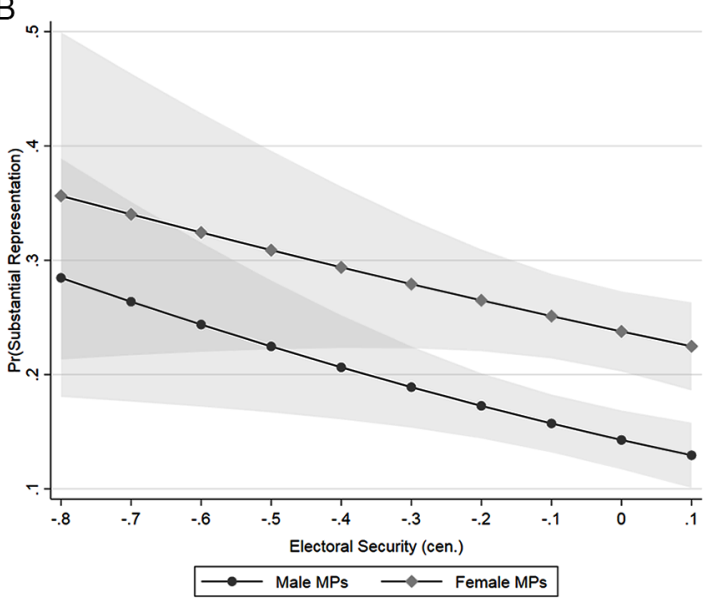

Figure I. Interaction effect of gender and electoral incentive structure on the general decision to represent women's issues (probability). (A) Marginal effect of female and (B) predicted probabilities.

Hurdle Model (Logit Regression). Shaded areas indicate 95 percent confidence intervals. All other variables enter the model with their empirically observed values.

presented in Figure 1 and the plots for the beta regression are shown in Figure 2.

Concerning the estimates for the effect of the electoral incentive structure on the general decision to promote women's interests in parliament, Figure 1A reveals that the marginal effect of gender is insignificant for low values of the re-election variable.

This means that if the electoral race in the district is not lopsided and the legislators are at the same time not backed up with a secure slot on the party list, female MPs 
A

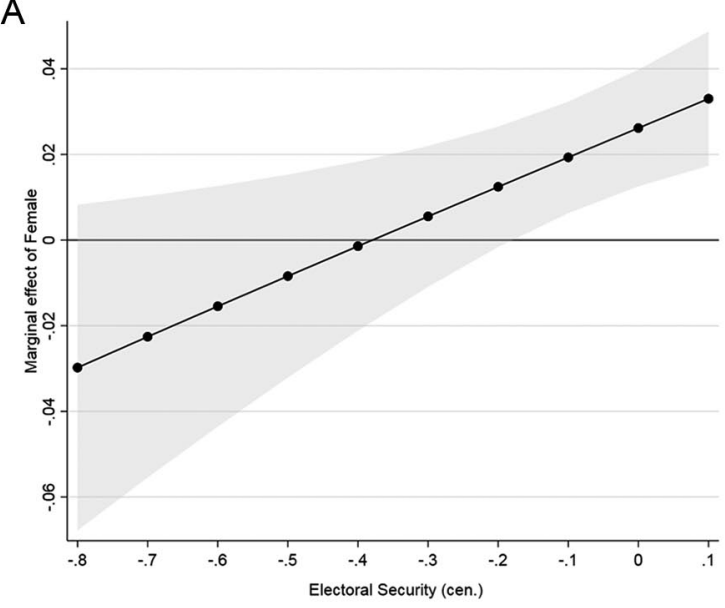

B

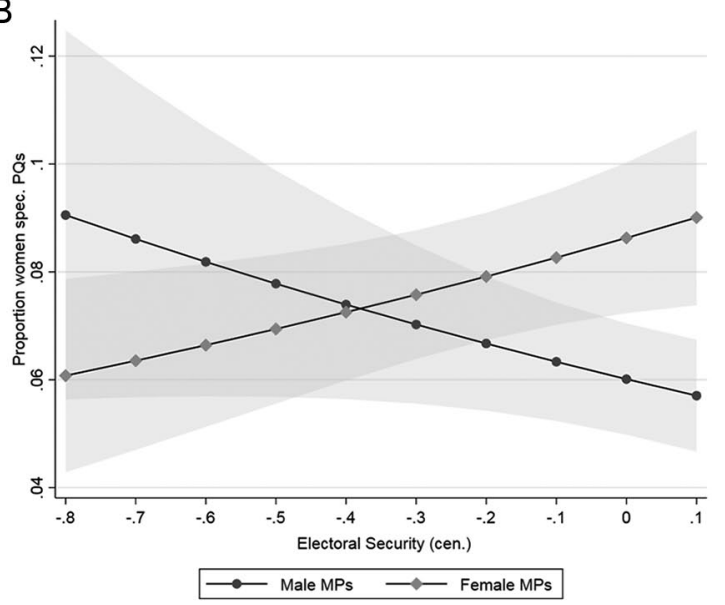

Figure 2. Interaction effect of gender and electoral incentive structure on the intensity of substantive representation of women. (A) Marginal effect of female and (B) predicted proportion of women specific questions. Hurdle Model (Beta Regression). Shaded areas indicate 95 percent confidence intervals. All other variables enter the model with their empirically observed values.

have to adhere to the incentives of the SMD tier and have to invest more time and resources in district-related activities. Consequently, women do not have a significantly higher probability of representing women's issues in parliament compared with their male colleagues. However, this picture changes as the re-election probability increases. In line with the theoretical expectations, the effect of gender increases for higher re-election probabilities. Compared with the men in parliament, female MPs more often decide to promote women-specific topics in parliament if their re-election to the Bundestag is secured. This effect is significant at the 5 percent level for the upper values of re-election probability. ${ }^{12}$ The probability for the representation of women-specific interests is almost 10 percentage points higher for female MPs compared with their male colleagues. Thus, it can be shown that female MPs more frequently act on behalf of women if they do not depend on the representation of local interests from the constituencies in their districts.

Surprisingly, however, the predicted probabilities from Figure 1B reveal that among the female legislators, the probability of promoting women's issues in parliament slightly decreases from 39 to 22 percent as electoral security increases. Nevertheless, given that this decline is significantly lower than among the male MPs (from 30 to 12 percent), we can observe the theoretically expected positive interaction effect between gender and the electoral incentive structure.

The results for the control variables indicate that members of the women's committee as well as MPs that generally submit a high number of PQs are more likely to actively represent women's issues in parliament. In contrast, MPs from governing parties are less likely to submit at least one women-specific PQ.

Let us now turn to the results of the beta regression to estimate the effect of gender and the electoral incentive structure on the intensity with which legislators promote the substantive representation of women. This model includes only those MPs who tabled at least one womenspecific question, namely they generally decided to represent women's issues in the parliamentary arena. The results are shown in Figure 2.

Again, the interaction effect between gender and electoral incentive structure is positive and significant at the 5 percent level for high values of the re-election variable. This means that female legislators more frequently act on behalf of women compared with male MPs if their reelection is safe (through either a lopsided district race or a promising position on the party list). Interestingly, the marginal effects (Figure 2A) and predicted probabilities (Figure 2B) reveal that if the prospects for re-election are low, men promote the interests of women more strongly than female MPs and on average they submit roughly 3 percentage points more women-specific questions. ${ }^{13}$ Nonetheless, the marginal effect is not significant anddue to the positive interaction effect - this pattern changes when the electoral security increases. The size of the marginal gender effect increases with increasing re-election probabilities and becomes positive and significant at the high end of the electoral security scale. Substantially, women table roughly 3 percentage points more womenspecific questions compared with male MPs if re-election 
prospects are high. Across the full range of the electoral security scale, the predicted probabilities for the share of women-specific questions increases from slightly above 6 percent to almost 9 percent for women and decreases from 8.5 to slightly under 6 percent for male MPs.

Ina Lenke, for example, a MP from the FDP whose re-election to parliament was almost certain $\left(s_{i}=0.99\right)$ tabled 89 women-specific PQs during the 16th LP of the Bundestag. In total, 67 percent of MP Lenke's PQs referred to women's interests. In contrast, Uta Zapf and Iris Gleicke (both SPD), both of whom had strong incentives to invest more time into district-related activities because their re-election probabilities only amounted to roughly 40 percent, did not submit any women-specific $\mathrm{PQ}$ at all.

The control variables show that MPs ask significantly more women-specific PQs if they are a member of the women's committee or a legislator from a governing party. The effect of the total number of PQs is also significant, but the effect size is negligible.

To summarize, the results confirm the theoretical expectations and show that female legislators act more strongly on behalf of women if their re-election is secured and if they do not have to fight for additional local votes from their district. Otherwise, the necessity to represent the local interests of their constituencies prevents female MPs from an exclusive representation of women's interests. This suggests that the unconditional "politics of presence" hypothesis (Phillips 1995) and the assumption of an automatic link between descriptive and substantive representation has to be qualified and should take the incentive structures of different electoral systems into account. ${ }^{14}$

\section{Conclusion}

This paper has empirically investigated the effect of the electoral incentive structures on the behavior of female legislators. Even though previous research has demonstrated that the incentives of different electoral systems affect the parliamentary behavior of MPs (Carey and Shugart 1995), these findings have never been explicitly transferred to the study of women and politics. Thus, the analysis fills a relevant gap in research on the links between descriptive and substantive representation of women and contributes to a better understanding of the institutional settings under which female legislators more strongly represent women-specific interests. Using the German mixed electoral system, the results indicate that female legislators act more strongly on behalf of women if their re-election is secured and if they do not have to fight for additional local votes from their local district. Based on Carey's (2007) CPT, this shows that whenever the electoral incentive structure does not force MPs to represent local issues of their districts, female legislators use this opportunity to more strongly act in the interest of women. The analysis thereby demonstrates that the assumption of a link between descriptive and substantive representation has to be qualified and should take the effect of different electoral incentive structures into account. This finding is noteworthy because it shows that electoral rules not only affect the number of elected women but that they also have strong effects on the subsequent legislative behavior of female MPs.

In future research, it would be interesting to observe whether the findings of this paper can be generalized to other countries and settings. As the present analysis is limited to the mixed electoral system of the German Bundestag, it has to be tested whether the findings also hold in settings with pure SMD or PR electoral systems. Assuming that female MPs generally perceive a stronger responsibility for the representation of women's issues than male MPs (Coffé and Reiser 2018), the results suggest that female MPs in pure PR systems - in which legislators have the possibility to focus on the representation of broad interests among the whole population - should be more likely to concentrate on the substantive representation of women compared to female MPs elected in SMD systems. These assumptions could be tested in cross-national analyses of countries with pure PR and SMD systems. Since parties in proportional systems have to appeal to different social groups, analyses of pure PR systems could also show which of the female MPs are more likely to engage in women's substantive representation and which rather focus on other diverse interest (e.g., migrants, working class).

Quite surprisingly, the results of the analysis show that men more strongly represent women's issues if they are electorally insecure, thus suggesting that they use this strategy to win additional votes from female voters. For a thorough understanding of the substantive representation of women it is therefore necessary to explore the institutional settings under which male MPs act on behalf of women. Several authors have already suggested that we should rethink the substantive representation of women and that we should move beyond analyzing only female MPs' behavior and the questions of how and when women represent the interests and preferences of their female constituents (e.g., Childs and Krook 2009; Celis et al. 2008; Celis and Erzeel 2015). The findings of this study corroborate this notion and demonstrate that further analyses of the effect of institutional variables on the decision of male MPs to become "critical actors" (Childs and Krook 2009) who represent women's interests in parliament are a necessary next step to deepen our understanding of how and when substantive representation of women occurs. This also requires an extension of the analysis to further legislative periods to observe whether the findings 
are stable over time or if the behavior of female and male MPs changes if the composition of the parliament becomes more gender-balanced.

\section{Acknowledgments}

I gratefully acknowledge helpful comments and suggestions by Ulrich Sieberer, Thomas Saalfeld, Christian Breunig, Elin Haugsgjerd Allern, and three anonymous reviewers. Previous versions of this article have been presented at the Conference of the European Political Science Association (Milan 2017), the Conference of the European Consortium for Political Research (Oslo 2017), and at talks at the Universities of Konstanz and Bamberg. I thank all participants for their valuable feedback. All errors and shortcomings are my own.

\section{Declaration of Conflicting Interests}

The author(s) declared no potential conflicts of interest with respect to the research, authorship, and/or publication of this article.

\section{Funding}

The author(s) received no financial support for the research, authorship, and/or publication of this article.

\section{Notes}

1. Replication data are available on the Harvard dataverse at https://doi.org/10.7910/DVN/PBK1T7.

2. For empirical tests of the mandate-divide hypothesis (Thames 2005) in the Bundestag, see Stratmann and Baur (2002), Zittel and Gschwend (2008), Sieberer (2010, 2015), Manow (2013), and Ohmura (2014).

3 . Since women make up roughly 50 percent of the population in each district, one could theoretically argue that female MPs could be elected if they win the votes from all women in her district. However, it is very unlikely that female candidates would win the vote of each and every woman in the district.

4. This assumption is corroborated by the empirical finding that the perceived prestige of a district mandate is generally higher than that of list MPs (Coffé 2018; Zittel and Gschwend 2008).

5. All PQs were coded by the author. To ensure the validity of the coding, a student research assistant was familiarized with the definition of women's substantive representation (see below) and was then asked to classify a random sample of 2,000 PQs (PQs that have been classified as womenspecific by the author were oversampled and made up 14\% of the sample). According to Krippendorff's $\alpha$, the intercoder reliability equals 0.94 . Among the women-specific PQs, the intercoder agreement is 95.2 percent.

6. Overall, 1,093 (84\%) MPs ran as dual candidates.

7. I would like to thank Michael Stoffel for the generous provision of data.

8. If two events (A, B) are not mutually exclusive, then $\mathrm{P}(\mathrm{A} \cup \mathrm{B})=\mathrm{P}(\mathrm{A})+\mathrm{P}(\mathrm{B})-\mathrm{P}(\mathrm{A} \cap \mathrm{B})$.
9. Conditional standard errors are estimated with the suest command (seemingly unrelated estimation) in Stata 15.

10. In order to control for regional differences within parties (SPD members from Berlin might be more progressive than SPD members from rural areas in Bavaria), I also calculated a model with dummy variables for each party-state combination. As the results do not deviate from the original model, I prefer the more parsimonious model including only party dummies.

11. The following offices are treated as leadership positions: chancellor, president of the Bundestag, cabinet minister, junior minister, committee chair, chair of a parliamentary party group, party whip, and member of the party's executive committee.

12. Given that most MPs have high re-election probabilities, most cases fall within this region.

13. This corroborates the notion that female MPs might not be the only actors in the substantive representation of women and emphasizes that men can also be "critical actors [who] act individually or collectively to bring about women-friendly policy change" (Childs and Krook 2009). The findings suggest that male MPs might not be blamed if they do not represent women's interests, but that they can gain additional credit if they support women's issues (Bergqvist, Bjarnegård, and Zetterberg 2018). Thus, male MPs will become more likely to speak on behalf of women if they have to fight for additional votes to get re-elected (see Conclusion).

14. Additional robustness checks can be found in the online appendix. Online Appendix A3 shows that all results remain stable if I use the absolute number instead of the share of question as the dependent variable. Moreover, the results do not change if I include additional control variables into the model (Online Appendix A4). Online Appendix A5 uses a dummy variable for list candidates instead of the electoral security as the independent variable. The results are insignificant, showing that it is indeed the combination of electoral incentives in both tiers that affects the parliamentary behavior of German MPs. Moreover, the results are not sensitive to the exclusion of MPs with an unusually high number of women-specific PQs (Online Appendix A6). The results are also robust to the exclusion of MPs from the FDP and the Greens which usually have very low re-election probabilities in the district.

\section{ORCID iD}

Daniel Höhmann (iD https://orcid.org/0000-0003-1740-5234

\section{Supplemental Material}

Supplemental materials for this article are available with the manuscript on the Political Research Quarterly (PRQ) website.

\section{References}

André, Audrey, and Sam Depauw. 2013. "District Magnitude and Home Styles of Representation in European Democracies." West European Politics 36 (5): 986-1006. 
Bäck, Hanna, Marc Debus, and Jochen Müller. 2014. "Who Takes the Parliamentary Floor? The Role of Gender in Speech-making in the Swedish Riksdag." Political Research Quarterly 67 (3): 504-18.

Bailer, Stefanie. 2011. “People's Voice or Information Pool? The Role of, and Reasons for, Parliamentary Questions in the Swiss Parliament." Journal of Legislative Studies 17 (3): 302-14.

Bailer, Stefanie, and Tamaki Ohmura. 2018. "Exploring, Maintaining, and Disengaging: The Three Phases of a Legislator's Life." Legislative Studies Quarterly 43 (3): 493-520.

Barnes, Tiffany. 2016. Gendering Legislative Behavior. New York: Cambridge University Press.

Bawn, Kathleen, and Michael Thies. 2003. "A Comparative Theory of Electoral Incentives: Representing the Unorganized Under PR, Plurality and Mixed-Member Electoral Systems." Journal of Theoretical Politics 15 (1): 5-32.

Bergqvist, Christina, Elin Bjarnegård, and Pär Zetterberg. 2018. "The Gendered Leeway: Male Privilege, Internal and External Mandates, and Gender-Equality Policy Change." Politics, Groups, and Identities 6 (4): 576-92.

Bernauer, Julian, and Simon Munzert. 2014. "Loyal to the Game? Strategic Policy Representation in Mixed Electoral Systems." Representation 50 (1): 83-97.

Bird, Karen. 2005. "Gendering Parliamentary Questions." British Journal of Politics and International Relations 7 (3): 353-70.

Brunsbach, Sandra. 2011. "Machen Frauen den Unterschied? Parlamentarierinnen als Repräsentantinnen frauenspezifischer Interessen im Deutschen Bundestag." ["Do women make the difference? Female MPs as Representatives of Women-Specific Interests in the German Bundestag"] Zeitschrift für Parlamentsfragen 42 (1): 3-24.

Cain, Bruce, John Ferejohn, and Morris Fiorina. 1987. The Personal Vote. Cambridge, MA: Harvard University Press.

Carey, John. 2007. "Competing Principals, Political Institutions, and Party Unity in Legislative Voting." American Journal of Political Science 51 (1): 92-107.

Carey, John, and Matthew Shugart. 1995. "Incentives to Cultivate a Personal Vote: A Rank Ordering of Electoral Formulas." Electoral Studies 14 (4): 417-39.

Carroll, Susan. 1994. Women as Candidates in American Politics. Bloomington: Indiana University Press.

Caul, Miki. 1999. “Women's Representation in Parliament: The Role of Political Parties." Party Politics 5 (1): 79-98.

Celis, Karen. 2008. "Studying Women's Substantive Representation in Legislatures: When Representative Acts, Contexts and Women's Interests Become Important." Representation 44 (2): 111-23.

Celis, Karen, Sarah Childs, Johanna Kantola, and Mona Krook. 2008. "Rethinking Women's Substantive Representation." Representation 44 (2): 99-110.

Celis, Karen, and Silvia Erzeel. 2015. "Beyond the Usual Suspects: Non-Left, Male and Non-Feminist MPs and the Substantive Representation of Women." Government and Opposition 50 (1): 45-64.

Childs, Sarah, and Mona Krook. 2009. “Analysing Women's Substantive Representation: From Critical Mass to Critical Actors." Government and Opposition 44 (2): 125-45.
Clark, Jennifer Hayes, and Veronica Caro. 2013. "Multimember Districts and the Substantive Representation of Women: An Analysis of Legislative Cosponsorship Networks." Politics \& Gender 9 (1): 1-30.

Coffé, Hilde. 2018. "MPs' Representational Focus in MMP Systems. A Comparison Between Germany and New Zealand." Representation 54 (4): 367-89.

Coffé, Hilde, and Marion Reiser. 2018. "Political Candidates' Attitudes Towards Group Representation." Journal of Legislative Studies 24 (3): 272-97.

Crisp, Brian, Maria Escobar-Lemmon, Bradford Jones, Mark Jones, and Michelle Taylor-Robinson. 2004. "VoteSeeking Incentives and Legislative Representation in Six Presidential Democracies." Journal of Politics 66 (3): 823-46.

Dodson, Debra. 2006. The Impact of Women in Congress. Oxford: Oxford University Press.

Dovi, Suzanne. 2002. "Preferable Descriptive Representatives: Will Just Any Woman, Black, or Latino Do?" American Political Science Review 96 (4): 729-43.

Fenno, Richard. 1978. Home Style. Boston: Little, Brown.

Ferrara, Federico, Erik Herron, and Misa Nishikawa. 2005. Mixed Electoral Systems. Basingstoke: Palgrave Macmillan.

Funk, Kendall, and Andrew Philips. 2019. "Representative Budgeting: Women Mayors and the Composition of Spending in Local Governments." Political Research Quarterly 72 (1): 19-33.

Gerrity, Jessica, Tracy Osborn, and Jeanette Morehouse Mendez. 2007. "Women and Representation: A Different View of the District?" Politics \& Gender 3 (2): 179-200.

Hardin, James, and Joseph Hilbe. 2012. Generalized Linear Models and Extensions. College Station: Stata Press.

Hennl, Annika. 2014. "Intra-Party Dynamics in Mixed-Member Electoral Systems: How Strategies of Candidate Selection Impact Parliamentary Behaviour." Journal of Theoretical Politics 26 (1): 93-116.

Hug, Simon, and Danielle Martin. 2012. "How Electoral Systems Affect MPs' Positions.” Electoral Studies 31 (1): 192-200.

Klingemann, Hans-Dieter, and Bernhard Wessels. 2001. "The Political Consequences of Germany's MixedMember System." In Mixed-Member Electoral Systems: The Best of Both Worlds? edited by Matthew Shugart and Martin Wattenberg, 279-96. Oxford: Oxford University Press.

Krook, Mona. 2018. “Electoral Systems and Women's Representation." In Oxford Handbook of Electoral Systems, edited by Erik Herron, Robert Pekkanen, and Matthew Shugart, 175-93. Oxford: Oxford University Press.

Kürschners Volkshandbuch. 2009-2010. Deutscher Bundestag. Rheinbreitenbach: Neue Darmstädter Verlagsanstalt.

Manow, Philip. 2013. "Mixed Rules, Different Roles? An Analysis of the Typical Pathways into the Bundestag and of MPs' Parliamentary Behaviour." Journal of Legislative Studies 19 (3): 287-308.

Mansbridge, Jane. 1999. "Should Blacks Represent Blacks and Women Represent Women? A Contingent Yes." Journal of Politics 61 (3): 628-57. 
Martin, Shane. 2011a. "Parliamentary Questions, the Behaviour of Legislators, and the Function of Legislatures: An Introduction.” Journal of Legislative Studies 17 (3): 25970 .

Martin, Shane. 2011b. "Using Parliamentary Questions to Measure Constituency Focus: An Application to the Irish Case." Political Studies 59 (2): 472-88.

Mullahy, John. 1986. "Specification and Testing of some Modified Count Data Models." Journal of Econometrics 33:341-65.

Müller, Wolfgang, and Kaare Strøm. 1999. Policy, Office, or Votes? Cambridge: Cambridge University Press.

Ohmura, Tamaki. 2014. "When Your Name Is on the List, It Is Time to Party: The Candidacy Divide in a Mixed-Member Proportional System." Representation 50 (1): 69-82.

Olivella, Santiago, and Margit Tavits. 2014. "Legislative Effects of Electoral Mandates." British Journal of Political Science 44 (2): 301-21.

Phillips, Anne. 1995. The Politics of Presence. Oxford: Clarendon Press.

Pitkin, Hanna. 1967. The Concept of Representation. Berkeley: University of California Press.

Reher, Stefanie. 2018. "Gender and Opinion-Policy Congruence in Europe.” European Political Science Review 10 (4): 613-35.

Saalfeld, Thomas. 2011. "Parliamentary Questions as Instruments of Substantive Representation: Visible Minorities in the UK House of Commons, 2005-10." Journal of Legislative Studies 17 (3): 271-89.

Saalfeld, Thomas, and Daniel Bischof. 2013. "Minority-Ethnic MPs and the Substantive Representation of Minority Interests in the House of Commons, 2005-2011." Parliamentary Affairs 66:305-28.

Schwindt-Bayer, Leslie. 2010. Political Power and Women's Representation in Latin America. New York: OxfordUniversity Press.

Sieberer, Ulrich. 2006. "Party Unity in Parliamentary Democracies: A Comparative Analysis." Journal of Legislative Studies 12 (2): 150-78.

Sieberer, Ulrich. 2010. "Behavioral Consequences of Mixed Electoral Systems: Deviating Voting Behavior of District and List MPs in the German Bundestag." Electoral Studies 29 (3): 484-96.

Sieberer, Ulrich. 2015. "Using MP Statements to Explain Voting Behaviour in the German Bundestag: An Individual Level Test of the Competing Principals Theory." Party Politics 21 (2): 284-94.

Smithson, Michael, and Jay Verkuilen. 2006. “A Better Lemon Squeezer? Maximum-Likelihood Regression with BetaDistributed Dependent Variables." Psychological Methods 11 (1): 54-71.
Stoffel, Michael. 2014a. "MP Behavior in Mixed-Member Electoral Systems." Electoral Studies 35:78-87.

Stoffel, Michael. 2014b. "A Unified Scale of Electoral Incentives." Representation 50 (1): 55-67.

Stoffel, Michael, and Ulrich Sieberer. 2018. "Measuring Re-Election Prospects Across Electoral Systems: A General Approach Applied to Germany." West European Politics 41 (5): 1191-1207.

Stratmann, Thomas, and Martin Baur. 2002. "Plurality Rule, Proportional Representation, and the German Bundestag: How Incentives to Pork-Barrel Differ across Electoral Systems." American Journal of Political Science 46 (3): 506-14.

Swers, Michele. 2002. The Difference Women Make. Chicago: University of Chicago Press.

Taylor-Robinson, Michelle. 2014. "Gender and Legislatures." In The Oxford Handbook of Legislative Studies, edited by Shane Martin, Thomas Saalfeld, and Kaare Strøm, 250-66. Oxford: Oxford University Press.

Thames, Frank. 2005. "A House Divided: Party Strength and the Mandate divide in Hungary, Russia, and Ukraine." Comparative Political Studies 38 (3): 1-22.

Tremblay, Manon. 2003. "Women's Representational Role in Australia and Canada: The Impact of Political Context." Australian Journal of Political Science 38 (2): 215-38.

Tremblay, Manon. 2006. "The Substantive Representation of Women and PR: Some Reflections on the Role of Surrogate Representation and Critical Mass." Politics \& Gender 2:502-11.

Volden, Craig, Alan Wiseman, and Dana Wittmer. 2018. "Women's Issues and Their Fates in the US Congress." Political Science Research and Methods 6 (4): 679-96.

Wängnerud, Lena. 2009. "Women in Parliaments: Descriptive and Substantive Representation." Annual Review of Political Science 12 (1): 51-69.

Xydias, Christina. 2007. "Inviting More Women to the Party: Gender Quotas and Women's Substantive Representation in Germany." International Journal of Sociology 37 (4): 52-66.

Xydias, Christina. 2013. "Mapping the Language of Women's Interests: Sex and Party Affiliation in the Bundestag." Political Studies 61 (2): 319-40.

Xydias, Christina. 2014. "Women's Rights in Germany: Generations and Gender Quotas." Politics \& Gender 10 (1): 4-32.

Zittel, Thomas, and Thomas Gschwend. 2008. "Individualised Constituency Campaigns in Mixed-Member Electoral Systems: Candidates in the 2005 German Elections." West European Politics 31 (5): 978-1003. 


\title{
Research Article
}

\section{When Do Female MPs Represent Women's Interests? Electoral Systems and the Legislative Behavior of Women}

\author{
Daniel Höhmann \\ (University of Bamberg) \\ Supplemental Material ${ }^{1}$
}

\footnotetext{
1 The dataset for the main analysis is available on the Harvard dataverse at https://doi.org/10.7910/DVN/PBK1T7. All datasets used for the robustness tests are available from the author upon request.
} 


\section{A1 Descriptive Statistics}

Table A1 Descriptive Statistics

\begin{tabular}{|c|c|c|c|c|c|}
\hline Variables & $\mathrm{N}$ & Mean & Stand. Dev. & Min & Max \\
\hline Share of women specific questions & 1293 & 0.016 & 0.07 & 0 & 1 \\
\hline At least 1 women specific question & 1295 & 0.18 & 0.39 & 0 & 1 \\
\hline Female & 1293 & 0.32 & 0.47 & 0 & 1 \\
\hline Re-election probability & 1271 & 0.84 & 0.23 & 0 & 1 \\
\hline No. of submitted questions (total) & 1293 & 32.4 & 53.9 & 0 & 332 \\
\hline Duration MP (years) & 1293 & 6.6 & 7.2 & 0 & 37 \\
\hline Member women's committee & 1295 & 0.05 & 0.22 & 0 & 1 \\
\hline Leadership position & 1292 & 0.49 & 0.5 & 0 & 1 \\
\hline Member governing party & 1293 & 0.63 & 0.48 & 0 & 1 \\
\hline $\mathrm{CDU} / \mathrm{CSU}$ & 1291 & 0.37 & 0.48 & 0 & 1 \\
\hline SPD & 1291 & 0.30 & 0.46 & 0 & 1 \\
\hline Greens & 1291 & 0.10 & 0.30 & 0 & 1 \\
\hline FDP & 1291 & 0.13 & 0.33 & 0 & 1 \\
\hline Left & 1291 & 0.10 & 0.30 & 0 & 1 \\
\hline 16th Bundestag (Time Dummy) & 1293 & 0.5 & 0.5 & 0 & 1 \\
\hline \multicolumn{6}{|l|}{ Additional control variables } \\
\hline First-time MP & 1295 & 0.26 & 0.44 & 0 & 1 \\
\hline Disengagement phase & 1295 & 0.19 & 0.39 & 0 & 1 \\
\hline Duration party member (years) & 1207 & 23.4 & 10.4 & 0 & 48 \\
\hline Member women's organization & 1292 & 0.11 & 0.31 & 0 & 1 \\
\hline Local politician & 1292 & 0.28 & 0.45 & 0 & 1 \\
\hline Own children & 1295 & 0.67 & 0.47 & 0 & 1 \\
\hline Catholic & 1293 & 0.28 & 0.45 & 0 & 1 \\
\hline Protestant & 1293 & 0.30 & 0.46 & 0 & 1 \\
\hline Female population (share) & 1291 & 0.51 & 0.007 & 0.49 & 0.54 \\
\hline Inhabitants $/ \mathrm{km}^{2}$ & 1248 & 948.2 & 1366.4 & 39.8 & $12,212.3$ \\
\hline Population under 18 (share) & 1248 & 17.4 & 2.4 & 11.5 & 24.9 \\
\hline East Germany & 1291 & 0.20 & 0.40 & 0 & 1 \\
\hline
\end{tabular}

Note: Data for the years 2005-2013. 


\section{A2 Categorized re-election probabilities across parties (2005-2013)}

Table A2 shows the categorized re-election probabilities across parties between 2005 and 2013. List $\left(p_{L}^{i}\right)$ as well as district probabilities $\left(p_{D}^{i}\right)$ are concentrated at the upper end point of the respective scale. Thus, the combination of these two indicators shows that the majority of MPs either competes in a safe district or is secured through a promising slot on the party list. For $72 \%$ of the German legislators, re-election to the Bundestag is almost certain.

Table A2 Distribution of categorized re-election probabilities across parties (2005-2013)

\begin{tabular}{llllll}
\hline $\begin{array}{l}\text { Re-election } \\
\text { probability }\end{array}$ & CDU/CSU & SPD & FDP & Greens & Left \\
\hline District & & & & & \\
$0.0-0.2$ & 14 & 29 & 97 & 91 & 71 \\
$0.2-0.5$ & 9 & 14 & 0 & 2 & 16 \\
$0.5-0.8$ & 25 & 29 & 0 & 0 & 9 \\
$0.8-1.0$ & 52 & 28 & 3 & 7 & 5 \\
List & & & & & \\
$0.0-0.2$ & 43 & 35 & 10 & 8 & 16 \\
$0.2-0.5$ & 11 & 9 & 16 & 5 & 37 \\
$0.5-0.8$ & 11 & 8 & 14 & 9 & 13 \\
$0.8-1.0$ & 35 & 48 & 60 & 78 & 131 \\
\hline$N$ & & & & & \\
\hline
\end{tabular}

Note: Entries are percentages. 


\section{A3 Robustness Test: Alternative operationalization of the dependent variable}

The robustness check shows that the results of the analysis are not sensitive to the choice of an alternative statistical model. Here, I use the absolute number of submitted questions with a women-specific concern as my dependent variable and estimate a hurdle model which consists of a logit model and a truncated negative binomial regression. Results for the beta regression and the truncated negative binomial regression are shown in Figure A1 and reveal that the coefficients differ only slightly and that the overall findings of the analysis remain stable. The interaction effect between gender and electoral incentive structure remains significant and even increases in size. The confidence interval gets slightly larger, but does not include zero.

Fig. A1 Robustness Check: Alternative Statistical Model

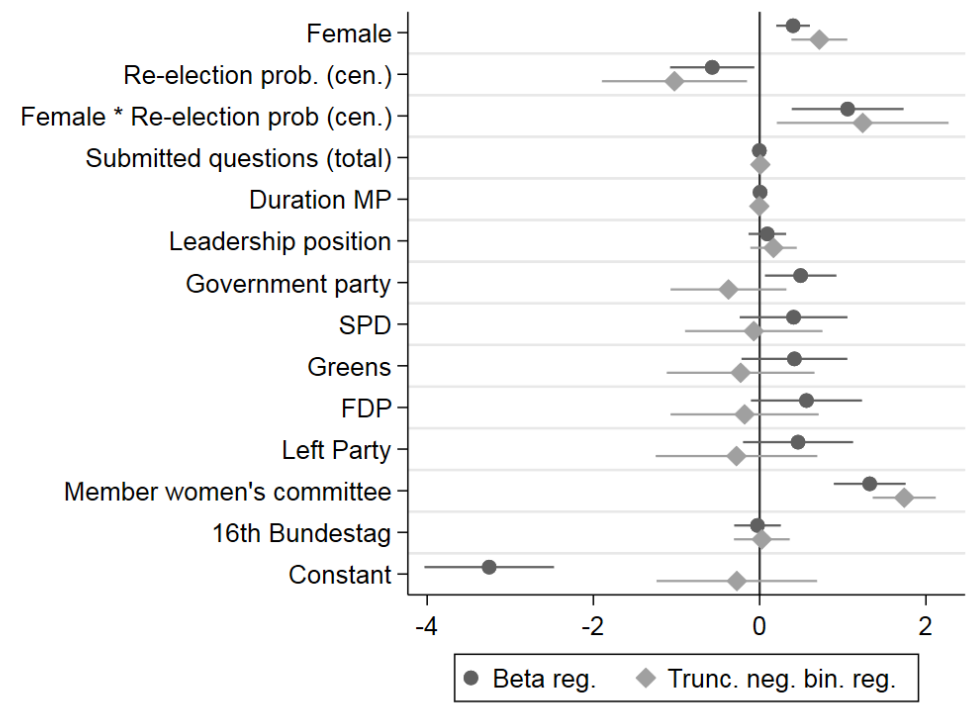

Note: Coefficients with 95 percent confidence interval. Results from Beta Regression Model and truncated negative binomial regression. 


\section{A4 Robustness Test: Inclusion of additional independent variables}

Appendix A4 presents a further robustness test in which I re-estimate the main model with additional independent variables. Here, I also include some alternative explanations that might have an effect on the substantive representation of women's issues. In particular, I added control variables for the career stage of MPs. For the case of the German Bundestag, Bailer and Ohmura (2018) show that early-career MPs are generally more likely to use PQs compared to legislators at the end of their parliamentary career. Therefore, I added a dummy variable for newly elected MPs (First-time MP). Moreover, following the example from Bailer and Ohmura (2018), I created a dummy variable indicating whether MPs are in the last legislative period of their political career (Disengagement phase). This variable identifies MPs who voluntarily chose to leave parliament (e.g. retirement, other career options), MPs who involuntarily chose not to run for re-election (e.g. due to a scandal or conflicts within the party) as well as MPs that wanted to run as a candidate in the next election but were not re-selected by their party. ${ }^{2}$ In anticipation of the end of their career, these MPs might either reduce their activity level in parliament or focus more strongly on particular types of activities (e.g. the representation of women). Furthermore, I added a dummy variable that controls for a membership in a women's organization or movement since these MPs, irrespective of their reelection probability, should be more inclined to submit women-specific questions. Another dummy variable indicates if MPs are politically active on the local level (mayor or member of the city council) because these legislators should generally be more concerned with issues that concern their local constituencies. Furthermore, I include the religious denomination of the MPs and if MPs have own children or not. Both variables could theoretically have an effect on the likelihood that an MP tables a women-specific question. Moreover, I additionally control for the number of inhabitants per $\mathrm{km}^{2}$ (as a proxy for rural and urban districts) and the share of people younger than 18 in each district. It is expected that MPs from urban districts with a high share of adolescents are more likely to represent women's interests to enhance their re-

\footnotetext{
${ }^{2}$ I am grateful to Stefanie Bailer and Tamaki Ohmura for sharing their data on legislative careers in Germany.
} 
election prospects in the district. ${ }^{3}$ An additional dummy variable indicates whether an MP has been elected in East Germany. Before Germany's reunification, the communist regime in East Germany actively promoted equal rights for women and men and officially declared that the 'woman question' was solved. Women and men participated equally in the labor force and; due to strict quota systems; women also gained a substantial amount of seats in the national parliament. After the breakdown of the GDR, however, large parts of the society tried to clearly distance themselves from the socialist ideals of the former communist regime. As a result, many women started to re-emphasize traditional gender roles and withdrew from the public sphere. Moreover, because equal rights in East Germany were rather 'given from above' by the communist regime and not accompanied by a comparable emancipation in the private sphere, women were often faced with a double productive and reproductive burden: In addition to their participation in the labor force, women were still the only person responsible for family and household duties. This experience further strengthened the intention of many women to withdraw from the public sphere and supported the renewed emphasis of traditional gender roles (e.g. Einhorn 1991, Nechemias 1994, Rueschemeyer 1998, Matland and Montgomery 2003). Thus, attitudes towards the substantive representation of women might differ between MPs elected in East and West Germany.

Table A3 presents the results and shows that none of the additional coefficients has a significant effect on the substantive representation of women. Moreover, all coefficients from the main model retain their original size and significance levels if the additional control variables are added to the model. Thus, the substantive interpretation of the interaction effect remains unchanged.

\footnotetext{
${ }^{3}$ Alternatively, one could directly control for the share of female population in the district. However, since there is only very little variation between the districts $(s d=0.007)$, the variable is not included in the model.
} 
Table A3 Robustness of the regression results to the inclusion of additional control variables, log-odds.

\begin{tabular}{|c|c|c|}
\hline Variables & $\begin{array}{l}\text { General decision (Hurdle; Logit- } \\
\text { Regression) }\end{array}$ & $\begin{array}{l}\text { Intensity of Substantive } \\
\text { Representation (Beta-Regression) }\end{array}$ \\
\hline Female & $0.77 * *(0.25)$ & $0.37 * * *(0.11)$ \\
\hline Re-election probability (centered) & $-2.20 * * *(0.66)$ & $-0.57(0.34)$ \\
\hline Female * Re-election prob.(centered) & $1.32(0.85)$ & $0.74 *(0.35)$ \\
\hline No. of submitted questions (in total) & $0.01 * * *(0.002)$ & $-0.004 * *(0.001)$ \\
\hline Duration MP & $0.04(0.02)$ & $-0.01(0.01)$ \\
\hline Member women's committee & $1.52 * * *(0.33)$ & $1.43 * * *(0.21)$ \\
\hline Leadership position & $-0.39(0.23)$ & $0.11(0.13)$ \\
\hline Member governing party & $-2.20 * * *(0.42)$ & $0.36(0.25)$ \\
\hline First-time MP & $0.11(0.28)$ & $-0.25(0.18)$ \\
\hline Disengagement phase & $-0.34(0.28)$ & $0.23(0.17)$ \\
\hline Duration party member & $0.001(0.01)$ & $-0.001(0.01)$ \\
\hline Member women's organization & $0.41(0.33)$ & $0.13(0.19)$ \\
\hline Local politician & $-0.30(0.27)$ & $-0.04(0.13)$ \\
\hline Own children & $-0.15(0.23)$ & $-0.01(0.12)$ \\
\hline Catholic & $-0.06(0.32)$ & $-0.06(0.16)$ \\
\hline Protestant & $-0.08(0.28)$ & $0.20(0.17)$ \\
\hline District pop. under 18 & $0.01(0.07)$ & $0.02(0.04)$ \\
\hline District inhabitants $/ \mathrm{km}^{2}$ (in 1000 ) & $-0.03(0.08)$ & $-0.002(0.03)$ \\
\hline East Germany & $0.58(0.35)$ & $0.10(0.22)$ \\
\hline 16th Bundestag (Time Dummy) & $0.06(0.25)$ & $-0.11(0.17)$ \\
\hline Party fixed-effects & $\checkmark$ & $\checkmark$ \\
\hline Constant & $-1.35(1.43)$ & $-3.29 * * *(0.84)$ \\
\hline $\mathrm{N}$ & 1148 & 210 \\
\hline Log-Pseudolikelihood & -348.91 & 379.46 \\
\hline $\mathrm{Chi}^{2}$ & $396.39 * * *$ & $206.36^{* * *}$ \\
\hline
\end{tabular}

Notes: Hurdle Model. DV Model 1: Dummy variable coded 1 if share of women-specific questions $>0$. DV Model 2: Share of women-specific PQs. Coefficients: Log-Odds. Standard errors (in parentheses) are clustered by MP. Reference category for parties: CDU/CSU. Significance Levels: ${ }^{*} \mathrm{p}<.05$; ** $\mathrm{p}<.01$; $* * * \mathrm{p}<.001$. 


\section{A5 Using a List-District Dummy instead of re-election probability as independent variable}

I test whether it is really the combination of list and district re-election probabilities that liberates female MPs from the necessity to represent local issues of her district. Table A4 shows the results of a hurdle regression model which, instead of the re-election probability, contains a dummy indicator for the electoral system as the main independent variable. The results show that the interaction effect of this indicator variable and female MPs is not significant in both parts of the model. Thus, the electoral system by itself is not a good indicator for the legislative behavior of female MPs. It is rather the combination of the reelection probabilities in both tiers that gives female MPs the possibility to represent women's interests in the legislative arena. 
Table A4 Re-estimation of the main model with a List-District Dummy as Independent Variable

\begin{tabular}{lll}
\hline Variables & $\begin{array}{l}\text { General decision (Hurdle; Logit- } \\
\text { Regression) }\end{array}$ & $\begin{array}{l}\text { Intensity of Substantive } \\
\text { Representation (Beta-Regression) }\end{array}$ \\
\hline Female & $1.16^{* *}(0.42)$ & $0.48^{*}(0.22)$ \\
List mandate & $0.62(0.33)$ & $-0.06(0.22)$ \\
Female * List mandate & $-0.45(0.46)$ & $-0.26(0.26)$ \\
No. of submitted questions (in total) & $0.01^{* * *}(0.002)$ & $-0.003^{* *}(0.001)$ \\
Duration MP & $0.01(0.01)$ & $0.004(0.01)$ \\
Member women's committee & $1.48^{* * *}(0.27)$ & $1.30^{* * *}(0.22)$ \\
Leadership position & $-0.48^{*}(0.21)$ & $0.08(0.11)$ \\
Member governing party & $-2.14^{* * *}(0.40)$ & $0.38(0.26)$ \\
SPD & $-0.47(0.40)$ & $0.45(0.35)$ \\
Greens & $-0.61(0.51)$ & $0.57(0.35)$ \\
FDP & $-0.32(0.49)$ & $0.59(0.33)$ \\
Left & $-0.48(0.51)$ & $0.47(0.34)$ \\
16th Bundestag (Time Dummy) & $0.06(0.19)$ & $-0.005(0.14)$ \\
Constant & $-1.60^{* *}(0.50)$ & $-3.13 * * *(0.46)$ \\
\hline L & 1290 & 236 \\
Chi ${ }^{2}$ & -408.07 & 420.32 \\
\hline Notes: Hur & $423.40^{* * *}$ & $157.16 * * *$ \\
\hline
\end{tabular}

Notes: Hurdle Model. DV Model 1: Dummy variable coded 1 if share of women-specific questions $>0$. DV Model 2: Share of women-specific PQs. Coefficients: Log-Odds. Standard errors (in parentheses) are clustered by MP. Reference category for parties: CDU/CSU. Significance Levels: * $\mathrm{p}<.05$; ** $\mathrm{p}<.01$; $* * * \mathrm{p}<.001$. 
A6 Robustness of regression results to the exclusion of cases with an extremely high number of women-specific PQs

To test whether the results are driven by MPs who tabled an unusually high number of women-specific PQs, I excluded all observations that are more than three standard deviations above the average number of submitted women-specific PQs (i.e. all MPs with more than 14 women-specific PQs) and re-estimated the model with the reduced sample $(\mathrm{N}=1256)$. Table A5 shows that the main findings are robust towards excluding the few clear outliers. 
Table A5 Robustness of regression results to the exclusion of cases with extreme values on the number of women-specific PQs, log-odds.

\begin{tabular}{lll}
\hline Variables & $\begin{array}{l}\text { General decision (Hurdle; Logit- } \\
\text { Regression) }\end{array}$ & $\begin{array}{l}\text { Intensity of Substantive } \\
\text { Representation (Beta-Regression) }\end{array}$ \\
\hline Female & $0.90^{* * *}(0.21)$ & $0.33^{* * *}(0.09)$ \\
Re-election probability (centered) & $-1.57^{* *}(0.53)$ & $-0.35(0.25)$ \\
Female * Re-election prob.(centered) & $0.51(0.71)$ & $0.78^{* *}(0.30)$ \\
No. of submitted questions (in total) & $0.01^{* * *}(0.002)$ & $-0.01^{* * *}(0.001)$ \\
Duration MP & $0.03(0.02)$ & $0.01(0.01)$ \\
Member women's committee & $1.40^{* * *}(0.30)$ & $0.79^{* * *}(0.21)$ \\
Leadership position & $-0.39(0.21)$ & $-0.02(0.10)$ \\
Member governing party & $-2.17^{* * *}(0.40)$ & $0.45^{*}(0.20)$ \\
SPD & $-0.48(0.40)$ & $0.32(0.28)$ \\
Greens & $-0.39(0.53)$ & $0.45(0.29)$ \\
FDP & $-0.22(0.49)$ & $0.30(0.27)$ \\
Left & $-0.73(0.54)$ & $0.38(0.30)$ \\
16 th Bundestag (Time Dummy) & $0.10(0.19)$ & $0.04(0.13)$ \\
Constant & $-1.40^{* *}(0.47)$ & $-2.97 * * *(0.34)$ \\
\hline N & 1256 & 222 \\
Log-Pseudolikelihood & -395.26 & 448.81 \\
\hline Chi & $393.37^{* * *}$ & $120.86^{* * *}$ \\
\hline
\end{tabular}

Notes: Hurdle Model. DV Model 1: Dummy variable coded 1 if share of women-specific questions $>0$. DV Model 2: Share of women-specific PQs. Coefficients: Log-Odds. Standard errors (in parentheses) are clustered by MP. Reference category for parties: CDU/CSU. Significance Levels: * $\mathrm{p}<.05$; $* * \mathrm{p}<.01$; $* * * \mathrm{p}<.001$. 


\section{References}

Bailer, Stefanie, and Tamaki Ohmura. 2018. "Exploring, Maintaining, and Disengaging - The Three Phases of a Legislator's Life.” Legislative Studies Quarterly 43(3): 493-520.

Einhorn, Barbara. 1991. “Where Have All the Women Gone? Women and the Women's Movement in East Central Europe.” Feminist Review 39(1): 16-36.

Nechemias, Carol. 1994. "Democratization and Women's Access to Legislative Seats: The Soviet Case, 1989-1991." Women and Politics 14(3): 1-18.

Rueschemeyer, Marilyn. 1998. Women in the Politics of Post-Communist Eastern Europe. Armonk: M.E. Sharpe.

Matland, Richard E. and Kathleen A. Montgomery (Eds.). 2003. Women's Access to Political Power in Post-Communist Europe. Oxford: Oxford University Press. 


\section{Aufsatz 2}

When Do Men Represent Women's Interests in Parliament? How the Presence of Women in Parliament Affects the Legislative Behavior of Male Politicians.

Daniel Höhmann

Publiziert im Jahr 2020 in Swiss Political Science Review 26(1): 31-50, https://doi.org/10.1111/spsr.12392. 


\title{
When Do Men Represent Women's Interests in Parliament? How the Presence of Women in Parliament Affects the Legislative Behavior of Male Politicians
}

\author{
Daniel Höhmann (D \\ University of Bamberg
}

\begin{abstract}
This paper analyzes the conditions affecting male Members of Parliaments' (MPs) proclivity for representing women's interests. It particularly explores whether the presence of female MPs has an effect on men's parliamentary behavior. Three contrasting effects are discussed in the literature: (1) A spillover effect which postulates that men will become more likely to act on behalf of women if the number of female MPs increases, (2) a group-threat effect which creates a hostile backlash among male MPs, or (3) a specialization effect which makes male MPs less likely to represent women because this is typically seen as a function that should be fulfilled by female MPs. Empirically, this paper analyzes the representation of women's issues in parliamentary questions tabled in the German Bundestag (1998-2013) by using automated content analysis. The results support the specialization hypothesis and show that male MPs reduce their intensity of women's representation if the proportion of female MPs is high.
\end{abstract}

KEYwORDS: Representation, gender, women's interests, male MPs, parliamentary questions

\section{Introduction}

What role do male legislators play in the substantive representation of women's interests? So far, this question has largely been ignored even though men make up the majority in almost every parliament in the world. Previous research in this field primarily stresses gender as a personal source of responsiveness and has therefore been focused on the behavior of female members of parliament (MPs) and the extent to which they are responsive to the interests of women. Theoretical studies on women's representation typically suggests that female MPs represent women-specific issues more strongly and more credibly since they share a social identity and gender-specific experiences with women in the population (Mansbridge 1999; Phillips 1995). Male MPs merely serve as the neutral base against which the behavior of female legislators is compared. The empirical evidence for this link between descriptive and substantive representation, however, is anything but conclusive, revealing that even if the share of female MPs increases beyond a critical mass of $30 \%$ (Kanter 1977), parliaments might not become more responsive to women's demands (Crowley 2004; Towns 2003; Wängnerud 2009). Based on these findings, this article challenges the underlying assumption of the politics of presence literature and postulates that female MPs not only directly influence the substantive representation of 
women, but that they also indirectly affect the level of responsiveness of parliaments via the reactions of their male counterparts (c.f. Childs and Krook 2008; Yoder 1991). This article, therefore, addresses the question to what extent the presence of female MPs affects men's parliamentary behavior and whether male MPs become more or less likely to act in women's interests if the proportion of female MPs is high. In doing so, it seeks to contribute to a broader understanding of the potential actors in the substantive representation of women and presents one of the first studies to analyze whether and under what conditions, male MPs become "critical actors" (Childs and Krook 2009) representing the interests and preferences of women.

On a theoretical level, I propose three contrasting hypotheses: On the one hand, one could expect a positive spillover effect. According to this argument, once female MPs put women's issues on the parliamentary agenda, men will take them up and start to act more strongly on behalf of women. On the other hand, a group-threat effect could occur which creates a negative backlash among male MPs (Blalock 1967; Yoder 1991). This effect implies that male MPs become hostile towards female MPs and their legislative agenda if they fear losing their majority status in parliament. The third hypothesis postulates a specialization effect between male and female MPs. Drawing on the theories of sociological and feminist institutionalism (Chappell and Waylen 2013), it expects that according to appropriate gendered behavior, the representation of women's interests is typically seen as a function that should be fulfilled by female MPs. Thus, if more women enter parliament, male MPs will not show any kind of hostile resentments against female MPs, but they will no longer feel responsible for the representation of women's issues and decrease the intensity with which they represent women's interests in parliament.

The empirical part of the paper analyzes the substantive representation of women by male MPs in the German Bundestag between 1998 and 2013. Since the proportion of female MPs in the Bundestag is constantly above a critical mass of $30 \%$, Germany provides a useful case from which to study the effect of a large group of women on male MPs' parliamentary behavior. Male MPs' responsiveness towards women's interests is measured with an automated content analysis of written and oral parliamentary questions (70438 questions in total) tabled by individual MPs in the Bundestag. The analysis identified all Parliamentary Questions (PQs) on topics that affect women disproportionally more than men, or that address a social condition in which women are disadvantaged compared to men (Carroll 1994; Celis 2008). Subsequently, all women-specific PQs were coded for direction and classified as feminist, neutral or anti-feminist.

The results of a hurdle regression model show that a pronounced presence of female MPs has a negative effect on the substantive representation of women by male MPs. Supporting the idea of a specialization-mechanism, male MPs do not completely refuse to represent women in parliament if the proportion of female MPs is high, but they significantly reduce the intensity with which they speak on behalf of women. Moreover, male legislators issue significantly less feminist PQs than female MPs and rather concentrate on the representation of neutral women-specific issues (e.g. women's health). Thus, female MPs represent women's interests in a more specialized way and more often push for an expansion of women's opportunities and rights.

These findings explicitly broaden our understanding of the potential actors and the multiple possibilities for representing women in parliament and provide an important contribution to the analysis of the conditions influencing the willingness of individual male MPs to represent women's interest. The article also helps to clarify the relationship 
between the descriptive and substantive representation of women and highlights that if we want to capture the whole dynamic of the women's representation, we have to explicitly consider the role of male MPs and the effects that female MPs can have on their individual responsiveness towards women.

\section{Substantive Representation of Women: The Importance of Critical Actors}

Traditionally, research on women's representation has mainly been focused on the question of whether women "make a difference" once they have been elected to parliament. Returning to Pitkin's (1967) seminal conceptualization of representation, researchers postulated a direct link between the descriptive and substantive representation of women, suggesting that female MPs would represent women-specific issues more strongly and credibly in the legislative arena than their male colleagues because they share gender-specific experiences and problems with women in the population (Mansbridge 1999; Phillips 1995).

Whereas some studies confirm that female MPs represent women's issues in parliament disproportionately (e.g. Bäck et al. 2014; Campbell et al. 2009; Childs and Withey 2004; Swers 2002; Thomas 1991; Wängnerud 2000), others find that female MPs do not always show strong commitments to the representation of women-specific interests and that the differences between men and women are often very small or even totally absent (Childs and Krook 2009; Höhmann 2019). Since the linkage between descriptive and substantive representation appears to be rather probabilistic than deterministic (Dodson 2006), several authors have suggested that we should rethink the substantive representation of women and that we should move beyond analyzing only female MPs' behavior and the questions of how and when women represent the interests and preferences of their female constituents (Celis and Erzeel 2015; Celis et al. 2008; Childs and Krook 2008; 2009; Grey 2006; Höhmann 2019; Mackay 2008). If we want to paint a complete picture of the substantive representation of women as such, Childs and Krook $(2008$, 2009) recommend moving the "analytical focus from the macro to the micro level, replacing attempts to discern 'what women do' to study 'what specific actors do" (Childs and Krook 2008: 734). This idea deviates from the notion that female MPs are the only actors in the substantive representation of women and emphasizes that men can also be critical actors who "act individually or collectively to bring about women-friendly policy change" (Childs and Krook 2009: 127). Some initial studies of male MPs' behavior buttress the importance of a broader research scope and an explicit analysis of the role of male MPs in the representation of women's interests: In an analysis of the 2008-11 PartiRep survey data, Celis and Erzeel (2015) revealed that almost equal proportions of male and female MPs spoke on behalf of women in their respective parliamentary party group (PPG) meetings. In a study of British MPs' voting behavior and debate contributions, Evans (2012) showed that a few male MPs represented women's concerns in their debate contributions. However, they were in the minority and spoke less if women's interests had already been expressed by many female MPs in these debates. More recently, Dingler et al. (2019) studied the preference congruence between MPs and mass publics in 21 European countries by gender. They found that women's preferences are more accurately represented in parliament than those of men, even though the proportion of female MPs is much lower than that of male MPs, suggesting that male MPs are equally competent to represent the interests of women. 
Celis and Erzeel (2015: 60) pointed out that beyond the sole description of the extent to which male MPs act as critical actors in the substantive representation of women, it is even more important to "examine under what institutional, political and discursive conditions they can both participate and contribute to a responsive process in representing women's interests". One important factor in this regard is the question whether male MPs' legislative behavior is affected by the presence of an increasing number of women in the parliament: Contrary to the expectations of critical mass theory (Dahlerup 1988; Kanter 1977), an increasing number of female MPs does not always result in a more intense substantive representation of women's issues (e.g. Crowley 2004; Dingler et al. 2019; Karpowitz et al. 2015; Mendelberg et al. 2014; Mendelberg and Karpowitz 2016; Towns 2003). This suggests that a greater proportion of women in the parliament not only affects the possibilities of female MPs working together on issues related to women, but will also affect the behavior of male MPs (Childs and Krook 2008; Yoder 1991). More than 20 years ago, Kathlene (1994) had already identified a backlash among male MPs in the US Congress who acted in a more verbally aggressive and controlling manner during committee hearings if the proportion of women increased.

Since then, the effect of women on male MPs' behavior has not been analyzed empirically. The only exception is a recent study from Kokkonen and Wängnerud (2017) who conducted a survey of locally elected politicians in 290 municipalities in Sweden to analyze the effect of female councilors on male MPs' attitudes towards the representation of women's interests. They found that the proportion of women has a significant negative effect on male MPs' willingness to act for women in the council. The more women are present in the council, the less likely it is that male MPs feel responsible for representing women's issues. Nevertheless, the analysis leaves two questions unanswered, which call for a further and more detailed analysis of the influence of women on male MPs' behavior: Firstly, it must be questioned whether the findings from Swedish local councils are also generalizable to national parliaments. Secondly, because Kokkonen and Wängnerud used survey data, they only analyzed male MPs' subjective attitudes. It is questionable, however, whether these self-reported claims are translated into actual behavior. The present study intends to fill these research gaps.

\section{Spillover, Backlash or Specialization? Theoretical Expectations About the Effect of an Increasing Proportion of Women on Male MPs' Behavior}

\section{Spillover Effect: How the Presence of Female MPs Can Turn Men into Critical Actors}

In an early study on the impact of women on US state legislation, Thomas (1991: 962) speculated that if the proportion of women in parliament increases, "the more likely it will be that women's attitudes permeate the wider legislative atmosphere. As women become more numerous and, as they address these [women-specific] issues, men are expected to be educated about the importance of governmental action in what have heretofore been under-addressed areas".

This statement mirrors the assumption of exposure-based explanations of attitudes, i.e. that people generally do not develop their attitudes and interests in isolation (Festinger 1954; Visser and Mirable 2004). People are embedded in a social network of individuals (e.g. family members, friends, co-workers) with whom they interact and exchange information on a regular basis and opinions and attitudes are influenced to a large degree 
by the social environment and by the attitudes of other members in these networks (Visser and Mirable 2004). Bolzendahl and Myers (2004: 761f.) applied this approach to feminists' attitudes and pointed out that "individuals develop or change their understanding of women's place in society and their attitudes toward feminists' issues when they encounter ideas and situations that resonate with feminist ideals". In particular, the authors hypothesized that the exposure to feminist ideals would create an awareness of gender equality and reduce their acceptance of typical gender stereotypes (Bolzendahl and Myers 2004: 762).

When applied to politics and the substantive representation of women, these theoretical considerations imply that male MPs develop an awareness of women's interests if they come into contact with an increasing number of female MPs and their gender-specific experiences. Exposure to women's specific interests and problems might either occur in discussions with female MPs or through direct observation if female MPs are able to introduce women's issues to the parliamentary agenda (e.g. speeches, bill proposals). ${ }^{1}$ If these experiences cause a positive spillover effect, then male MPs will not only change their attitudes towards gender equality, but also express these issues in their actual parliamentary behavior and become more responsive to women's interests. Concerning the types and directionality of women issues that get represented, male MPs should become more likely to represent women's issues in a feminist direction rather than stressing traditional or anti-feminist gender roles.

Contrary to Kokkonen and Wängnerud (2017), who postulate that the proportion of women in parliament as a whole is the decisive factor affecting male MPs' behavior, I hypothesize that a potential spillover effect is caused by the proportion of women in the PPG. Empirical tests of exposure-based theories of interest formation show that our preference formations are mainly affected by people with whom we have contact on a regular basis and with whom we share similar norms, values, and ideologies (Festinger 1954; Visser and Mirable 2004). The literature on legislative organization and parliamentary behavior shows that PPGs are the most relevant actors in the parliamentary process and that the parliamentary work of individual MPs is mainly organized by and around the PPG (e.g. Sieberer 2006). Due to this central role in the internal organization of the parliament, MPs are in more frequent contact with colleagues from their own PPG (e.g. in the weekly meetings of the PPG's working groups), they usually vote together (Sieberer 2006), and - most importantly - also share similar political norms and ideologies with their party colleagues. Thus, the influence of female MPs on male MPs in the same PPG is much stronger than that of the overall proportion of women in the parliament (see Greene and O'Brien 2016).

$H_{I}$ : The higher the proportion of female MPs in the PPG, the more strongly will male MPs represent women's interests in parliament (spillover effect).

\section{Group Threat Effect: How the Presence of Female MPs Can Provoke a Hostile Backlash Effect Among Male MPs}

A potential negative backlash effect among male MPs can be explained by group-threat theories (Blalock 1967; Yoder 1991). Research on the representation of racial minorities in

\footnotetext{
${ }^{1}$ This argument implies that female MPs have an underlying intrinsic motivation to represent women's issues in parliament (Swers 2002).
} 
parliaments indicates that members of the majority feel threatened if formerly excluded groups (e.g. people of immigrant origin) gain increasing access to parliament. Since growing proportions of formerly excluded groups imply a change in the balance of power and influence in parliament, majority members fear losing their dominant and powerful positions and, thus, react with hostility to limit the minority's growing influence (Blalock 1967; Kanthak and Krause 2010; Kroeber 2018). Similar group-threat mechanisms also occur if women gain access to previously male-dominated workplaces. Yoder (1991) has shown that whenever men believe that the prestige of their own occupation and their privileged position in society is threatened by the growing presence of women, they are more likely to engage in discriminatory behavior towards their new female colleagues. Applied to the legislative arena, which has always been dominated by men, this means that male MPs perceive women as intruders and therefore become more hostile towards female MPs' interests. Because men fear losing their dominant and powerful position in parliament, group-threat theories hypothesize that male MPs will try to limit women's influence on the legislative agenda and will try to prevent their interests from being heard in the legislative process (Grey 2006; Kanthak and Krause 2010).

Hence, group-threat theories lead to the expectations that an increasing proportion of women creates a hostile resistance among male MPs and that men will completely refuse to represent women's issues in parliament. Additionally, male MPs will get less supportive of gender equality and become more likely to (if at all) concentrate on anti-feminist interventions that stress traditional gender roles and the prerogatives of men in the public and private sphere.

As explained in the previous section, I again hypothesize that it is not the proportion of women in the parliament as a whole, but rather the proportion of women in the respective PPG, which has the strongest influence on male MPs' behavior. Therefore, the following hypothesis can be formulated:

$\mathrm{H}_{2}$ : If the proportion of female MPs in the PPG is high, men will refuse to represent women's interests in parliament (group-threat effect).

\section{Specialization Effect: How the Presence of Female MPs Can Make Men Less Likely to Represent Women's Issues}

Contrary to the extreme expectation that men will become hostile towards women and the representation of their interests, the specialization hypothesis stresses a horizontal division of labor between male and female MPs based on traditional gender-roles. Building on sociological institutionalism and its "logic of appropriateness", gender scholars have developed a feminist variant of institutionalism and a corresponding "gendered logic of appropriateness" within institutional arenas (Chappell and Waylen 2013; Krook and Mackay 2011). Drawing on these theoretical studies, one can expect that informal rules about appropriate and acceptable gendered behavior, produce distinct roles for male and female MPs (Chappell and Waylen 2013; Towns 2003). Since female MPs share genderspecific experiences with women in the population (Phillips 1995), one of these "appropriate" roles for female legislators is to be a representative of women's interests (Bäck et al. 2014; Towns 2003). Even though male MPs are not hostile towards women's interests, gender norms prescribe that female MPs are mainly responsible for the representation of women's issues. If there are enough women in parliament, male MPs feel that they no longer have to be responsive to women's interests because female MPs can 
represent these issues more credibly (Evans 2012; Wängnerud 2000). Similar patterns of gendered division of labor can be found in portfolio allocations, committee assignments, and speech-making (e.g. Bäck et al. 2014; Towns 2003), where female MPs deal disproportionally with "soft" or "feminine" topics such as education, family affairs or welfare.

If we observe a specialization-mechanism, this does not necessarily mean that men completely refuse to represent women's issues since we do not expect any hostile or discriminatory reactions towards women. Male MPs would rather reduce the intensity of their efforts to represent the female population's concerns and rely on their female colleagues to cover these issues. Concerning the directionality of women's representation, Campbell (2006) has shown that women are generally more likely than men to hold feminist attitudes. Thus, if a high number of female MPs results in a specialization effect within PPGs, I expect that male MPs represent women's interest in a neutral rather than feminist way since they are not directly affected by gender inequalities in the society. Female MPs on the other hand should be more inclined to advance a feminist agenda and strive for more gender equality.

Given that cross-party cooperation between MPs from different parties is extremely rare in the German Bundestag, I hypothesize that a potential division of labor only occurs within party factions. Therefore, it is again the proportion of women in the respective PPG that would have the strongest effect on male MPs' behavior:

$H_{3}$ : If the proportion of female MPs in the PPG is high, male MPs will decrease the intensity with which they represent women's interests, but they will not entirely cease to speak on behalf of women (specialization effect).

\section{Methods and Data}

To put the three competing hypotheses to an empirical test, I analyze the representation of women's interests in the German Bundestag between 1998 and 2013. ${ }^{2}$ The German Bundestag represents a very useful case for several reasons. After the election in 1998, the percentage of women in the German Bundestag had risen above 30\% for the first time and since then, it has never fallen below this critical mass. Thus, there is a sufficiently large group of female MPs which theoretically has the potential to affect male MPs' decisions to become active in the substantive representation of women. Moreover, there is significant variation in the proportion of women between and within the five different parties represented in the Bundestag between 1998 and 2013. Table A1 in the Online Appendix gives information on the proportion of female MPs across parties and shows that the presence of female MPs differs considerably between the PPGs $(s d=12.4)$. Whereas for example, during the $14^{\text {th }}$ Bundestag (1998), only $18 \%$ of the conservative $\mathrm{CDU} / \mathrm{CSU}$ legislators were women, the proportion of women for the Green Party amounted to nearly $60 \%$ during the same legislative period. Changes within PPGs are not as pronounced, but we can still observe substantial variation in the number and share of women. ${ }^{3}$ At the same time, analyzing a single country over time enables me to hold all time-invariant country-specific characteristics (e.g. culture, institutional setting) constant.

\footnotetext{
${ }^{2}$ Data is available on the Harvard Dataverse at https://doi.org/10.7910/DVN/WIE8L4.

3 The percentage of women in the Left Party for example fell from 59\% in 1998 to $47 \%$ in 2005.
} 


\section{Dependent Variable: Definition and Coding of Women-Specific PQs}

The analysis' central dependent variable is the substantive representation of women by male legislators. To reduce the impact of party discipline, I use written and oral parliamentary questions to measure how strongly MPs focus on the representation of women-specific interests (Bird 2005; Martin 2011). Since parliamentary questions are not officially controlled by the party leadership, they provide a direct measurement of the extent to which individual legislators substantively represent the interests of certain social groups (Bailer 2011; Martin 2011; Saalfeld and Bischof 2013). The more strongly a legislator is committed to the substantive representation of women, the more questions about women-specific issues he should submit.

The definition of women's interests is a controversial and widely debated topic. To acknowledge that women are a diverse group with different life experiences and attitudes, the analysis refrains from using a predefined list of women-specific interests and uses the often-cited definitions from Susan Carroll (1994) and Karen Celis (2008) instead. According to Carroll (1994: 15), women's issues are those "where policy consequences are likely to have a more immediate and direct impact on significantly larger numbers of women than of men". Accordingly, a question is classified as women-specific, if it refers to a topic that for either biological or social reasons, affects women disproportionally more than men, or if it addresses a social condition in which women are disadvantaged compared to men (Celis 2008). The majority of questions coded as women-specific address issues such as gender pay gaps, legal protection of working mothers or sexual violence against women, as well as legal provisions concerning prenatal examinations and abortion. Questions about professions that are more frequently pursued by women than men (e.g. midwives) are also coded as women-specific. PQs about topics that have traditionally been described as "soft" or "female", such as youth policies, education, or health, are only coded as women-specific if they explicitly refer to discrimination against women or girls.

For the empirical analysis, a data set was compiled of all the written and oral questions that were tabled by the MPs during the $14^{\text {th }}, 15^{\text {th }}, 16^{\text {th }}$, and $17^{\text {th }}$ Bundestag (1998-2013) (70438 questions in total). ${ }^{4}$ Due to the large amount of data, the analysis combines a supervised machine learning algorithm (Naïve Bayes classifier) and a dictionary-based approach to code each PQ as either referring to a women-specific issue or not (e.g. Grimmer and Stewart 2013; Lucas et al. 2015). ${ }^{5}$ For the supervised machine learning algorithm, all PQs from the $16^{\text {th }}$ and $17^{\text {th }}$ Bundestag (2005-2013) were hand-coded by the author to identify women-specific questions. ${ }^{6}$ After the required pre-processing of the data $^{7}$, this set of hand-coded questions was used to train a Naïve Bayes classifier (Grimmer and Stewart 2013) which then automatically classified all PQs tabled during the

\footnotetext{
${ }^{4}$ PQs can be downloaded from the Bundestag's online archive (PDok, DIP; http://pdok.bundestag.de and http:// dipbt.bundestag.de/dip21.web/bt).

5 All quantitative text analyses are estimated using the quanteda-package in $R$.

${ }^{6}$ To test the validity of the classification, a student research assistant was familiarized with the definition of women's substantive representation and was then asked to classify a random sample of 2000 PQs (PQs that have been classified as women-specific by the author were oversampled and made up $14 \%$ of the sample). According to Krippendorff's $\alpha$, the intercoder reliability equals 0.94 . Among the women-specific PQs, the intercoder agreement is $95.2 \%$.

${ }^{7}$ This includes the tokenization of PQs, removal of stop words as well as of very rare and frequent words, the transformation of words to lowercase, and the reduction of words to their stem form (Grimmer and Stewart 2013; Lucas et al. 2015;).
} 
$14^{\text {th }}$ and $15^{\text {th }}$ Bundestag. ${ }^{8}$ To identify obviously women-specific questions that the Naïve Bayes classifier had missed, a dictionary-based approach was applied independently of the supervised machine learning algorithm. Based on the hand-coded questions from the $16^{\text {th }}$ and $17^{\text {th }}$ Bundestag, a dictionary of women-specific keywords was created and all the questions were then searched for these keywords and classified as women-specific if they contain at least one of them. ${ }^{9}$ The dependent variable for the statistical analysis is then expressed as the ratio of the number of women-specific questions to the total number of PQs submitted by an individual MP during a single legislative period. A detailed description of the coding procedure and its validation as well as a list of all dictionary keywords can be found in the Online Appendix (A3 and A4).

The main statistical analysis of the article relies on this rather broad classification of PQs and does not take into account whether the PQs advocate for equal rights and promote the status and well-being of women or whether they rather restrict gender equality and stress traditional perceptions of the role of women in the society. For a more meaningful interpretation of the results of the statistical model, all women-specific PQs were subsequently hand-coded for direction and classified according to whether they were feminist, anti-feminist or neutral. Following the example of Childs and Withey (2004) and Reingold (2000), PQs were coded as feminist if their aim was an expansion of women's opportunities or a mitigation of inequalities between men and women. If MPs stressed traditional gender roles or asked the government to restrict equal rights for women, those PQs are coded as anti-feminist. In most instances these were questions about the provision of contraceptive pills or women's access to abortion. Issues which could not be clearly identified as being either feminist or anti-feminist were coded as neutral. Most of these neutral PQs were about women's health (e.g. regulations concerning the treatment of breast cancer). The distribution of feminist, anti-feminist and neutral women-specific PQs is then used in combination with the results from the statistical model to more thoroughly differentiate between the three hypotheses (see below).

\section{Independent and Control Variables}

The main explanatory variable is the respective proportion of women in the PPG in a single legislative period. Information on the number of female and male legislators in the factions of the Bundestag is taken from the Bundestag Roll Call Vote Data Set (BTVote, Sieberer et al. 2018, see Table A1 in the Online Appendix).

Although many country-specific factors are controlled for by design, several control variables have been introduced. First, all models control for a membership in the Women's Committee since these MPs, irrespective of the proportion of female MPs, should be more inclined to submit women-specific questions. Previous research has shown that proportional electoral systems have a strong and positive effect on the number of women in parliament (Wängnerud 2009) as well as on the representation of broad interests (Carey 2007). In Germany's mixed electoral system, half of the MPs are elected in single member districts using first past the post and the other half is elected via proportional representation. Thus, the model contains a dummy variable that indicates whether MPs

\footnotetext{
${ }^{8}$ Results of a V-fold cross-validation indicate an averaged balanced accuracy of 0.78 and a recall rate of 0.7 (see Online Appendix A3).

9 All questions that had been identified as women-specific by either the Naïve Bayes classifier or the dictionaryapproach were reviewed manually to determine the validity of the classification.
} 
have been elected in a district or via their respective party list (base category). ${ }^{10} \mathrm{I}$ include an additional dummy variable that indicates if an MP holds an executive or parliamentary office because these legislators usually do not submit parliamentary questions at all. ${ }^{11}$ To control for potential intervening effects of parliamentary experience, I include the duration of parliament membership (measured in years) into the models. The MP's age (in years) is added to the model because older legislators tend to have more conservative attitudes towards gender equality (Kokkonen and Wängnerud 2017). Data for these variables stem from the BTVote dataset (Sieberer et al. 2018).

The likelihood of submitting a women-specific question also depends on the number of questions that a legislator submits. Previous studies show that MPs from opposition parties usually submit more PQs than government MPs (Russo and Wiberg 2010). One simple way to control for this would be the inclusion of a dummy variable for opposition status. However, since it is hard to argue that opposition status affects the share of female MPs, this study uses a more straightforward approach and directly controls for the total number of PQs tabled by an MP in the respective legislative term. ${ }^{12}$ An additional dummy variable indicates whether the MP was elected in East Germany.

Moreover, dummies for party membership are included in the model because it is conjectured that left parties (SPD, Greens, Left Party) are generally more in favor of gender equality and therefore facilitate the descriptive as well as the substantive representation of women (Caul 1999). Lastly, the postulated effect of the presence of women on the parliamentary behavior of male MPs could also be biased by potential time trends. If feminist values and positive attitudes towards gender equality become more prevalent in the population over time, this could have a positive effect on the proportion of women in parliament, while also making male MPs more attentive to gender-specific interests. Thus, all models include time dummy variables for the different legislative periods. Due to the inclusion of the party and time dummies, the effect estimations of the model are rather conservative because they are mainly based on changes of the share of women within parties and on the variation in time-variant factors between the PPGs. Table A5 in the Online Appendix contains descriptive statistics for all the variables.

\section{Statistical Model: Hurdle Regression Model}

The unit of analysis for the empirical analysis is an individual MP in a single legislative period. The overwhelming majority of Bundestag MPs does not table any women-specific question and receive a score of 0 for the dependent variable. To model this extremely right-skewed distribution that is bounded on the [0;1] interval, I estimated a hurdle regression model consisting of two different equations which are estimated as separate processes.

In the first step, the hurdle-component models male MPs' general decision whether or not to become active in the substantive representation of women. If this hurdle is

\footnotetext{
${ }^{10}$ Using re-election probabilities as an alternative measurement of electoral incentives (Stoffel and Sieberer 2018) has no effect on the results.

11 The following offices are treated as leadership positions: Chancellor, president of the Bundestag, cabinet minister, junior minister, chair of a permanent committee, chair of PPG, party whip.

12 The results do not change if I additionally control for opposition status. Robustness checks also show that the results remain stable if I control for the share of female population in the district. Since there is only very little variation between the districts $(s d=0.007)$, the variable is not included in the main model.
} 
overcome, the explanatory variable's effect on the strength or intensity of the dependent variable is estimated in the second step. More specifically, in the first equation the dependent variable is expressed as a dummy variable that receives a value of 1 if the proportion of women-specific questions is not equal to 0. A logistic regression model is then fitted to determine the effect of the proportion of female MPs on male MPs' general decision whether or not to represent women's issues in parliament. In the second step, a beta regression estimates the independent variable's influence on the strength or intensity of the dependent variable. This equation uses only those observations which have submitted at least one question with a women-specific topic and estimates the effect of the presence of female MPs on the proportion of women-specific questions that an individual male MP submitted during a single legislative period. The beta regression model assumes that the data are distributed according to a beta distribution which is bounded between 0 and 1 ( 0 and 1 not included). It is very flexible and therefore very well suited to describing unimodal as well as bimodal distributions (Cook et al. 2008: 863; Smithson and Verkuilen 2006). ${ }^{13}$

In addition to the skewed distribution, the statistical model must also take into account that the dataset contains multiple observations for the same MP (in different legislative periods) which are not independent from each other. Therefore, all models are calculated with robust standard errors that are clustered at the level of MPs. This paper is solely interested in the behavior of male MPs and their decision whether to become critical actors in the substantive representation of women. In particular, female MPs are not taken as the reference category against which male MPs are compared. I have intentionally refrained from including an interaction effect of gender and the proportion of female MPs in the analysis and calculated the regression models exclusively with male legislators.

What are my expectations concerning the three different hypotheses? If female MPs create a positive spillover effect among male MPs $\left(H_{1}\right)$, I expect to find significant positive effects in both equations of the hurdle regression model. Men should generally become more likely to represent women's interests and they should also increase the intensity of their substantive representation of women. For a potential group-threat effect, I expect to find significant negative coefficients in both equations $\left(\mathrm{H}_{2}\right)$. If male MPs react with hostility towards women in parliament, they become less likely to represent women's issues at all (negative effect in logit regression) and they also substantially reduce the intensity with which they act in the interest of women (negative effect in beta regression). If the specialization mechanism applies $\left(H_{3}\right)$, men only reduce the intensity of their responsiveness to women's demands because they expect that female MPs are better able to represent women's interests. Their general decision whether or not to represent women, however, should be unaffected by the proportion of female MPs since a specialization effect does not cause a complete withdrawal based on resentments against women among male MPs. Thus, I expect to find no effect in the logit regression but a significant negative effect in the beta regression model.

However, there are a few potential objections to this interpretation: If in the absence of a large number of female MPs, male MPs mainly submit PQs promoting traditional gender roles or anti-feminist standpoints, but reduce this behavior when more women enter the parliamentary arena, negative effects in the analysis would speak for a positive

\footnotetext{
${ }^{13}$ Standard errors of the beta regression are conditional on the results from the logit regression. This accounts for the fact that although the two models are estimated with two separate equations, they are dependent on one another.
} 
spill-over effect. On the contrary, if men increasingly table PQs with an anti-feminist direction if the more women enter parliament, this would rather support the group-threat hypothesis. Moreover, the group-threat and specialization hypothesis both expect a reduction in women's representation by male MPs. I therefore use the distribution of feminist, neutral, and anti-feminist PQs across male and female MPs to substantiate the findings of the hurdle regression model and to better differentiate between the three hypotheses. As explained above, we should see many feminist PQs tabled by male MPs if a positive spill-over effect occurs. If men are afraid to lose their dominant status in the parliament and react with hostility towards an influx of female MPs (group-threat effect), male MPs should stress anti-feminist viewpoints in their PQs and should try to push for traditional gender roles that confine women to the private sphere. In the case of a specialization effect between male and female MPs, I expect that male MPs rather focus on neutral women's interest and - contrary to the group-threat hypothesis - will not stress any anti-feminist ideas.

\section{Results}

Of the 70438 written and oral PQs that were tabled by the members of the Bundestag between 1998 and 2013, only $2.9 \%$ (2012) tackled a topic which particularly concerns the interest of women. The descriptive statistics show that $1286(63 \%)$ of these women-specific questions were tabled by female MPs, showing that, in general, female legislators focus more strongly on the substantive representation of women's issues than their male colleagues. Nevertheless, male MPs tabled 726 (36\%) questions referring to women's interests, making it clear that men are by no means totally uninterested in women's issues and that, at least some of them, can be characterized as potential critical actors in the substantive representation of women. ${ }^{14}$ In the following, we will see whether this commitment is affected by the presence of women in the respective PPG.

After the data set was reduced to only male MPs, 1773 observations could be used to estimate the logit model and 253 observations were used for the calculation of the beta regression model. The results of the analysis are reported in Table 1. Estimates of the logit regression (effect on the decision whether or not to act on behalf of women) are shown on the left, and the results from the beta regression (effect on the intensity of substantive representation) are presented in the right part of the table. All coefficients are presented as $\log$ odds with robust standard errors clustered at the individual MP level. The beta regression standard errors are conditional on the results of the logit regression to account for the fact that although the two models are estimated in two separate steps, they are dependent on one another.

The results for the effect of the proportion of women on male MPs' general decision to promote women's interests in parliament show that the presence of female MPs neither sparks a spillover effect among male MPs nor provokes a hostile backlash. Even though the coefficient for the proportion of women has a positive sign, it is statistically insignificant and therefore indistinguishable from zero. Among the control variables, the total number of submitted questions, a membership in the women's committee, and being elected in Eastern Germany have positive effects on the male MPs' general decision to become active in the substantive representation of women. By contrast, older MPs and

\footnotetext{
${ }^{14}$ Figure A1 in the Online Appendix shows the distribution of women-specific PQs tabled by male MPs over time and across parties.
} 
Table 1: The Effect of Female MPs on the Substantive Representation of Women: Male MPs, 19982013 Log-Odds

\begin{tabular}{llc}
\hline Variables & $\begin{array}{c}\text { General decision } \\
\text { (Logit-Regression) }\end{array}$ & $\begin{array}{c}\text { Intensity of Substantive Representation } \\
\text { (Beta Regression) }\end{array}$ \\
\hline Share of women in PPG & $0.07(0.050)$ & $-0.06^{* *}(0.020)$ \\
Member women's committee & $1.04^{*}(0.429)$ & $0.60^{*}(0.279)$ \\
Leadership position & $-0.05(0.211)$ & $0.27(0.180)$ \\
Duration MP & $0.01(0.015)$ & $-0.001(0.009)$ \\
Age & $-0.02^{*}(0.010)$ & $-0.002(0.005)$ \\
District mandate & $-0.42^{*}(0.192)$ & $-0.03(0.106)$ \\
No. of submitted questions (in total) & $0.03^{* * *}(0.003)$ & $-0.01^{* * *}(0.002)$ \\
CDU/CSU & $1.87^{*}(0.880)$ & $-1.57^{* * *}(0.447)$ \\
FDP & $1.68^{*}(0.741)$ & $-1.19^{* *}(0.379)$ \\
Greens & $-1.75(1.079)$ & $0.75^{*}(0.346)$ \\
Left & $-0.72(0.987)$ & $0.80^{*}(0.329)$ \\
East Germany & $0.48^{*}(0.200)$ & $0.12(0.100)$ \\
Time fixed effects & $\boldsymbol{V}$ & $\boldsymbol{V}$ \\
Constant & $-4.41^{*}(1.904)$ & $0.39(0.823)$ \\
N & 1773 & 253 \\
Log-Pseudolikelihood & -543.09 & 502.76 \\
Chi ${ }^{2}$ & $381.34^{* * *}$ & $124.41^{* * *}$ \\
\hline
\end{tabular}

Notes: Hurdle Regression Model. DV Model 1: Dummy variable coded 1 if share of women-specific questions $>0$. DV Model 2: Share of women-specific questions. Coefficients: Log-Odds. Standard errors (in parentheses) are clustered by MP. Reference category for parties: SPD. Significance Levels: $* \mathrm{p}<.05 ; * * \mathrm{p}<.01 ; * * * \mathrm{p}<.001$.

those that are directly elected in a district are less likely to submit at least one question with a women-specific topic. Quite surprisingly, male legislators from the conservative CDU/CSU and from the FDP are more likely to promote women's interests in parliament than the SPD's male MPs (base category).

Since the male MPs' general decision to start or to stop being active in the promotion of women's interests is not affected by the presence of women, I will now turn to the results of the beta regression. This model only includes those male MPs who have tabled at least one women-specific question, that is, those who have generally decided to represent women's issues in the parliamentary arena. The calculation then estimates the effect of the proportion of women on the intensity with which male legislators promote the substantial representation of women (i.e. the share of submitted women-specific PQs).

The results in Table 1 show that the proportion of women has a significant negative effect on theproportion of women-specific questions submitted by male MPs. These results support the theoretical expectations that female MPs make men less likely to represent women's issues, meaning that male MPs table less PQs relating to women's interests if the proportion of women in the PPG is high. Since a substantial interpretation of the log-odds is not very intuitive, I estimated marginal effects and predicted probabilities to assess the actual effect size of the presence of women on the men's parliamentary behavior. ${ }^{15}$ The predictions in Figure 1a show that the proportion of women-specific questions submitted

\footnotetext{
15 All other variables enter the estimation with their empirically observed values.
} 
Figure 1: The Effect of the Presence of Women on the Intensity of Substantive Representation of Women, Male MPs

(a) Predicted Proportion of Women-Specific Questions (With 95\% Cls)

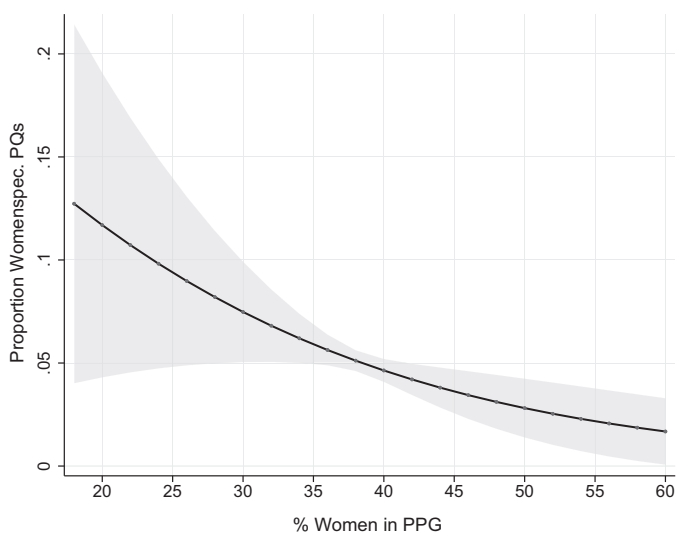

(b) Marginal Effects (With 95\% Cls)

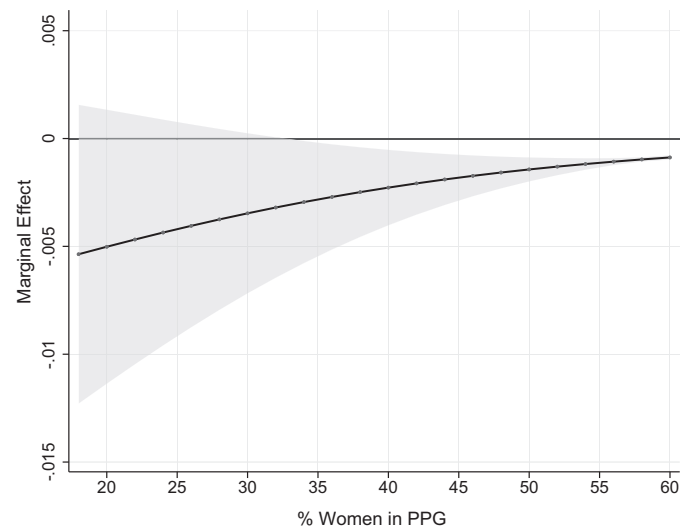

Note: Beta Regression. All other variables enter the model with their empirically observed values.

by each male MP is roughly $13 \%$ at the lowest proportion of female MPs which we observed in the data set $(18 \%)$ ). If the proportion of female MPs increases, the proportion of PQs dealing with a women's issue decreases steadily: When women make up $30 \%$ of the PPG, male MPs represent women's issues in only $7.5 \%$ of their submitted PQs. When more than half of the members of the PPG are female, the proportion of women-specific questions falls below $3 \%$ and further decreases to $1.8 \%$ until the proportion of female MPs reaches its maximum $(59 \%)$. The marginal effects in Figure $1 \mathrm{~b}$ indicate that the negative effect is particularly strong at low levels of women's presence in the PPG. If the proportion of female MPs is above $50 \%$, the effect on male MPs' behavior is almost zero. This indicates that a potential negative effect among male MPs is strongest if the additional female MPs are highly visible. The predicted probabilities demonstrate that despite only moderate variations in the share of women within PPGs the estimated effects on the behavior of male MPs are pretty robust and substantial. These effects might even be larger in other parliaments where changes in the share of female MPs within parties over time are more pronounced.

The results for the control variables show that male MPs ask significantly fewer womenspecific questions if their total number of submitted PQs increases, whereas members of the women's committee table significantly more questions referring to women's issues. The party fixed effects indicate that in comparison to the SPD, members of the CDU/CSU and FDP submitted less women-specific questions, whereas MPs from the Greens and the Left Party had a higher proportion of questions dealing with a women's issue. ${ }^{16}$

The results of the hurdle regression model allow two important conclusions to be drawn: First, a high number of women in parliament does not trigger any spillover effects among male MPs, meaning that men do not become more likely to be responsive to women's interests if more women are present in parliament. Contrary to the expectations

\footnotetext{
${ }^{16}$ The effect of the party fixed effects should not be over-interpreted because they are only included as control variables (see Conclusion).
} 
of $H_{1}$, this implies that male MPs do not become critical actors in the substantive representation of women once they come into contact with female MPs and their genderspecific experiences. Second, the results indicate that female legislators make male MPs less likely to speak on behalf of women and this rather happens in the form of a specialization than a group threat effect: The null-effect of the proportion of women on the male MPs' general decision to represent women's issues, demonstrates that men are not showing any form of hostile resentment against women and that they are not becoming more likely to refuse to represent women's interests at all if more women enter the parliamentary arena. In contrast, a high number of female MPs only affects the intensity with which male MPs act in the interest of women.

This interpretation is corroborated by the distribution of feminist, anti-feminist and neutral PQs, which is shown in Table 2. Of the 726 women-specific PQs submitted by male MPs, only $32(4.4 \%)$ were coded as anti-feminist. This clearly contradicts the expectations of the group-threat hypothesis which expect that male MPs should (if at all) advocate for traditional gender role models and anti-feminist opinions. By contrast, 374 (51.5\%) were classified as feminist and $320(44.1 \%)$ fell into the neutral category. The distribution for female MPs appears similar, however, they submitted significantly more feminist PQs $(67.4 \%)$. In situations where only a few women were present, male MPs did not represent traditional or anti-feminist standpoints, but rather represented women's interests in a more neutral way. When the proportion of women increases, male MPs ask fewer womenspecific PQs and female MPs take over the responsibility for representing women's interests. In doing so, they cover these issues from a more feminist perspective. Together with the results from the regression model, this pattern supports the specialization argument $\left(H_{3}\right)$ more than any alternative explanation. Although male MPs do not have an inherent personal source of responsiveness (i.e. they do not share gender-specific experiences with women), a certain number of male MPs is generally willing to represent women's issues in parliament. However, if women are highly represented in the PPG, it is expected that female MPs will cover the "gender angle" more competently (Evans 2012) and that they represent their gender-specific interest on their own. ${ }^{17}$

\section{Conclusion}

So far, research on the substantive representation of women has been focused on female MPs' behavior; asking how and when women are responsive to their female constituents' interests and preferences. This paper goes beyond this notion of an automatic link between descriptive and substantive representation and investigates to what extent and under which conditions male MPs act on behalf of women. In particular, the study provides one of the first empirical tests of the extent to which the presence of female MPs affects the likelihood of male MPs articulating women's interests in the legislative arena. To measure the strength of substantive representation, the analysis compiled a data set of all the PQs tabled by members of the German Bundestag between 1998 and 2013 and employed automated content analyses to classify each question according to whether or not it

\footnotetext{
${ }^{17}$ Further robustness checks can be found in the Online Appendix. A test for a curvilinear relationship (spill-over effect at low-levels of women's representation, backlash-effect if the proportion of women is high), does not yield any significant results (Online Appendix A6). Online Appendix A7 includes the proportion of female MPs in the subsequent legislative term $(\mathrm{t}+1)$ as its main independent variable to test whether male MPs anticipate an increase in the number of female MPs after the next election. The results are statistically insignificant.
} 
Table 2: Distribution of Feminist, Anti-Feminist and Neutral Women-Specific PQs by Sex

\begin{tabular}{lrccr}
\hline Type & Feminist PQs & Neutral PQs & Anti-Feminist PQs & \multicolumn{1}{c}{ Total } \\
\hline Male MPs & $374(51.5 \%)$ & $320(44.1 \%)$ & $32(4.4 \%)$ & $726(100 \%)$ \\
Female MPs & $867(67.4 \%)$ & $405(31.5 \%)$ & $14(1.1 \%)$ & $1286(100 \%)$ \\
Total & $1241(61.7 \%)$ & $725(36.0 \%)$ & $46(2.3 \%)$ & $2012(100 \%)$ \\
\hline
\end{tabular}

Note: Cell entries indicate absolute number of women-specific PQs. Row percentages in brackets. $X^{2}$ $=61.78 * * *$

referred to a women-specific issue. In line with a specialization-logic, the results show that male MPs are generally willing to act on behalf of women, however, if the proportion of women in their respective PPG is high, they leave this field to female MPs and reduce the intensity with which they represent women's issues.

The results of this study emphasize that by explicitly analyzing male MPs, we can develop a more thorough understanding of the multiple ways in which the substantive representation of women occurs. Men should not only be taken as a neutral reference category against which female MPs' behavior is compared, instead they should be understood as important actors who can play a significant role in the articulation of women's issues. The analysis of male MPs' behavior also highlights why having a critical mass of women is not always enough to produce more women-friendly outcomes (c.f. Karpowitz et al. 2015; Mendelberg and Karpowitz 2016; Mendelberg et al. 2014). Even if a greater proportion of women in parliament allows female MPs to work together effectively to push for the representation of women's interests, this influx of women simultaneously provokes a negative effect among male MPs, making them less willing to act on women's behalf. In this way female MPs do not only have a direct effect on the substantive representation of women, but they also indirectly affect the level of responsiveness of parliaments via the reactions of their male counterparts. If we were to ignore women's influence on men, we would paint an incomplete picture of female MPs' impact on the representation of women's interests in the parliamentary process. This is even more important since the analysis has also shown that female MPs speak about feminist issues more frequently, whereas men represent more neutral, women-specific topics instead.

This paper is only a first step in analyzing the factors determining whether male MPs become active in the substantive representation of women. Further studies are necessary to gain a deeper understanding of male MPs' representational behavior. Future research should consider the impact of political parties and analyze whether the effect of the presence of female MPs varies according to the ideological spectrum of the parties in the German Bundestag. The party fixed effects in Table 1 indicate significant differences in the behavior of male MPs from right-wing and left-wing parties. Since the party dummies only serve as control variables, their effect should not be over-interpreted, however, the results from the beta regression suggest that backlash effects rather occur in right-wing parties that are less in favor of gender equality (CDU/CSU, FDP) and that spillover effects might be more likely to observe in more progressive left-wing parties. Further studies should explore this in more detail and analyze whether there are any structural differences between the PPGs that make the representation of women interests more or less likely (e.g. proportion of women in leadership positions). Qualitative case studies of single parties and interviews with male MPs about their preferences and underlying motivations would be a 
useful complement to the present quantitative analysis. A more in-depth analysis of the direction of women's representation could also show whether some parties are more likely to represent traditional or anti-feminist opinions when they discuss women-specific issues. Drawing on the assumptions of sociological institutionalism, future studies should also examine whether the personal background and socialization of male MPs have an effect on their willingness to represent women-specific issues (c.f. Saalfeld and Bischof 2011). Their educational background, having their own children, as well as personal experiences with gender-based discrimination, abortions or breast cancer in the own family, could be significant factors which shape male MPs' representational behavior. From a rationalchoice perspective, it would be interesting to see whether the electoral situation of male MPs affects their decision to act on behalf of women. If we assume that re-election is the primary goal of all MPs, men should - besides a general increase in the salience of women's issues - only cater more strongly to female voters if they are electorally insecure, since this unexpected behavior could help them to win additional votes from women in their constituency.

The findings from this study suggest that the explicit analysis of male MPs as potential critical actors is an important and promising extension of previous research and a necessary next step for developing a comprehensive understanding of the substantive representation of women on parliament.

\section{Acknowledgments}

I am grateful to Rosie Campbell and Thomas Zittel for their detailed comments on an earlier version of this article. I also would like to thank Ulrich Sieberer, Thomas Saalfeld, Stefanie Bailer, Lucas Geese, Lukas Hohendorf, and three anonymous reviewers for their very helpful feedback as well as Jonas Wenzig for excellent research assistance. Previous versions of this article were presented at the ECPR Joint Sessions of Workshops 2018 (Nicosia, Cyprus) and at the Comparative Politics Colloquium at the University of Bamberg. I thank all participants for their helpful suggestions. All remaining errors are my own.

\section{References}

Bäck, H., M. Debus and J. Müller (2014). Who Takes the Parliamentary Floor? The Role of Gender in Speech-making in the Swedish Riksdag. Political Research Quarterly 67(3): 504-518.

Bailer, S. (2011). People's Voice or Information Pool? The Role of, and Reasons for, Parliamentary Questions in the Swiss Parliament. Journal of Legislative Studies 17(3): 302-314.

Bird, K. (2005). Gendering Parliamentary Questions. British Journal of Politics and International Relations 7(3): 353-370.

Blalock, H. (1967). Toward a Theory of Minority-Group Relations. New York: Wiley.

Bolzendahl, C. and D. Myers (2004). Feminist Attitudes and Support for Gender Equality: Opinion Change in Women and Men, 1974-1998. Social Forces 83(2): 759-789.

Campbell, R. (2006). Gender and the Vote in Britain. Colchester: ECPR Press.

Campbell, R., S. Childs and J. Lovenduski (2009). Do Women Need Women Representatives? British Journal for Political Science 40(1): 171-194.

Carey, J. (2007). Competing Principals, Political Institutions, and Party Unity in Legislative Voting. American Journal of Political Science 51(1): 92-107. 
Carroll, S. (1994). Women as Candidates in American Politics. Bloomington: Indiana University Press.

Caul, M. (1999). Women's Representation in Parliament: The Role of Political Parties. Party Politics 5(1): 79-98.

Celis, K. (2008). Studying Women's Substantive Representation in Legislatures: When Representative Acts, Contexts and Women's Interests Become Important. Representation 44(2): $111-123$.

Celis, K., S. Childs, J. Kantola and M. L. Krook (2008). Rethinking Women's Substantive Representation. Representation 44(2): 99-110.

Celis, K. and S. Erzeel (2015). Beyond the Usual Suspects: Non-Left, Male and Non-Feminist MPs and the Substantive Representation of Women. Government and Opposition 50(1): 45-64.

Chappell, L. and G. Waylen (2013). Gender and the Hidden Life of Institutions. Public Administration 91(3): 599-615.

Childs, S. and M. Krook (2008). Critical Mass Theory and Women's Political Representation. Political Studies 56(3): 725-736.

- (2009). Analysing Women's Substantive Representation: From Critical Mass to Critical Actors. Government and Opposition 44(2): 125-145.

Childs, S. and J. Withey (2004). Women Representatives Acting for Women: Sex and the Signing of Early Day Motions in the 1997 British Parliament. Political Studies 52(3): 552-564.

Cook, D., R. Kieschnick and B. McCullough (2008). Regression Analysis of Proportions in Finance with Self Selection. Journal of Empirical Finance 15(5): 860-867.

Crowley, J. (2004). When Tokens Matter. Legislative Studies Quarterly 29(1): 109-136.

Dahlerup, D. (1988). From a Small to a Large Minority: Women in Scandinavian Politics. Scandinavian Political Studies 11(4): 275-298.

Dingler, S., C. Kroeber and J. Fortin-Rittberger (2019). Do Parliaments Underrepresent Women's Policy Preferences? Journal of European Public Policy 26(2): 302-321.

Dodson, D. (2006). The Impact of Women in Congress. Oxford: Oxford University Press.

Evans, E. (2012). From Finance to Equality: The Substantive Representation of Women's Interests by Men and Women MPs in the House of Commons. Representation 48(2): 183-196.

Festinger, L. (1954). A Theory of Social Comparison Processes. Human Relations 7(2): 117-140.

Greene, Z. and D. O'Brien (2016). Diverse Parties, Diverse Agendas? Female Politicians and the Parliamentary Party's Role in Platform Formation. European Journal of Political Research 55(3): $435-453$.

Grey, S. (2006). Numbers and Beyond: The Relevance of Critical Mass in Gender Research. Politics\&Gender 2(4): 492-502.

Grimmer, J. and B. Stewart (2013). Text as Data: The Promise and Pitfalls of Automatic Content Analysis Methods for Political Texts. Political Analysis 21(3): 267-297.

Höhmann, D. (2019). When do Female MPs Represent Women's Interests? Electoral Systems and the Legislative Behavior of Women. Political Research Quarterly. Advanced Online: https://doi. org/10.1177/1065912919859437 [accessed: 25.07.2019].

Kanter, R. (1977). Some Effects of Proportions on Group Life: Skewed Sex Ratios and Responses to Token Women. American Journal of Sociology 82(5): 965-990.

Kanthak, K. and G. Krause (2010). Valuing Diversity in Political Organizations: Gender and Token Minorities in the U.S. House of Representatives. American Journal of Political Science 54(4): 839854.

Karpowitz, C., T. Mendelberg and L. Mattioli (2015). Why Women's Numbers Elevate Women's Influence, and when they do not: Rules, Norms, and Authority in Political Discussion. Politics, Groups, and Identities 3(1): 149-177. 
Kathlene, L. (1994). Power and Influence in State Legislative Policymaking: The Interaction of Gender and Position in Committee Hearing Debates. American Political Science Review 88(3): $560-576$.

Kokkonen, A. and L. Wängnerud (2017). Women's Presence in Politics and Male Politicians Commitment to Gender Equality in Politics: Evidence from 290 Swedish Local Councils. Journal of Women, Politics \& Policy 38(2): 199-220.

Kroeber, C. (2018). Growing Numbers, Growing Influence? A Comparative Study of Policy Congruence Between Parliaments and Citizens of Immigrant Origin. European Journal of Political Research 57(4): 900-918.

Krook, M. and F. Mackay (eds.) (2011). Gender, Politics and Institutions: Towards a Feminists Institutionalism. Basingstoke: Palgrave.

Lucas, C., R. Nielsen, M. Roberts, B. Stewart, A. Storer and D. Tingley (2015). Computer-Assisted Text Analysis for Comparative Politics. Political Analysis 23(2): 254-277.

Mackay, F. (2008). 'Thick' Conceptions of Substantive Representation: Women, Gender and Political Institutions. Representation 44(2): 125-139.

Mansbridge, J. (1999). Should Blacks Represent Blacks and Women Represent Women? A Contingent "Yes". Journal of Politics 61(3): 628-657.

Martin, S. (2011). Using Parliamentary Questions to Measure Constituency Focus: An Application to the Irish Case. Political Studies 59(2): 472-488.

Mendelberg, T. and C. Karpowitz (2016). Women's Authority in Political Decision-Making Groups. Leadership Quarterly 27(3): 487-503.

Mendelberg, T., C. Karpowitz and N. Goedert (2014). Does Descriptive Representation Facilitate Women's Distinctive Voice? How Gender Composition and Decision Rules Affect Deliberation. American Journal of Political Science 58(2): 291-306.

Phillips, A. (1995). The Politics of Presence. Oxford: Clarendon Press.

Pitkin, H. (1967). The Concept of Representation. Berkeley: University of California Press.

Reingold, B. (2000). Representing Women: Sex, Gender, and Legislative Behavior in Arizona and California. Chapel Hill: University of North Carolina Press.

Russo, F. and M. Wiberg (2010). Parliamentary Questioning in 17 European Parliaments: Some Steps towards Comparison. Journal of Legislative Studies 16(2): 215-232.

Saalfeld, T. and D. Bischof (2013). Minority-Ethnic MPs and the Substantive Representation of Minority Interests in the House of Commons, 2005-2011. Parliamentary Affairs 66(2): 305-328.

Sieberer, U. (2006). Party Unity in Parliamentary Democracies: A Comparative Analysis. Journal of Legislative Studies 12(2): 150-178.

Sieberer, U., T. Saalfeld, T. Ohmura, H. Bergmann and S. Bailer (2018). Roll-Call Votes in the German Bundestag, 1949-2013. British Journal of Political Science. Advanced Online: https://doi. org/10.1017/S0007123418000406 [accessed: 25.07.2019].

Smithson, M. and J. Verkuilen (2006). A Better Lemon Squeezer? Maximum-Likelihood Regression With Beta-Distributed Dependent Variables. Psychological Methods 11(1): 54-71.

Stoffel, M. and U. Sieberer (2018). Measuring Re-Election Prospects Across Electoral Systems: A General Approach Applied to Germany. West European Politics 41(5): 1191-1207.

Swers, M. (2002). The Difference Women Make: The Policy Impact of Women in Congress. Chicago: University of Chicago Press.

Thomas, S. (1991). The Impact of Women on State Legislative Policies. Journal of Politics 53(4): 958-976.

Towns, A. (2003). Understanding the Effects of Larger Ratios of Women in National Legislatures: Proportions and Gender Differentiation in Sweden and Norway. Women \& Politics 25(1-2): 1-29. 
Visser, P. and R. Mirabile (2004). Attitudes in the Social Context: The Impact of Social Network Composition on Individual-Level Attitude Strength. Journal of Personality and Social Psychology 87(6): 779-795.

Wängnerud, L. (2000). Testing the Politics of Presence: Women's Representation in the Swedish Riksdag. Scandinavian Political Studies 23(1): 67-91.

(2009). Women in Parliaments: Descriptive and Substantive Representation. Annual Review of Political Science 12: 51-69.

Yoder, J. (1991). Rethinking Tokenism: Looking beyond Numbers. Gender \& Society 5(2): 178192.?\}supp_info_\$^!"boolean(//supportingInformation)" >

\section{Supporting Information}

Additional Supporting Information may be found in the online version of this article:

Daniel Höhmann is a $\mathrm{PhD}$ candidate at the University of Bamberg, Germany. His current research focuses on political representation, women and politics, and coalition governance. His work was published among others in the Journal of Politics, West European Politics, Political Research Quarterly, Public Choice, and the Journal of Legislative Studies. Email: daniel.hoehmann@uni-bamberg.de 
Research Article

When Do Men Represent Women's Interests in Parliament? How the Presence of Women in Parliament Affects the Legislative Behavior of Male Politicians

Daniel Höhmann

(University of Bamberg)

Swiss Political Science Review

Online Appendix 
A1 Share and Number of Female MPs Across Parties (1998-2013)

Appendix A1 presents descriptive information on the share and number of female MPs across parties in the German Bundestag over time (1998-2013).

Table A1: Share and Number of Female MPs Across Parties (1998-2013)

\begin{tabular}{lccccc}
\hline Legislative Period & CDU/CSU & SPD & FDP & Greens & Left \\
\hline \hline \multirow{2}{*}{$14(1998-2002)$} & 18.2 & 36.0 & 24.4 & 58.0 & 59.0 \\
& $(47)$ & $(110)$ & $(11)$ & $(29)$ & $(23)$ \\
$15(2002-2005)$ & 23.4 & 38.8 & 23.6 & 59.7 & - \\
& $(60)$ & $(100)$ & $(13)$ & $(34)$ & - \\
\multirow{3}{*}{$16(2005-2009)$} & 19.8 & 36.4 & 23.8 & 55.4 & 47.3 \\
& $(47)$ & $(83)$ & $(15)$ & $(31)$ & $(26)$ \\
$17(2009-2013)$ & 20.0 & 39.6 & 24.0 & 52.0 & 53.9 \\
& $(49)$ & $(61)$ & $(24)$ & $(39)$ & $(42)$ \\
\hline \multirow{2}{*}{ Average } & 20.4 & 36.7 & 23.3 & 56.5 & 53.4 \\
& $(51)$ & $(93)$ & $(17)$ & $(34)$ & $(30)$ \\
\hline
\end{tabular}

Note: Absolute number of women in the PPG in parentheses.

\section{A2 Number of Women-Specific Parliamentary Questions Tabled by Male MPs (1998-2013)}

Figure A1: Number of Women-Specific Parliamentary Questions Tabled by Male MPs Across Parties $(1998-2013)$

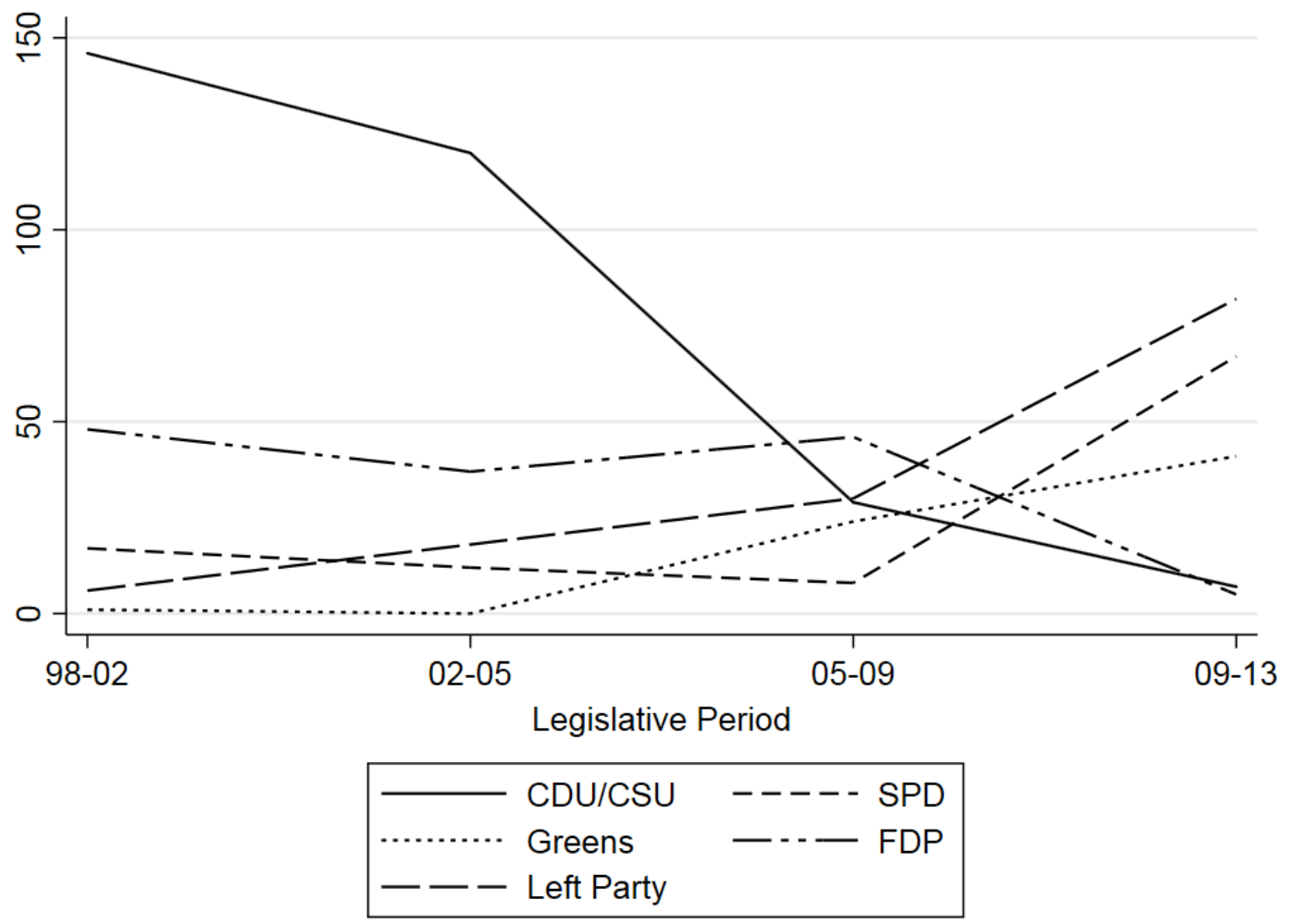




\section{A3 Description and Validation of the Automated Coding of Parliamentary Questions}

Appendix A3 provides a detailed description of the automated coding procedure of women-specific parliamentary questions (PQs).

The analysis uses a combination of two different methods of automated content classification: (1) A supervised machine learning algorithm (Naïve Bayes classifier) and (2) a dictionary-based approach.

Prior to the analysis, the PQ text corpus had to be transformed into a sparse document-term-matrix (DTM) which required extensive pre-processing of the original PQs (Welbers et al. 2017; Grimmer and Stewart 2013): All the documents were tokenized to split each question into single words and then normalized into a more uniform form. This includes transforming all features (words) to lowercase and reducing them to their stem form (e.g. the words family and families are reduced to famil). Moreover, stop words with no semantic meaning (e.g. the or $a$ ) as well as very rare (appearance in less than 10 documents) and very frequent (appearance in more than $20 \%$ of the documents) features were deleted from the corpus to reduce the size of the vocabulary and to improve the efficiency and accuracy of the subsequent classification (Lucas et al. 2015; Welbers et al. 2017).

The basic idea of supervised learning models is quite simple: A subset of documents is classified into specific categories by human coders. An algorithm then uses this training set to learn specific patterns and attributes determining the classification of the documents into one of the categories. If the training set is sufficiently large, the algorithm can then be used to classify the rest of the corpus into the pre-determined categories. In order to create the training set for the present analysis, all the questions from the 16th and 17th Bundestag (2005-2013) were hand-coded by the author to identify whether or not they dealt with a women-specific topic (the definition of women's interests can be found in the main paper).

All the training set's questions were used to train a Naïve Bayes classifier the relationship between document features and the classification of questions as women-specific. The classifier uses Bayes' rule 1 and a multinomial distribution of features within the documents to infer the probability that, based on the word profile of the document, a specific question belongs to the category of womenspecific questions (Grimmer and Stewart 2013). The trained classifier was then used to classify all PQs which were tabled during the Bundestag's $14_{\text {th }}$ and 15th legislative periods.

Since this supervised model is intended to automate the hand coding of questions, it was necessary to carefully validate the algorithm's performance after the classifier had been trained. At first, it is advisable to look at the most important features (words) which determine the classification of questions into the women's interest category. These are: frau* (women*), schwanger* (pregnant*), elternzeit (parental leave), kinderbetreuung (childcare), and alleinerziehend (single mother). Moreover, results of a $V$-fold cross-validation with 20 subgroups indicate that the classifier achieved an averaged balanced accuracy of 0.78 , which means that $78 \%$ of all questions have been correctly

\footnotetext{
${ }^{1} P($ womenspecific $\mid$ feature $)=\frac{P(\text { feature } \mid \text { womenspecific }) * P(\text { womenspecific })}{P(\text { feauture })}$
} 
classified as either women-specific or non-women-specific. When only the questions that referred to a women's issue were considered, the classifier was able to identify $70 \%$ of the questions that had been coded as women-specific by the human coder (recall). However, the classifier's precision (number of questions that the classifier correctly labelled as women-specific divided by the total number of questions that the classifier coded as women-specific) was only $17 \%$, which means that the Naïve Bayes algorithm tended to produce many false-positives.

Even though the classifier had reached a comparatively high level of accuracy and recall (see Grimmer and Stewart 2013), a dictionary-based approach was applied independently of the supervised machine learning algorithm, to further enhance the classification's validity and to identify obviously women-specific questions that the Naïve Bayes classifier had erroneously classified as non-women-specific. In general, dictionary-based approaches use the frequency of keywords to classify texts into specific categories (Grimmer and Stewart 2013). Thus, a dictionary of womenspecific keywords was created, based on the hand-coded questions from the 16th and 17th Bundestag. All the questions were then searched for these keywords and classified as women-specific if they contain at least one of them. A list of all the keywords can be found below.

Of the 28748 PQs that were automatically coded, both methods identified 3648 questions as referring to a women-specific issue. Since both methods tend to have high recall-levels, but only low precision (i.e. they produce a high number of false-positives), all questions that had been identified as womenspecific by either the Naïve Bayes classifier or the dictionary-approach, were reviewed manually in the last step of the classification to determine whether it really dealt with a women's issue. This reduced the number of women-specific questions to 774.413 of the 774 women-specific questions were identified by both methods. 34 questions were only identified by the supervised learning algorithm whereas 327 were only coded as women-specific by the dictionary-based approach. Thus, the combination of both methods and the subsequent human control seem to be an appropriate way to enhance the validity and the accuracy of the automated coding of PQs. 


\section{A4 Keywords Dictionary Approach}

A3 provides a full list of all keywords that have been used in the dictionary-approach to identify women-specific PQs. All words have been used in singular and plural (if applicable). Words with a * have been truncated in the search. Exemplary results for truncated searches in brackets. Please see below for English translations.

Frau* (Frauenanteil, Frauenquote, Frauenrechte, Frauenspezifisch, Frauenhandel, Frauenhaus, Frauenarzt, Frauenhaftanstalt, Frauengefängnis, Frauenhändler, Ombudsfrau, Ehefrau), weiblich*, Geschlecht* (Geschlechtsspezifisch), Gender*, Gender Mainstreaming, Mädchen* (Mädchenhandel, Mädchenhändler), Schwanger* (Schwangerschaft, Schwangerschaftsabbruch, Schwangerenvorsorge), Geburt* (Geburtshilfe), Baby* (Babyklappe), Embryo, Entbindung, Kontrazeptiva, Verhütung, Pille, Notfallkontrazeptiva, Abtreibung, Reproduktionsmedizin, Ungeboren, Künstliche Befruchtung, Präimplantationsdiagnostik, Kinder* (Kinderbetreuung, Kindertagesstätte, Kindergarten, Kinderkrippe, Kindererziehung, Kinderfreibetrag), Krippe, Kita, Ganztagesschule, Ganztagsbetreuung, Erziehung* (Erziehungsgeld, Erziehungsurlaub), Mutterschutz, Stillzeit, Tagesmutter, Mutter*, Vater* (Vaterschaftstest, Vaterschaft), Eltern* (Elterngeld, Elternzeit), Alleinerziehend, Familie* (Familiensplitting, Familienförderung), Ehe* (Ehegattensplitting), Gleichstellung* (Gleichstellungsbeauftragte, Gleichstellungspolitik), Feminismus, Feministin, Feministisch, Gleichberechtigung, Gleichbehandlung, Chancengleichheit, Ungleichheiten, Equal Pay, Diskriminierung, diskriminierend, Vergewaltigung, Vergewaltigt, Belästigung, Prostitution, Prostituierte, Genitalverstümmelung, Beschneidung, Zwangsheirat, Zwangshochzeit, Zwangsverheiratung, Sex* (Sexuell, Sexualstraftäter, Sextourismus), Häusliche Gewalt, Ehrenmord, Menschenhandel, Scheidung, Geschieden, Unterhalt, Witwe, Hinterbliebenenrente, Betreuung*, Lesbe, Lesbisch, Damen, Kopftuch, Verschleierung, Gynäkologe, Gynäkologie, Brustkrebs, Mammographie, Gebärmutter*, Eierstock*, Unfruchtbar, Unfruchtbarkeit, Klimakterisch, Klimakterium, Wechseljahre, Menopause, Menstruation, Östrogen, Brustimplantat, Silikonimplantat, Hebamme, Sekretärin, Krankenschwester, Soldatin, Professorin, Politikerin, Podologin, Arzthelferin, Altenpflege, Aupair, Au-pair, Pflege, Haushaltskraft

\section{English Translation (Without Examples of Truncated Searches)}

Woman, women-specific, female, gender, gender mainstreaming, women's rights, girl, pregnancy, abortion, prenatal care, birth, embryo, child, childcare, contraceptive, contraception, abortion, reproductive medicine, artificial insemination, preimplantation diagnostics, kindergarten, all-day school, full-day care, parent, parental leave, maternity leave, breast-feeding, childminder, nanny, mother, father, paternity, wife, single mother, family, marriage, equality, quota, feminism, feminist, equal rights, equal treatment, equal opportunities, inequality, equal pay, pay gap, discrimination, rape, harassment, prostitution, prostitute, genital mutilation, forced marriage, sex, sexual, domestic violence, honor killing, human trafficking, divorce, divorced, alimony, child support, widow, care, elderly care, lesbian, lady, headscarf, veil, gynecologist, gynecology, breast cancer, mammography, uterus, ovary, infertile, infertility, menopause, climacteric, menstruation, estrogen, breast implant, silicone implant, midwife, secretary, nurse, au pair, nursing 


\section{A5 Descriptive Statistics}

This appendix shows descriptive statistics for all variables used in the analysis.

Table A5: Descriptive Statistics

\begin{tabular}{|c|c|c|c|c|c|c|c|c|c|c|}
\hline \multicolumn{6}{|c|}{ Full Data Set } & \multicolumn{5}{|c|}{ Male MPs only } \\
\hline Variables & $\mathrm{N}$ & Mean & $\begin{array}{l}\text { Stand. } \\
\text { Dev. }\end{array}$ & Min & Max & $\mathrm{N}$ & Mean & $\begin{array}{l}\text { Stand. } \\
\text { Dev. }\end{array}$ & Min & Max \\
\hline Share women-specific quest. & 2619 & 0.02 & 0.07 & 0 & 1 & 1773 & 0.01 & 0.06 & 0 & 1 \\
\hline Women-specific quest. $>0$ & 2619 & 0.18 & 0.38 & 0 & 1 & 1773 & 0.14 & 0.35 & 0 & 1 \\
\hline Share of women PPG & 2619 & 32.3 & 12.4 & 18.2 & 59.7 & 1773 & 30.0 & 11.4 & 18.2 & 59.7 \\
\hline Member women's committee & 2619 & 0.05 & 0.21 & 0 & 1 & 1773 & 0.02 & 0.15 & 0 & 1 \\
\hline Leadership position & 2619 & 0.24 & 0.43 & 0 & 1 & 1773 & 0.23 & 0.42 & 0 & 1 \\
\hline Duration MP (years) & 2619 & 6.89 & 6.70 & 0 & 37 & 1773 & 7.43 & 7.44 & 0 & 37 \\
\hline Age & 2619 & 49.47 & 9.41 & 19 & 74 & 1773 & 50.11 & 9.60 & 22 & 74 \\
\hline District mandate & 2619 & 0.47 & 0.50 & 0 & 1 & 1773 & 0.53 & 0.50 & 0 & 1 \\
\hline No. of submitted questions & 2619 & 26.81 & 45.45 & 0 & 332 & 1773 & 25.25 & 43.21 & 0 & 332 \\
\hline SPD & 2619 & 0.36 & 0.48 & 0 & 1 & 1773 & 0.33 & 0.47 & 0 & 1 \\
\hline $\mathrm{CDU} / \mathrm{CSU}$ & 2619 & 0.38 & 0.49 & 0 & 1 & 1773 & 0.45 & 0.50 & 0 & 1 \\
\hline FDP & 2619 & 0.10 & 0.30 & 0 & 1 & 1773 & 0.11 & 0.32 & 0 & 1 \\
\hline Greens & 2619 & 0.09 & 0.29 & 0 & 1 & 1773 & 0.06 & 0.24 & 0 & 1 \\
\hline Left & 2619 & 0.07 & 0.25 & 0 & 1 & 1773 & 0.05 & 0.21 & 0 & 1 \\
\hline Female population (share) & 2619 & 0.51 & 0.007 & 0.49 & 0.54 & 1773 & 0.51 & 0.007 & 0.49 & 0.54 \\
\hline East Germany & 2619 & 0.21 & 0.41 & 0 & 1 & 1773 & 0.20 & 0.40 & 0 & 1 \\
\hline
\end{tabular}

Note: Data for the years 1998-2013. 


\section{A6 Test for a Curvilinear Relationship Between Share of Women and Substantive Representation of Women by Male MPs}

This appendix tests for a curvilinear relationship between the share of women and men's parliamentary behavior (spill-over effect at low-levels of women's representation, backlash-effect if the proportion of women is high). The results are statistically insignificant.

Table A6: Quadratic Regression: Substantive Representation of Women by Male MPs, 1998-2013 Log-Odds

\begin{tabular}{lll}
\hline Variables & General decision (Logit-Regression) & $\begin{array}{l}\text { Intensity of Substantive } \\
\text { Representation (Beta Regression) }\end{array}$ \\
\hline Share of women in PPG & $0.14(0.142)$ & $-0.07(0.086)$ \\
Share of women in PPG (squared) & $-0.001(0.002)$ & $0.0001(0.001)$ \\
Member women's committee & $1.04 *(0.427)$ & $0.60^{*}(0.290)$ \\
Leadership position & $-0.05(0.210)$ & $0.27(0.181)$ \\
Duration MP & $0.01(0.015)$ & $-0.001(0.009)$ \\
Age & $-0.02 *(0.010)$ & $-0.002(0.005)$ \\
District mandate & $-0.42^{*}(0.191)$ & $-0.03(0.105)$ \\
No. of submitted questions (in total) & $0.03 * * *(0.003)$ & $-0.01 * * *(0.002)$ \\
CDU/CSU & $2.22(1.162)$ & $-1.64 *(0.666)$ \\
FDP & $1.93 *(0.909)$ & $-1.24 *(0.524)$ \\
Greens & $-1.65(1.107)$ & $0.73^{*}(0.365)$ \\
Left & $-0.64(0.988)$ & $0.78^{*}(0.335)$ \\
East Germany & $0.49^{*}(0.200)$ & $0.12(0.100)$ \\
Time fixed effects & $\checkmark$ & $\checkmark$ \\
Constant & $-5.66(3.302)$ & $0.66(1.822)$ \\
\hline L & 1773 & 253 \\
Chi ${ }^{2}$ & -542.10 & $124.57^{* * *}$ \\
\hline$N$ Pseudolikelihood & $381.53^{* * *}$ & 502.78 \\
\hline
\end{tabular}

Notes: Hurdle Regression Model. DV Model 1: Dummy variable coded 1 if share of women-specific questions $>0$. DV Model 2: Share of women-specific questions. Coefficients: Log-Odds. Standard errors (in parentheses) are clustered by MP. Reference category for parties: SPD. Significance Levels: ${ }^{*} \mathrm{p}<.05 ; * * \mathrm{p}<.01 ;{ }^{* * *} \mathrm{p}<.001$. Source: Own calculations. 


\section{A7 Effect of Anticipated Share of Female MPs After the Next Election}

Appendix A5 includes the proportion of female MPs in the subsequent legislative term $(t+1)$ as its main independent variable to test whether male MPs anticipate an increase in the number of female MPs after the next election. The results are statistically insignificant.

Table A7: Substantive Representation of Women by Male MPs, 1998-2013. Independent Variable: Share of Women in PPG at $\mathrm{t}+1$ (Subsequent Legislative Term)

\begin{tabular}{lll}
\hline Variables & General decision (Logit-Regression) & $\begin{array}{l}\text { Intensity of Substantive } \\
\text { Representation (Beta Regression) }\end{array}$ \\
\hline Share of women in PPG at t+1 & $0.01(0.022)$ & $-0.01(0.008)$ \\
Member women's committee & $0.82(0.573)$ & $0.35(0.276)$ \\
Leadership position & $0.02(0.237)$ & $0.26(0.198)$ \\
Duration MP & $-0.01(0.018)$ & $-0.01(0.011)$ \\
Age & $-0.01(0.012)$ & $-0.001(0.005)$ \\
District mandate & $0.01(0.233)$ & $-0.16(0.124)$ \\
No. of submitted questions (in total) & $0.03^{* * *}(0.004)$ & $-0.01 * * *(0.002)$ \\
CDU/CSU & $1.26^{* *}(0.481)$ & $-1.17 * * *(0.251)$ \\
FDP & $1.50^{* *}(0.533)$ & $-1.04 * * *(0.218)$ \\
Greens & $0.18(0.757)$ & $-0.55(0.321)$ \\
Left & $0.33(1.108)$ & $-0.10(0.453)$ \\
East Germany & $0.42(0.229)$ & $-0.02(0.100)$ \\
Time fixed effects & $\checkmark$ & $\checkmark$ \\
Constant & $-3.12^{* *}(1.118)$ & $-0.67(0.467)$ \\
\hline $\mathrm{N}$ & 1336 & 196 \\
Log-Pseudolikelihood & -398.67 & $150.68^{* * *}$ \\
\hline Chi & $327.27^{* * *}$ & \\
\hline
\end{tabular}

Notes: Hurdle Regression Model. DV Model 1: Dummy variable coded 1 if share of women-specific questions $>0$. DV Model 2: Share of women-specific questions. Coefficients: Log-Odds. Standard errors (in parentheses) are clustered by MP. Reference category for parties: SPD. Significance Levels: ${ }^{*} \mathrm{p}<.05 ; * * \mathrm{p}<.01 ;{ }^{* * *} \mathrm{p}<.001$. Source: Own calculations. 


\section{References}

Grimmer, J. and B. Stewart (2013). Text as Data: The Promise and Pitfalls of Automatic Content Analysis Methods for Political Texts. Political Analysis 21(3): 267-297.

Lucas, C., R. Nielsen, M. Roberts, B. Stewart, A. Storer and D. Tingley (2015). Computer-Assisted Text Analysis for Comparative Politics. Political Analysis 23(2): 254-277.

Welbers, K., W. van Atteveldt and K. Benoit (2017). Text Analysis in R. Communication Methods and Measures 11(4): 245-265. 


\section{Aufsatz 3}

Male MPs, Electoral Vulnerability, and the Substantive Representation of Women's Interests.

Daniel Höhmann

Mary Nugent

Unveröffentlichtes Manuskript 


\title{
Male MPs, Electoral Vulnerability, and the Substantive Representation of Women's Interests
}

\author{
Daniel Höhmann (University of Bamberg) \\ Mary Nugent (Rutgers University)
}

\begin{abstract}
What are the political conditions affecting male MPs' willingness to represent women's interests in parliament? This paper explores the role of electoral vulnerability in this regard and analyzes whether male MPs' re-election prospects affect their likelihood of paying attention to women's concerns. Theoretically, we expect that male MPs are not blamed if they do not represent women's interests, but can gain additional credit for doing so. Thus, male MPs will become more likely to speak on behalf of women if their electoral vulnerability is high and if they need to win additional votes to be re-elected. Empirically, the paper analyzes the representation of women's issues in the British House of Commons, by using Early Day Motions tabled between 2001 and 2015. The results show that male MPs become more likely to represent women's interests when their re-election is at risk.
\end{abstract}

Key Words: Representation, gender, women's interests, male MPs, electoral vulnerability, House of Commons 


\section{Introduction}

The last few decades have witnessed many examples of male politicians actively engaging in gender equality politics. For example, Mikael Gustafsson became Chairmen of the European Parliament's Committee on Women's Rights and Gender Equality in 2011, Barack Obama was among the many male supporters of the United Nation's 2014 HeForShe ${ }^{1}$ campaign, and the Canadian Prime Minister Justin Trudeau appointed a parity cabinet including at least $50 \%$ female ministers and proposed measures for equal pay and longer parental leave in his 2018 budget proposal. However, despite these positive examples, the role of male politicians in the substantive representation of women has, so far, largely been ignored.

Based on the assumption that political interests are attached to the identity of individual people or specific groups, previous studies have usually focused on the relationship between identity and parliamentary behavior and identified female members of parliament (MPs) as the central actors in the substantive representation of women's interests because they share gender-specific experiences with women in the population (Phillips 1995; Mansbridge 1999; Childs 2002). ${ }^{2}$

Contrary to the well-known assumption that there is a direct link between descriptive and substantive representation (Pitkin 1967), this paper seeks to contribute to a broader understanding of the potential actors in the substantive representation of women and to analyze whether and under what conditions, male MPs become critical actors (Childs and Krook 2009) in the representation of women's interests and preferences.

This question is explored from a rational choice perspective, analyzing whether male MPs' electoral situation affects their decision to act on behalf of women. On a theoretical level, we draw on different literatures from the field of women and politics and feminist institutionalism. In particular, the concept of a gendered leeway (Bergqvist, Bjarnegård and Zetterberg 2018) is applied to explain why and under which conditions, male MPs can gain electoral benefits from engaging in women's substantive representation. The expectation is that in contrast to their female colleagues, male MPs are not expected to be

\footnotetext{
${ }^{1}$ The campaign encourages men and boys to support gender equality.

2 We adopt a broad conception of women's substantive representation including the representation of women's interests, issues, and preferences (Beckwith 2011).
} 
active on women's issues and will not be held accountable if they do not actively promote these issues in parliament. However, if they do act in women's interests, they can gain additional credit because it is not generally perceived as a duty that male politicians should fulfil. In other words, "[f]emale politicians are blamed if they do not pursue 'women's issues' while male politicians get credit if they do" (Bergqvist, Bjarnegård, and Zetterberg 2018: 581). By conceptualizing male MPs as rational, vote-seeking actors, we therefore hypothesize that men are more likely to speak on behalf of women if their electoral security is low and they are forced to fight for additional votes to be re-elected. In situations of high electoral uncertainty, engaging in women's substantive representation presents a promising strategy for male MPs, because catering to additional female voters might bring them the votes needed for re-election to parliament.

The empirical part of the paper analyzes the substantive representation of women by male MPs in the British House of Commons, between 2001 and 2015. Given that the British parliament and its electoral system are characterized by high levels of party influence, we rely on an analysis of Early Day Motions (EDMs) to measure the extent to which individual male MPs try to cater to female voters. EDMs are short, non-binding parliamentary motions that can be introduced by individual MPs without being strongly influenced by the party leadership. Other MPs can sign tabled EDMs to indicate their support for a motion (Kellermann 2013). Even though EDMs are rarely debated on the floor, they allow MPs to publicize their political statements and to draw attention to specific events or issues. All the EDMs that were tabled in the parliamentary sessions prior to the General Elections in 2001, 2005, 2010, and 2015 were collected and all the motions which referred to a topic affecting women disproportionally more than men, or that addressed a social condition in which women are disadvantaged in comparison to men, were identified. Based on this coding, an original data set was created containing information on the number of women-specific EDMs that were either proposed or signed by individual male MPs.

The results of a hurdle regression model corroborate the expectation that male MPs have a gendered leeway regarding women's substantive representation. We find a significant positive effect of electoral vulnerability on male MPs' general decision to represent women's interests in parliament, meaning that male MPs are more likely to either sign or propose a women-specific EDM, if their re-election is at risk. 
This analysis of male MPs' role in the substantive representation of women, makes two important contributions: Given that very little is known about the role of male MPs in the substantive representation of women, this is one of the first empirical studies to explicitly broaden the understanding of the potential actors and the multiple possibilities for representing women in parliament. Secondly, the finding that men's parliamentary behavior is affected by their electoral situations, provides an important first step in analyzing the conditions influencing individual male MPs' willingness to represent women's interest in parliament.

\section{Male MPs and the Representation of Women's Interests}

Do male MPs represent women's interests in parliament? And if so, what conditions make men more likely to act on behalf of women? Since previous research has rightly focused on the presence and behavior of female MPs, relatively little is known about the role of male MPs in women's representation. Relying on Pitkin's (1967) taxonomy of representation and Phillips' (1995) politics of presence, earlier studies were mainly interested in the link between the descriptive and substantive representation of women and whether and under which conditions, female MPs represent women's concerns in parliament due to them sharing gender-specific experiences with women in the population (Wängnerud 2009). Male MPs have not been given much attention in these analyses, having merely served as the neutral base category against which the female MPs' behavior was compared.

There are some pioneering studies concerning the descriptive representation of men and women in parliament, which explicitly focus on men's overrepresentation in parliament, thus shifting the interest away from an analysis of the factors that constrain the election of women, to the conditions which enable men to preserve their numerical dominance in parliaments around the world (Bjarnegård 2013; Murray 2014; Bjarnegård and Murray 2018). In the same vein, several scholars have also called for a reframing of women's substantive representation and argued for a broader understanding of the potential actors that might act as representatives for women's interests. Based on mixed empirical findings for the question of whether women make a difference when elected to parliament (see Wängnerud 2009), Childs and Krook (2008; 2009) recommend abandoning the exclusive focus on female MPs' behavior and suggest shifting the "analytical focus from 
the macro to the micro level, replacing attempts to discern 'what women do' to study 'what specific actors do'" (Childs and Krook 2008: 734) and to identifying potential critical actors who "act individually or collectively to bring about women-friendly policy change" (Childs and Krook 2009: 127).

Although not explicitly mentioned by Childs and Krook, this revived an idea that had already been suggested by Pitkin (1967) in her classical conceptualization of representation. Aside from Pitkin's common conception that political interests are attached to a specific person or group's identity (e.g. women's interests), she points out that representatives can also act in favor of interests that are unattached to their own personal identity (Pitkin 1967: 168-189; Staehr Harder 2019). This idea of unattached interests, as well as Childs and Krook's (2009) notion of critical actors, both deviate from the assumption that female legislators are the only actors in the substantive representation of women and underline the need to examine whether and under what institutional and political conditions, men speak on behalf of women in parliament (Celis and Erzeel 2015).

Apart from these theoretical calls for a more inclusive study of the actors in women's substantive representation, there are very few empirical studies that explicitly analyze male MPs' role in the representation of women's interests. On a descriptive level, Celis and Erzeel (2015) analyzed PartiRep survey data from 10 European countries and found that an almost equal number of male and female legislators indicated that they promoted women's interests in parliamentary party group (PPG) meetings. In a consideration of British MPs' voting behavior and debate participation, Evans (2012) showed that a small group of male MPs did represent women's concerns in their debate contributions. However, they were in the minority and spoke less if the women's interests had already been represented by a large number of female MPs. Drawing on assumptions from sociological and feminist institutionalism, a few studies were able to show that male MPs' legislative behavior is affected by the presence of an increasing number of women in parliament. Kokkonen and Wängnerud (2017) conducted a survey of locally elected politicians in 290 Swedish municipalities and found that the presence of women has a significant negative effect on male MPs' willingness to act for women in the council. Similar results have been found by Höhmann (2020), who shows that while male MPs in the German Bundestag are generally willing to act on behalf of women, they will leave 
this field to female MPs and reduce the intensity of their representation of women's issues if the proportion of women in their respective PPG increases. As well as being influenced by the presence of female MPs, Olofsdotter Stensota (2020) shows that male MPs' personal backgrounds and socializations also affect their legislative priorities and their inclination to represent women-specific issues. In a study of Swedish MPs, she found that men became more likely to express an interest in social policy if they had been on parental leave during their time in office.

However, apart from these initial analyses, very little is known about male MPs' role in the substantive representation of women, or about the incentives influencing individual male MPs' willingness to represent women's interests in parliament. Previous studies predominantly used assumptions from sociological and feminist institutionalism to explain male MPs' behavior in terms of gendered perceptions about appropriate roles, which could change as a result of personal experiences or the increased presence of women in parliament. To date, however, no study has analyzed male MPs' willingness to represent women's issues from a rational-choice perspective.

This is surprising, given that research on women's suffrage and on the adoption of quota laws, has already shown that male elites tend to behave as strategic and rational actors regarding the extension of women's rights (Valdini 2019). In the context of quota laws, a growing body of studies suggests that electoral incentives are among the key factors explaining why male party elites support the introduction of quotas for female candidates. Parties have a higher likelihood of adopting quota laws in times of high electoral uncertainty, as an attempt to distinguish themselves from other parties and to increase their support among female voters (Murray, Krook and Oppelo 2012; Catalano Weeks 2018). This effect is even more pronounced if parties are faced with an electoral threat from rising left-wing parties (Catalano Weeks 2018). Similar results have been found for the enfranchisement of women. Teele (2018), for instance, found that male elites in US states were more likely to grant women the right to vote if the parties were operating in electorally competitive environments and if the party leaders believed that the new female voters would support their party (McConnaughy 2013).

The present paper considers the behavior of individual legislators and explicitly studies whether male MPs can be described as re-election oriented, rational actors, who only act 
on behalf of women if they are electorally vulnerable and obliged to win additional votes from women in their constituency.

\section{When Should Men Represent Women's Interests? - A Gendered Leeway for Male MPs}

To analyze the role of men in the substantive representation of women, MPs are perceived as rational actors who are mainly incentivized by vote-seeking, in order to continue and advance their political careers (Müller and Strøm 1999). It is therefore expected that MPs adapt their parliamentary activity to their electoral prospects, and that they engage in women's substantive representation to increase their chances of being reelected. In order to hypothesize about the conditions under which it is electorally beneficial for male MPs to represent women's issues, we build on a synthesis of previous contributions from the literature on feminist institutionalism and women's substantive representation, and to a great extent draw on the concept of a gendered leeway which was recently introduced by Bergqvist, Bjarnegård and Zetterberg (2018).

In a nutshell, this leeway gives men an opportunity which female MPs are usually denied: Whereas female MPs are typically expected to act on behalf of women, men are free to choose whether or not they want to represent women's issues in parliament. Bergqvist, Bjarnegård and Zetterberg (2018) built their argument on the distinction between external and internal mandates for substantive representation of women. External mandates are the ascribed expectations, that MPs are responsible for the representation of specific groups or issues. An internal mandate is the extent to which individual legislators internalize these types of expectation and feel a sense of responsibility to act on an issue. The results of previous research on women's substantive representation, show that women are subject to both types of mandates in a way that men are not. Concerning the external mandate, feminist institutionalists (Krook and Mackay 2011) have shown that the informal rules and expectations contained in the parliamentary process create a gendered logic of appropriateness that encourages and/or constrains certain types of behaviors by male and female MPs (Chappell and Waylen 2013). Since female MPs share gender-specific experiences with women in the population, it is expected that they will address women-specific issues more strongly than their male colleagues and that they will push for a gender-equality agenda in parliament. Thus, due to their linked fate with other women and their possible personal experiences of 
gender inequalities and discrimination, it is expected that female MPs will have a specific mandate to represent women's interests through their legislative activities (Bergqvist, Bjarnegård and Zetterberg 2018). This external mandate to act on behalf of women, is also internalized by female MPs. Several empirical studies have shown that female legislators see themselves as the female electorate's representatives and that they believe that women can better represent women's interests in parliament (e.g. Childs 2002; Coffé and Reiser 2018).

In contrast, since male MPs are not directly (at least not negatively) affected by genderinequalities, they perceive neither an internal nor a strong external, mandate to substantively represent women. Given that men represent the political norm in almost every parliament in the world, it is not necessary for them to actively engage in the representation of women's issues. In accordance with the assumptions of a gendered logic of appropriateness, the representation of women's interests is not generally perceived to be an obligation which male MPs must fulfil (Bergqvist, Bjarnegård and Zetterberg 2018). In the absence of any internal or external mandates, male MPs enjoy the gendered leeway which gives them "the privilege of a larger maneuvering room that enables them to speak within the gender-equality discourse without being delegitimized when they prioritize other issues" (Bergqvist, Bjarnegård and Zetterberg 2018: 581).

The crucial point for this paper's theoretical argument is that the gendered leeway leads to a perceived double standard in terms the perception of duty and praise: "Female politicians are blamed if they do not pursue 'women's issues' while male politicians get credit if they do." (Bergqvist, Bjarnegård and Zetterberg 2018: 581). In other words, male MPs receive special praise for engaging on women's issues because it is not a duty automatically expected of male politicians. However, female MPs who substantively represent women, are fulfilling a generally accepted expectation and as a result, do not receive particular praise. On the contrary, a female MP's lack of activity on women's issues might even be criticized and the MP blamed by the media, feminist activists or women's organizations. Consequently, men are able to get credit for even fairly minimal levels of engagement on women's issues which are considered normal for women MPs (Nugent 2019).

Given that men are not criticized by the voters for not representing women's interests, it follows that there is no need for male MPs who are electorally secure to become active in 
the substantive representation of women. They can leave this area to their female collogues and focus on other issues instead. However, since they can gain additional credit if they support women's issues, it is expected that male MPs will be more likely to speak on behalf of women if their electoral security is low and they are therefore forced to fight for additional votes in order to be re-elected. If their re-election to parliament is hanging in the balance and they are faced with a competitive race in the district, male MPs discover women as an additional source of votes which might ensure their reelection. Male MPs engage in women's representation in the sense of an anticipatory representation (Mansbridge 2003), to cater to future voters for the next election. They make use of their gendered leeway by representing women's issues; they are doing something unexpected which might secure them the additional women's votes needed to return them to parliament.

Regarding the British case, acting in women's interests might be particularly promising given that women's issues have usually featured prominently in the election campaigns and all major parties have made attempts to target women voters (Campbell and Childs 2010; Campbell and Childs 2015). For example, the 2010 election is often referred to as the Mumsnet election because the parties and media consistently stressed the importance of the women vote. ${ }^{3}$ This is exemplified by Douglas Alexander, Labour's campaign coordinator, who stated that "Labour needs to win back middle-income female voters with children in marginal seats" (see Campbell and Childs 2010: 761). Thus, we posit the following hypothesis:

Hypothesis: The higher their electoral vulnerability, the more strongly will male MPs represent women's interests in parliament.

If male MPs are indeed incentivized by vote-seeking and if they represent women's issues opportunistically to enhance their electoral prospects, it is further expected that men will mainly engage in low-cost activities that are not very time- and labor-intensive. This enables them to present themselves as acting in the interests of women, while still being able to spend most of their time on issues that are higher on their personal

\footnotetext{
${ }^{3}$ Mumsnet is a popular webpage and discussion forum for parents in the UK. The media widely reported about appearances of Gordon Brown, David Cameron and Nick Clegg trying to appeal to female voters during web chats on the Mumsnet webpage.
} 
agendas. It is therefore assumed that male MPs are more likely to sign women-specific EDMs, than to write and introduce their own motions related to a women's issue. Accordingly, electoral vulnerability should primarily affect male MPs' signing behavior, making them more likely to support women-specific EDMs proposed by their colleagues. The effect on the introduction of their own motions, should be less pronounced. Moreover, we assume that only male MPs enjoy a gendered leeway. Electoral vulnerability should only affect mens' behavior and have no effect on female MPs' parliamentary activities because female MPs are generally expected to engage in gender equality policies.

\section{Methods and Data}

The empirical analysis for this article examines the representation of women's interests in the British House of Commons between 2001 and 2015. As a Westminster parliamentary system, the House of Commons is usually characterized by high levels of party cohesion and pronounced party leadership control over candidate selection. Carey and Shugart (1995) argue that of the single member district systems, the British electoral system offers the least incentive to cultivate a personal vote because voters vote primarily for a party and not for an individual candidate (Carey and Shugart 1995). Analyzing the effect of electoral vulnerability on the behavior of individual MPs in the UK therefore presents a least-likely case, since individual legislators generally have very little influence on electoral outcomes. If male MPs adapt their behavior to different levels of electoral vulnerability despite this, it would provide strong evidence for the hypothesis that men only cater to female voters if they want to improve their electoral prospects.

\subsection{Using Early Day Motions to measure women's substantive representation}

High levels of party discipline create a problem concerning the measurement of the individual MPs' parliamentary behavior. Namely, that common indicators of representational activities such as voting, the introduction of bill proposals, or debate participation tend to reflect the party's position rather than the individual MPs' preferences and behavior. Therefore, in order to reduce the impact of party cohesion, the introduction and signing of Early Day Motions (EDMs) is used to measure how strongly male MPs represented women's interests in parliament. EDMs are formal notices of 
motions submitted by individual MPs for debate in the House of Commons for which no date has been fixed (House of Commons Information Office 2010). They can be tabled by any MP on any topic and must consist of a single sentence of no more than 250 words. Although, in practice, these motions are rarely debated, other MPs can express their support by signing individual EDMs. EDMs, together with their sponsor and the names of the signing MPs, appear in the printed vote bundle of bills before parliament every day and are reprinted whenever an MP's signature is added (Kellermann 2013). The number of EDMs has increased significantly in recent decades, with there regularly being more than 1,000 motions and over 20,000 signatures per session (Nugent 2019). ${ }^{4}$ The usefulness of EDMs as a measure of parliamentary behavior has been questioned. Since they have no formal policy implications and are not actually debated or voted upon on the floor of the House, some MPs refuse to introduce or sign EDMs due to their ineffectiveness and in protest at the administrative costs (Nugent 2019). McLean (1995: 126) argues that EDMs constitute a form of cheap talk, rather than an indicator of behavior or underlying preferences.

However, there are also several arguments supporting that the importance of EDMs should not be underestimated and that they have several characteristics that make them suitable indicators for our study.

First, there are many examples showing that the submission of EDMs is much more than simple cheap talk and these short motions can initiate debates in parliament that can ultimately lead to substantial policy changes. One famous example is MP Christine McCafferty who tabled three widely supported Early Day Motions in 1997 asking the government to classify women's sanitary products as essential to the family budget and to reduce the associated Value Added Tax (VAT) to zero. In response to these motions, three years later, the Labour Government reduced the VAT for sanitary products from 15\% to $5 \%$ in their 2000 budget (see Childs and Withey 2006).

Relatedly, Childs (2002) and Childs and Withey (2004) have shown that EDMs are a viable way for MPs to substantially represent the interests of women. By interviewing several female Labour MPs, Childs (2002) found that EDMs were frequently mentioned as an important tool for raising and promoting issues important to women.

\footnotetext{
${ }^{4}$ All tabled EDMs are available at the official EDM database of the House of Commons (https://edm.parliament.uk/).
} 
Second, EDMs are indicators of individual MPs' actual behavior and their efforts to enhance their own electoral prospects. Although they may be used for a variety of different reasons (e.g. to send signals to the party leadership or interest groups), they represent one of MPs few opportunities to generate publicity in their constituencies, to raise issues that are important to them, and to differentiate themselves from the official party agenda. In this way, EDMs serve as a signaling device which individual MPs can use to demonstrate their responsiveness to their constituencies and to cultivate personal reputations in their local districts (Nugent 2019). EDMs go on official record, allowing MPs to say that they have 'tabled a motion in Parliament', thus demonstrating that they care about their local constituencies' needs. It is also quite common for MPs to publicize sponsored or signed EDMs on their personal webpages and social media channels. ${ }^{5}$ Moreover, the parties and whips' influence on the introduction and signing of EDMs is less than for many other parliamentary activities (e.g. voting). Therefore, previous studies have used EDMs to measure MPs' individual preferences and attitudes (Finer, Berrington and Bartholomew 1961; Franklin and Tappin 1977), to calculate MPs' position on an ideological left-right dimension (Kellermann 2012), or to measure cohesion within political parties (Bailey and Nason 2008).

Third, and crucially for the theoretical argument of this paper, previous research has demonstrated that voters are aware of their respective MP's EDM activities and that these activities are also rewarded electorally. Kellermann (2013) found that EDMs attract a considerable amount of media attention from national and local newspapers and that the number of EDMs tabled has a positive effect on the media coverage received by individual MPs. In addition, his study demonstrated that MPs from competitive constituencies introduced more EMDs than those from less competitive districts, and that higher rates of EDM introduction are associated with larger winning margins in subsequent elections. EDMs' effectiveness as a political tool for building an electoral connection with local voters has been corroborated in a recent study by David Parker (2019). Using data from the 2015 British Election study, he found that the number of constituency-related EDMs positively affected the likelihood that the respondent would

$5 \quad$ E.g. http://tommysheppardmp.scot/index.php/blog/tommys-blog/entry/prevention-ofincitement-to-sexual-crime-and-violence). 
perceive the MP to be a constituency servant who cares about local concerns and who brings the district's issues to parliament.

Given their limited policy implications, EDMs are, of course, only one of many components in a larger electoral campaign (Parker 2019). Nevertheless, they provide a useful tool for MPs to gain potential voters' attention and are a way of influencing their individual election outcomes. In this article, we therefore use the introduction and signing of EDMs as a proxy for the male MPs' overall electoral strategy and the extent to which they are used to address women's issues and to cater to additional female voters in the constituency, will be analyzed.

We collected all EDMs proposed during the last parliamentary sessions immediately before the 2001, 2005, 2010, and 2015 general elections. ${ }^{6}$ Given that women in Britain are consistently overrepresented in the group of undecided voters who make their voting choice relatively close to the election (Campbell and Childs 2015: 219), marginal male MPs' attempts to cater to female voters should become particularly pronounced in the immediate run up to an election (Baumann, Debus and Gross 2019). Each EDM was then hand-coded by the authors to identify whether or not it dealt with a woman specific topic. ${ }^{7}$ To be as inclusive as possible and to acknowledge that women are a diverse group with heterogeneous life experiences and preferences, all EDMs were coded as womenspecific if they explicitly had women, or some subset of women, "as their primary subject matter" (Reingold 2000: 166-167). This includes all issues "where policy consequences are likely to have a more immediate and direct impact on significantly larger numbers of women than of men" (Carroll 1994: 15). Accordingly, EDMs were categorized as womenspecific, if they referred to a topic that for either biological or social reasons, affects women disproportionally more than men, or if it addresses a social situation in which women are disadvantaged compared to men (Celis 2008). Topics that have traditionally been described as soft or female, such as youth policies, education, or health, were only coded as women-specific if they explicitly referred to discrimination against women (c.f. Höhmann 2019).

\footnotetext{
${ }^{6}$ In the UK, legislative periods are usually divided into five parliamentary years. These "sessions" generally run from spring to spring.

7 To ensure the validity of the coding, EDMs were coded independently by both authors. Divergent classifications were discussed between the authors to reach a final coding decision.
} 
Accordingly, the women-specific EDMs addressed a wide range of different topics, including domestic and sexual violence against women, discrimination at work (e.g. gender pay gaps), legal protection for working mothers, medical care for women with breast or ovarian cancer, and legal provisions concerning abortions and prenatal examinations.

Below is an example of an EDM that was submitted by a male MP and that we classified as women-specific:

EDM 756, 2014-15, Means Testing For Female Victims Of Domestic Violence: That this House believes all women suffering domestic violence should have the right to safe accommodation when at risk of harm; notes that employed women are means tested at the point they attempt to access accommodation resulting in some women having to self-fund their time in refuges; further notes that domestic violence often includes financial abuse that prevents some women from having access to money; believes women's immediate safety should be prioritised above their ability to access private funds at a time of personal crisis and serious risk of physical harm; further believes that the Government's call to end violence against women and girls: strategic vision should recognise the risks posed by means testing employed women; and calls for the means testing for eligibility of public funding to include an assessment of the economic impact of abusive and controlling relationships. (Andrew McDonald, Labour)

Based on this classification, the final dataset includes information on the number of women-specific EDMs introduced by each individual MP, as well as the number of women-specific EDMs that an MP has signed. Three different dependent variables were then created for the statistical analysis. For the first dependent variable, the number of women-specific EDMs that each individual either proposed or signed was counted and this amount was then divided by the total number of EDMs proposed or signed by the MP during a single legislative session. To give a more nuanced picture, the second dependent variable only looks at male MPs' signing behavior and is expressed as the ratio of the number of women's EDMs signed to the total number of EDMs that the MP signed. The third dependent variable is constructed in the same way for the number of women's EDMs that the MP proposed.

\subsection{Independent and control variables}

For the main explanatory variable of the analysis, a measure of the individual legislators' electoral vulnerability was needed to indicate whether or not an MP faces a competitive race in the next election. Following previous research, we use the vote margin of victory 
in the prior election to operationalize electoral vulnerability. Such margins measure the distance between the first two candidates in a district and are calculated as the percentage of the winning candidate's votes minus the closest competitor's percentage of the votes (Blais and Lago 2009). The smaller the distance between the winner and the second-best candidate, the more uncertain the outcome of the next election and the higher the incentives for the incumbent MP to fight for additional votes to guarantee reelection. Using the winner's margin of victory is by now the conventional measure of district competitiveness in SMD elections and has been frequently used in studies on the effect of electoral safety on MPs' behavior in the UK (see Blais and Lago 2009). To calculate a measure of electoral vulnerability, the winning vote margin was simply subtracted from 100, so that high values express high electoral vulnerability. The information on election results and vote margins, is taken from Geese et al. (forthcoming).

Several control variables are included in the analysis. The first group of control variables includes structural characteristics of the electoral districts that might affect the MPs' electoral prospects, as well as their representational behavior. In general, it is assumed that districts with more progressive populations offer higher incentives for male MPs to play the women card, in order to win additional votes. At the same time, competitive districts might not be randomly distributed among MPs. Parties may strategically assign more gender-friendly male MPs to marginal districts that are more liberal and progressive. Two different proxies were used to measure the districts' progressiveness. First, we include the population density (number of inhabitants per hectare) to distinguish between rural and urban districts. Education is used as a second proxy, by adding the proportion of the population with higher education (Level 4 or above, according to the Regulated Qualifications Framework). Information on district characteristics was taken from the 2001 and 2011 Census data. Moreover, presenting themselves as being responsive to female voters, might be more important to incumbent male MPs who are running against a female challenger in their electoral district (Murray 2008). ${ }^{8}$ Therefore, we include a control variable indicating whether the major electoral

8 In the Online Appendix, we also test for potential interaction effects between district characteristics and electoral vulnerability (Online Appendix A4). The results, however, are statistically insignificant. 
contender in the district (i.e. candidate with the second-most votes) was a woman. The data on electoral candidates stem from Pippa Norris' British Parliamentary Constituency Database and the British General Election Constituency Results dataset. ${ }^{9}$

The second group of control variables includes the MPs' personal characteristics. A dummy variable was included for government ministers and for the speaker and the deputy speakers of the House, because, according to parliamentary conventions, they are not expected to table or sign EDMs (Childs and Withey 2004). At the same time, these highly visible legislators could have better re-election chances than backbench MPs. For similar reasons, an additional dummy variable was used to indicate frontbench MPs with a leadership role in their parliamentary party group (parliamentary party leader, whip, spokespersons). The MPs' age (in years) in years was added because older legislators tend to have more conservative attitudes towards gender equality (Kokkonen and Wängnerud 2017). Moreover, we control for potential career effects since the MPs' parliamentary behavior could change over time (Bailer and Ohmura 2018). Thus, a dummy variable was added for newcomer MPs, who are serving their first term in the House of Commons, as well as a dummy variable for MPs in their last term, who are not running again in the next election. Additionally, we control for a membership in the Children, Schools and Families Committee since these MPs should be more likely to represent women's issues, irrespective of their electoral vulnerability.

Besides these personal characteristics of MPs, potential party-related biases were also controlled for. First, all models include the MPs' party affiliation, to account for ideological differences in the MPs' affinity to gender equality, as well as for general differences in the different parties' electoral prospects and that of their candidates. Second, prior research has shown that the increased presence of women in parliament might negatively affect male MPs' likelihood of representing women's interests (Kokkonen and Wängnerud 2017; Höhmann 2020). The analysis therefore controls for the share of female MPs in the respective male MP's party. Data for the above-mentioned variables stem from the PATHWAYS project (Morales, Saalfeld and Sobolewska forthcoming). ${ }^{10}$

\footnotetext{
${ }^{9}$ Available at https://www.pippanorris.com/data (last retrieved on February 9, 2020).

${ }^{10}$ See www.pathways.eu for more information.
} 
Although, in the UK, the electoral vulnerability of individual MPs is mainly determined by the previous vote margin in the respective district, MPs might also consider the current political situation on the national level when they assess their personal electoral prospects. In order to take these general political trends at the national level into account, we include the national poll results regarding the voting intention for the main parties six month prior to the election in the model. ${ }^{11}$ Lastly, the postulated effect of electoral vulnerability on male MPs' parliamentary behavior could be biased by potential time trends. If feminist values and positive attitudes towards gender equality become more prevalent in the population over time, this could make male MPs more attentive to gender-specific interests. Failing to control for these temporal trends, would risk overestimating the effect of electoral competitiveness. Therefore, we include a linear time trend via the year of the parliamentary session. Appendix A1 contains descriptive statistics for all the variables used in the analysis. Appendix A2 shows the distribution of electoral vulnerability for male MPs in the British House of Commons.

\subsection{Statistical model: Hurdle regression model}

The unit of analysis for the empirical analysis is an individual MP in a single parliamentary session. The overwhelming majority of the MPs did not table any womenspecific EDMs and received a score of 0 on the dependent variable. To model this extremely right-skewed distribution that is bounded on the $[0 ; 1]$ interval, we estimate a hurdle regression model, consisting of two different equations which are estimated as separate processes (Kellermann 2013).

In the first step, the hurdle-component models a male MPs' general decision whether or not to become active in the substantive representation of women. If this hurdle is overcome, the explanatory variable's effect on the strength or intensity of the dependent variable, is estimated in the second step. More specifically, the dependent variable in the first equation is expressed as a dummy variable which receives a value of 1 if an MP tables at least one women-specific EDM. A logistic regression model is then fitted to determine the effect of electoral vulnerability on a male MPs' general decision whether or not to represent women's issues in parliament. In the second step, a beta regression model estimates the independent variable's influence on the dependent variable's

${ }^{11}$ We use polling data from ICM Research. 
strength or intensity. This equation uses only those observations which have submitted at least one women-specific EDM and estimates the effect of electoral vulnerability on the proportion of women-specific EDMs submitted by an individual male MP during the parliamentary session. The beta regression model assumes that the data are distributed according to a beta distribution which is bounded between 0 and 1 (0) and 1 not included). It is very flexible and therefore, very well suited to describing unimodal as well as bimodal, distributions (Smithson and Verkuilen 2006; Cook, Kieschnick and McCullough 2008). ${ }^{12}$

In addition to the skewed distribution, the statistical model must also take the fact that the dataset contains multiple observations for the same MP (in different parliamentary sessions), which are not independent from each other, into account. Therefore, all the models are calculated with robust standard errors that are clustered at the level of individual MPs.

\section{Results}

During the parliamentary sessions prior to the 2001, 2005, 2010, and 2015 general elections, we identified 103 EDMs with a women-specific concern which, in total, received 5,055 signatures from the MPs in the House of Commons. While female MPs proposed slightly more women's EDMs (52), men were more likely to sign women EDMs than their female counterparts (3,982 signatures came from male MPs). ${ }^{13}$ The following relates to the multivariate analysis to test the hypothesis about how male MPs' electoral vulnerability affects their likelihood of proposing and signing women's EDMs. Four different model-specifications were calculated. As explained above, the main model uses the combined number of women's EDMs proposed and signed, as its dependent variable. The second and third models re-estimate the same model specification for signing and proposing women EDMs separately (results are reported in Appendix A3).

\footnotetext{
${ }^{12}$ Standard errors of the beta regression are conditional on the results from the logit regression. This accounts for the fact that although the two models are estimated using two separate equations, they are dependent on each other.

${ }^{13}$ Of course, these descriptive statistics do not take into account that the number of male MPs is much higher compared to female MPs.
} 
Table 1. The effect of electoral vulnerability on the substantive representation of women by male MPs. Proposing or signing women's EDMs, 2001-2015.

\begin{tabular}{|c|c|c|}
\hline Variables & $\begin{array}{l}\text { General decision (Logit } \\
\text { Reg.) }\end{array}$ & $\begin{array}{l}\text { Intensity of substantive } \\
\text { representation (Beta } \\
\text { Reg.) }\end{array}$ \\
\hline Electoral vulnerability & $\begin{array}{l}0.013 * * * \\
(0.004)\end{array}$ & $\begin{array}{l}-0.001 \\
(0.002)\end{array}$ \\
\hline Population density (in district) & $\begin{array}{l}0.003 \\
(0.003)\end{array}$ & $\begin{array}{l}-0.002 \\
(0.001)\end{array}$ \\
\hline Higher Education (share in district) & $\begin{array}{l}-0.001 \\
(0.009)\end{array}$ & $\begin{array}{l}0.013 * * * * \\
(0.003)\end{array}$ \\
\hline Female challenger & $\begin{array}{l}-0.011 \\
(0.120)\end{array}$ & $\begin{array}{l}0.003 \\
(0.047)\end{array}$ \\
\hline Government Minister & $\begin{array}{l}-2.058 * * * * \\
(0.384)\end{array}$ & $\begin{array}{l}0.223 \\
(0.140)\end{array}$ \\
\hline Frontbench MP & $\begin{array}{l}-0.729 * \cdots * \% \\
(0.136)\end{array}$ & $\begin{array}{l}0.025 \\
(0.058)\end{array}$ \\
\hline Age & $\begin{array}{l}0.039 * * * * \\
(0.008)\end{array}$ & $\begin{array}{l}0.001 \\
(0.003)\end{array}$ \\
\hline Newcomer MP & $\begin{array}{l}0.096 \\
(0.147)\end{array}$ & $\begin{array}{l}0.056 \\
(0.048)\end{array}$ \\
\hline Last term & $\begin{array}{l}-0.371 * \\
(0.151)\end{array}$ & $\begin{array}{l}-0.063 \\
(0.052)\end{array}$ \\
\hline $\begin{array}{l}\text { Children, Schools and Families } \\
\text { Committee }\end{array}$ & $\begin{array}{l}1.553 * \\
(0.622)\end{array}$ & $\begin{array}{l}-0.251 \\
(0.172)\end{array}$ \\
\hline Conservative Party & $\begin{array}{l}-1.547 * * * * \\
(0.438)\end{array}$ & $\begin{array}{l}0.082 \\
(0.099)\end{array}$ \\
\hline Labour Party & $\begin{array}{l}-0.138 \\
(0.627)\end{array}$ & $\begin{array}{l}0.039 \\
(0.176)\end{array}$ \\
\hline Liberal Democrats & $\begin{array}{l}0.208 \\
(0.420)\end{array}$ & $\begin{array}{l}-0.179 * \\
(0.080)\end{array}$ \\
\hline Share of women in PPG & $\begin{array}{l}-0.189 \\
(2.607)\end{array}$ & $\begin{array}{l}-0.985 \\
(1.111)\end{array}$ \\
\hline Polling results (national) & $\begin{array}{l}-4.074 * * * * \\
(1.129)\end{array}$ & $\begin{array}{l}0.805 \\
(0.416)\end{array}$ \\
\hline Time trend & $\checkmark$ & $\checkmark$ \\
\hline Constant & $\begin{array}{l}107.305 * * \\
(34.325)\end{array}$ & $\begin{array}{l}-60.460 * * ; \\
(18.157)\end{array}$ \\
\hline $\mathrm{N}$ & 2046 & 805 \\
\hline Log-Pseudolikelihood & -1139.47 & 1958.79 \\
\hline $\mathrm{Chi}^{2}$ & $245.08 * * * *$ & $69.77 * * * *$ \\
\hline
\end{tabular}

Notes: Hurdle Regression Model. DV Logit Reg.: Dummy variable coded 1 if share of proposed or signed women's EDMs > 0. DV Beta Reg.: Share of signed or proposed women's EDMs. Coefficients: Log-Odds. Standard errors (in parentheses) are clustered by MP. Reference category for parties: Other. Significance Levels: * $\mathrm{p}<.05 ; * * \mathrm{p}<.01 ; * * * \mathrm{p}<.001$ 
Since this paper is only interested in men's behavior and their decision to represent women in parliament, all three models only include data on male MPs' behavior. To demonstrate that only male MPs enjoy gendered leeway, the fourth model estimates the effect of electoral vulnerability on female MPs' behavior. The results of the main analysis are reported in Table 1. Results for female MPs are shown in Table 2.

Estimates of the logit regression (effect on the decision whether or not to act on behalf of women) are shown on the left side of the table, and the results from the beta regression (effect on the intensity of substantive representation) are presented on the right. All coefficients are presented as log odds, with robust standard errors clustered at the individual MP level. The beta regression standard errors are conditional on the results of the logit regression to account for the fact that although the two models are estimated in two separate steps, they are dependent on each other. The central explanatory variable is male MPs' electoral vulnerability (higher values indicate higher competition in the district). ${ }^{14}$

The results for the logit regression show that electoral vulnerability has a significant positive effect on male MPs' general decisions to represent women's interests. These results corroborate the theoretical expectations of a gendered leeway, meaning that male MPs are more likely to become active in women's substantive representation if their reelection is at risk.

Since a substantial interpretation of the log-odds is not very intuitive, we estimated marginal effects and predicted probabilities to assess the actual effect size of electoral vulnerability on men's parliamentary behavior. ${ }^{15}$

The predictions in Figure 1 show that the predicted probability of male MPs tabling or signing at least one women-specific EDM is $28.3 \%$ at the lowest level of electoral insecurity observed in the dataset. However, if the electoral vulnerability increases, the probability that male MPs will represent women's issues increases steadily. For competitive districts with vote margins of less than 20 percentage points (i.e. where electoral vulnerability is high), the predicted probability that male MPs will try to cater to

\footnotetext{
${ }^{14}$ Since our model is factor-centric, we are focusing on the effect of our main independent variable and do not discuss the coefficients of the control variables (Keele, Stevenson and Elwert 2020).

${ }^{15}$ All other variables enter the estimation with their empirically observed values.
} 
Figure 1. The effect of electoral vulnerability on the substantive representation of women by male MPs. Predicted probability of proposing or signing women's EDMs (with 95\% CIs).

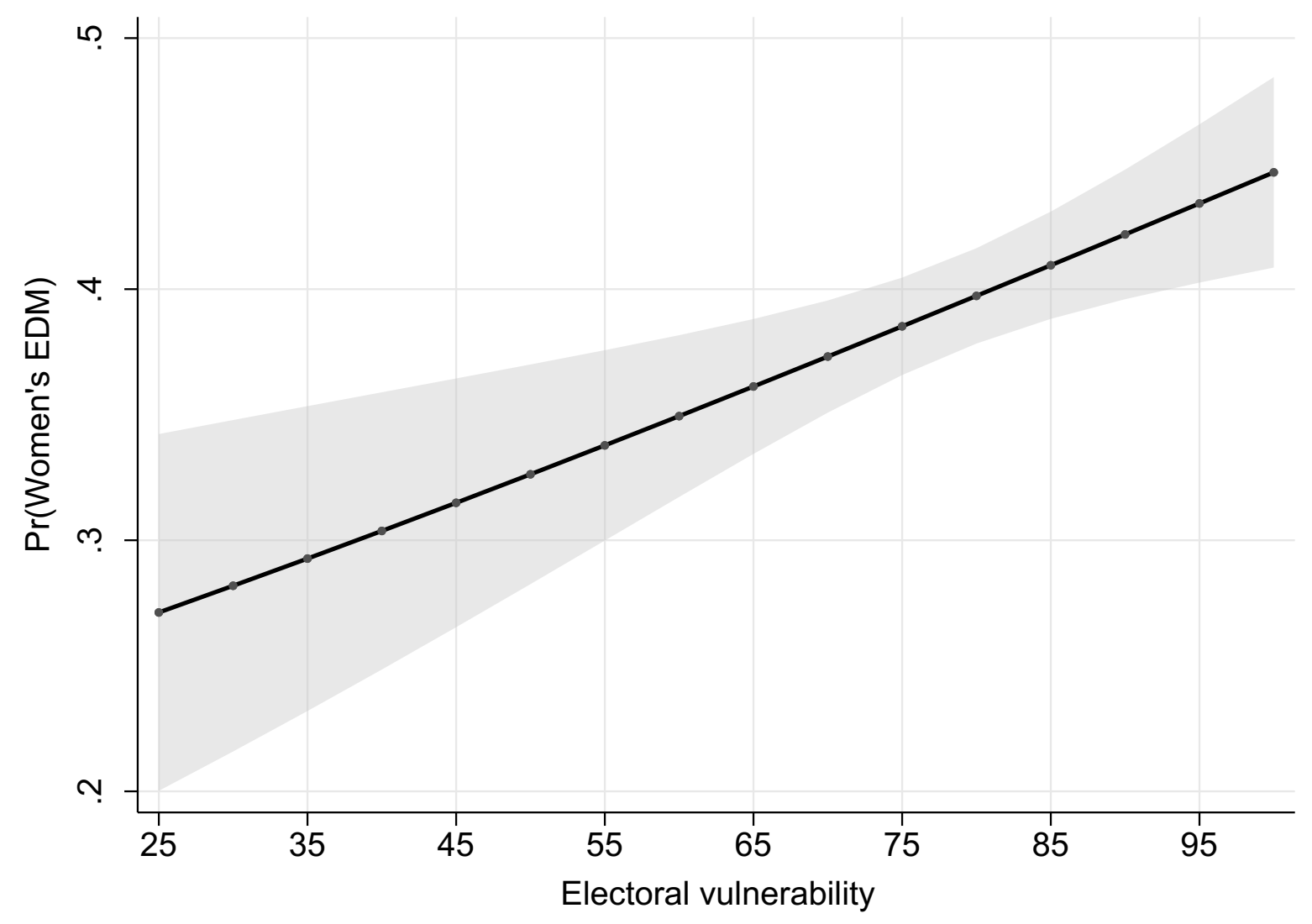

Note: Logit Regression. All other variables enter the model with their empirically observed values.

female voters rises to above $40 \%$ and continues to increase to roughly $44 \%$ for the maximum value of electoral vulnerability. The marginal effects (not shown) indicate that the positive effect is significantly different from zero for all levels of electoral vulnerability.

The results of the beta regression will now be considered. This model only includes those male MPs who have tabled or signed at least one women-specific EDM, that is, those who have made a general decision to represent women's issues in the parliamentary arena. The calculation then estimates the effect of electoral vulnerability on the intensity with which male legislators promote the substantial representation of women. In contrast to the model's first step, the results in Table 1 indicate that the electoral situation's effect on the proportion of women-specific EDMs is insignificant and therefore indistinguishable from zero. Thus, the parliamentary behavior of those 
male MPs who already represent women's interests, is not affected by their electoral situation and they do not intensify their efforts to act in women's interests if their reelection is in jeopardy.

To sum up, the results of the hurdle regression support the hypothesis of a gendered leeway. If male MPs' re-election is almost certain, they are less likely to act in women's interests since nobody expects it from them and they need not fear any negative consequences. However, if their re-election is uncertain, male MPs discover women as an additional group of voters to which they could cater in order to enhance their prospects on Election Day.

In order to further assess whether male MPs are primarily extrinsically motivated and only represent women's interests to win additional votes, we separately analyzed the number of signed and proposed EDMs. According to the theoretical assumptions, it was expected that men would mainly engage in low-cost representational activities; i.e. those that are not very time- and labor-intensive. The results (see Appendix A3) confirm this expectation and indicate that the electoral vulnerability effect is mainly driven by male MPs signing women's EDMs. We find no significant electoral vulnerability effect on either the general decision to propose a women's EDM or on the proportion of women's EDMs tabled. This corroborates our interpretation that male MPs mainly engage in women's representation in order to enhance their electoral prospects. If men decide to represent women in parliament, they engage primarily in low-cost activities, such as signing a women's EDM. This gives them the opportunity to present themselves as active advocates of their female voters' interests, however, they are not willing to make a more credible commitment and to invest a significant amount of time and effort in proposing their own women's EDMs.

Moreover, the main model was re-estimated for female MPs, in order to corroborate the evidence for a gendered leeway. The results in Table 2 are insignificant, showing that, in contrast to their male colleagues, electoral vulnerability has no effect on female MPs' decisions to actively represent women's issues in parliament. This supports the hypothesis that men are free to choose whether or not they want to represent women's interests and that they use this leeway strategically, to enhance their electoral prospects. 
Table 2. The effect of electoral vulnerability on the substantive representation of women by female MPs. Proposing or signing women's EDMs, 2001-2015.

\begin{tabular}{|c|c|c|}
\hline Variables & $\begin{array}{l}\text { General decision (Logit } \\
\text { Reg.) }\end{array}$ & $\begin{array}{l}\text { Intensity of substantive } \\
\text { representation (Beta } \\
\text { Reg.) }\end{array}$ \\
\hline Electoral vulnerability & $\begin{array}{l}0.017 \\
(0.009)\end{array}$ & $\begin{array}{l}0.003 \\
(0.004)\end{array}$ \\
\hline Population density (in district) & $\begin{array}{l}0.001 \\
(0.006)\end{array}$ & $\begin{array}{l}0.001 \\
(0.002)\end{array}$ \\
\hline Higher Education (share in district) & $\begin{array}{l}0.016 \\
(0.018)\end{array}$ & $\begin{array}{l}-0.004 \\
(0.006)\end{array}$ \\
\hline Female challenger & $\begin{array}{l}-0.404 \\
(0.266)\end{array}$ & $\begin{array}{l}0.204 \\
(0.116)\end{array}$ \\
\hline Government Minister & $\begin{array}{l}-1.424 \\
(0.795)\end{array}$ & $\begin{array}{l}0.241 \\
(0.323)\end{array}$ \\
\hline Frontbench MP & $\begin{array}{l}-1.384 * \cdots * * \\
(0.270)\end{array}$ & $\begin{array}{l}0.228 \\
(0.159)\end{array}$ \\
\hline Age & $\begin{array}{l}0.042 * * * \\
(0.016)\end{array}$ & $\begin{array}{l}-0.006 \\
(0.006)\end{array}$ \\
\hline Last term & $\begin{array}{l}0.279 \\
(0.314)\end{array}$ & $\begin{array}{l}-0.158 \\
(0.103)\end{array}$ \\
\hline Newcomer MP & $\begin{array}{l}-0.168 \\
(0.296)\end{array}$ & $\begin{array}{l}-0.263 * \\
(0.127)\end{array}$ \\
\hline $\begin{array}{l}\text { Children, Schools and Families } \\
\text { Committee }\end{array}$ & $\begin{array}{l}-0.899 \\
(0.868)\end{array}$ & $\begin{array}{l}-0.116 \\
(0.183)\end{array}$ \\
\hline Conservative Party & $\begin{array}{l}-1.964 \\
(1.126)\end{array}$ & $\begin{array}{l}-0.388 \\
(0.205)\end{array}$ \\
\hline Labour Party & $\begin{array}{l}-2.048 \\
(1.549)\end{array}$ & $\begin{array}{l}-0.343 \\
(0.497)\end{array}$ \\
\hline Liberal Democrats & $\begin{array}{l}1.503 \\
(1.239)\end{array}$ & $\begin{array}{l}-0.310 * \\
(0.139)\end{array}$ \\
\hline Share of women in PPG & $\begin{array}{l}2.608 \\
(7.695)\end{array}$ & $\begin{array}{l}-0.421 \\
(3.571)\end{array}$ \\
\hline Polling results (national) & $\begin{array}{l}-0.642 \\
(2.593)\end{array}$ & $\begin{array}{l}3.145 * * \\
(1.019)\end{array}$ \\
\hline Time trend & $\checkmark$ & $\checkmark$ \\
\hline Constant & $\begin{array}{l}226.127 * \\
(106.725)\end{array}$ & $\begin{array}{l}-51.887 \\
(49.652)\end{array}$ \\
\hline $\mathrm{N}$ & 499 & 206 \\
\hline Log-Pseudolikelihood & -266.94 & 388.73 \\
\hline $\mathrm{Chi}^{2}$ & $81.21 * * * *$ & $42.16 * * * *$ \\
\hline
\end{tabular}

Notes: Hurdle Regression Model. DV Logit Reg.: Dummy variable coded 1 if share of proposed or signed women's EDMs > 0. DV Beta Reg.: Share of signed or proposed women's EDMs. Coefficients: Log-Odds. Standard errors (in parentheses) are clustered by MP. Reference category for parties: Other. Significance Levels: * $\mathrm{p}<.05 ; * * \mathrm{p}<.01 ; * * * \mathrm{p}<.001$. 
Female MPs, on the other hand, engage in women's substantive representation irrespective of their electoral vulnerability. ${ }^{16}$

\section{Conclusion}

When do male MPs represent women's issues in parliament? This article tries to develop an understanding for male MPs' role in the substantive representation of women and presents the first empirical test of the extent to which electoral vulnerability affects the likelihood of male MPs articulating women's interests. The analysis of male MPs' behavior in terms of signing and proposing of women-specific EDMs in the House of Commons prior to the 2001, 2005, 2010, and 2010 elections, supports the hypothesis of a gendered leeway and shows that men are more likely to engage in women's substantive representation if their re-election security is low. No such effect was found for female MPs and it is therefore interpreted as a rational strategy used by male politicians to cater to female voters in order to win additional votes from the women in their constituencies. More generally, this study provides evidence that male MPs do represent women's interests in parliament. However, one of the key drivers of this behavior is a rational calculation of how they can enhance their Election Day prospects, rather than an intrinsic motivation to stand up for women's rights and gender equality. Moreover, we observed qualitative differences in the representation of women's interests by male and female MPs. Whereas women in the House of Commons are more likely to introduce their own EDMs on a women's issue, men engage instead in low-cost activities and merely sign women's EDMs, rather than writing their own motions.

16 As a further robustness check, we tested for potential interaction effects of electoral vulnerability and district characteristics, assuming that the representation of women's interests is more beneficial for male MPs running in ideologically progressive districts or against a female challenger. None of the interaction effects has a statistically significant effect. The results can be found in Appendix A4.

Additionally, all women-specific EDMs were hand-coded for direction and classified according to whether they were feminist, anti-feminist or neutral. Following the example of Childs and Withey (2004) and Reingold (2000), EDMs were coded as feminist if their aim was an expansion of women's opportunities or a mitigation of inequalities between men and women. If MPs stressed traditional gender roles or asked the government to restrict equal rights for women, those EDMs are coded as anti-feminist. Issues that could not be clearly identified as being either feminist or anti-feminist were coded as neutral. Due to the small number of anti-feminist EDMs the results do not change if we only analyze feminist or neutral EDMs. 
By broadening the understanding of potential actors and their incentives for participating in the parliamentary representation of women's interests, these findings not only contribute to the literature on women's representation, but also add to a more general discussion about the interactions between descriptive and substantive representation, and how a specific group's identity shapes the role that non-group members can play in its substantive representation. More than 200 years ago, Edmund Burke argued for the benefits of a 'virtual representation' of interests and famously stated that it was not necessary for the people of Birmingham to send a representative to parliament, because their feelings are already represented by the representative elected in Bristol (Pitkin 1967: 168ff.).

However, the current results are rather pessimistic regarding a potential virtual representation of women's interests by men. Given that male MPs are mainly extrinsically motivated and only speak on behalf of women in order to win elections, their representation of women's interests is rather second-class. In accordance with the idea of an external mandate (Bergqvist, Bjarnegård and Zetterberg 2018), the term women's interests implies that these interests are attached to women's identity and experiences, and suggests that female MPs are the key actors responsible for the promotion of these issues in parliament.

The likelihood of male MPs' successful engagement in women's substantive representation also hinges on the potential linkages between descriptive, substantive, and symbolic representation. According to Pitkin (1967), symbolic representation concerns people's affective beliefs about whether they feel represented by their political representatives. This goes beyond merely analyzing the extent of male MP's engagement in women's substantive representation, and raises the questions of whether women in the population feel that they are represented if men speak on their behalf or whether they believe that their views and interests are more thoroughly represented by female MPs (English, Pearson and Strolovitch 2019). This question should be elaborated in more detail in further studies.

In connection to the general debate about non-group members' role in substantive representation, future research should also analyze whether vulnerable male MPs only attempt to win women's votes, or whether they also try to cater to other underrepresented social groups. For example, non-minority MPs could start to articulate 
issues relevant to ethnic minorities (e.g. immigration policy), in order to enhance their share of votes from minority constituents in their districts.

Lastly, analyzing the effect of electoral vulnerability from an intra-party perspective, with a focus on the candidate selection process, would also be fruitful. In the light of the more widespread use of measures to promote the recruitment of female candidates in British parties (e.g. all-women shortlists; Campbell and Childs 2010), male MPs might represent women's issues not only to increase their re-election chances, but also to send signals to the party selection committee to secure their re-selection for the upcoming election (c.f. Meserve, Pemstein and Bernhard 2020). Male incumbents might be more likely to diversify their issue agenda, including the representation of women, if they are confronted with a promising female contender from within their own party.

An all-encompassing analysis of the conditions and incentives that make male MPs more likely to advocate in favor of women's interests, would therefore be an important step toward a better understanding of the multiple ways in which women can be represented in the legislative arena. 


\section{References}

Bailer, Stefanie, and Tamaki Ohmura. 2018. "Exploring, Maintaining, and Disengaging The Three Phases of a Legislator's Life.” Legislative Studies Quarterly 43 (3): 493-520.

Bailey, Daniel, and Guy P. Nason. 2008. "Cohesion of Major Political Parties.” British Politics 3 (3): 390-417.

Baumann, Marcus, Marc Debus, and Martin Gross. 2019. "Strategic Issue Emphasis in Parties' Election Campaign Statements." Party Politics. OnlineFirst. https://doi.org/10.1177/1354068819864091.

Beckwith, Karen. 2011. “Interests, Issues, and Preferences: Women's Interests and Epiphenomena of Activism.” Politics Q Gender 7 (3): 424-29.

Bergqvist, Christina, Elin Bjarnegård, and Per Zetterberg. 2018. “The Gendered Leeway: Male Privilege, Internal and External Mandates, and Gender-Equality Policy Change.” Politics, Groups, and Identities 6 (4): 576-92.

Bjarnegård, Elin. 2013. Gender, Informal Institutions and Political Recruitment: Explaining Male Dominance in Parliamentary Representation. Basingstoke: Palgrave.

Bjarnegård, Elin, and Rainbow Murray. 2018. "Revisiting Forms of Representation by Critically Examining Men.” Politics a Gender 14 (2): 265-70.

Blais, André, and Ignacio Lago. 2009. “A General Measure of District Competitiveness.” Electoral Studies 28 (1): 94-100.

Campbell, Rosie, and Sarah Childs. 2010. “'Wags', 'Wives' and 'Mothers'... But What About Women Politicians?” Parliamentary Affairs 63 (4): 760-77.

Campbell, Rosie, and Sarah Childs. 2015. "All Aboard the Pink Battle Bus? Women Voters, Women's Issues, Candidates and Party Leaders." Parliamentary Affairs 68 (1): 206-23.

Carey, John M., and Matthew S. Shugart. 1995. “Incentives to Cultivate a Personal Vote: A Rank Ordering of Electoral Formulas.” Electoral Studies 14 (4): 417-39.

Carroll, Susan. 1994. Women as Candidates in American Politics. Bloomington: Indiana University Press. 
Catalano Weeks, Ana. 2018. "Why Are Gender Quota Laws Adopted by Men? The Role of Inter- and Intraparty Competition." Comparative Political Studies 51 (14): 1935-73.

Celis, Karen. 2008. “Studying Women's Substantive Representation in Legislatures: When Representative Acts, Contexts and Women's Interests Become Important." Representation 44 (2): 111-23.

Celis, Karen, and Silvia Erzeel. 2015. "Beyond the Usual Suspects: Non-Left, Male and Non-Feminist MPs and the Substantive Representation of Women." Government and Opposition 50 (1): 45-64.

Chappell, Louise, and Georgina Waylen. 2013. "Gender and the Hidden Life of Institutions." Public Administration 91 (3): 599-615.

Childs, Sarah. 2002. “Hitting the Target: Are Labour Women MPs 'Acting for' Women?” Parliamentary Affairs 55 (1): 143-53.

Childs, Sarah, and Mona L. Krook. 2008. “Critical Mass Theory and Women's Political Representation.” Political Studies 56 (3): 725-36.

Childs, Sarah, and Mona L. Krook. 2009. “Analysing Women's Substantive Representation: From Critical Mass to Critical Actors." Government and Opposition 44 (2): $125-45$.

Childs, Sarah, and Julie Withey. 2004. "Women Representatives Acting for Women: Sex and the Signing of Early Day Motions in the 1997 British Parliament.” Political Studies 52 (3): 552-64.

Childs, Sarah, and Julie Withey. 2006. “The Substantive Representation of Women: The Case of the Reduction of VAT on Sanitary Products." Parliamentary Affairs 59 (1): 1023.

Coffé, Hilde, Reiser, Marion. 2018. “Political Candidates' Attitudes Towards Group Representation." Journal of Legislative Studies 24 (3): 272-97.

Cook, Douglas O., Robert Kieschnick, and B. D. McCullough. 2008. "Regression Analysis of Proportions in Finance with Self Selection.” Journal of Empirical Finance 15 (5): 86067. 
English, Ashley, Kathryn Pearson, and Dara Z. Strolovitch. 2019. "Who Represents Me? Race, Gender, Partisan Congruence, and Representational Alternatives in a Polarized America." Political Research Quarterly 72 (4): 785-804.

Evans, Elisabeth. 2012. "From Finance to Equality: The Substantive Representation of Women's Interests by Men and Women MPs in the House of Commons." Representation 48 (2): 183-96.

Finer, Samuel E., Hugh B. Berrington, and D. J. Bartholomew. 1961. Backbench Opinion in the House of Commons, 1955-59. Oxford: Pergamon Press.

Franklin, Mark N., and Michael Tappin. 1977. "Early Day Motions as Unobtrusive Measures of Backbench Opinion in Britain.” British Journal of Political Science 7 (1): 49-69.

Geese, Lucas, C. Janssen, C. Sanhueza Petrarca, and Diana Schacht. forthcoming. "The Descriptive Representation of Citizens of Immigrant-Origin in Majoritarian and Proportional Representation Electoral Systems." In Understanding the Patterns of Political Representation of Citizens of Immigrant Origin in Europe, eds. Laura Morales, Thomas Saalfeld and Maria Sobolewska. Oxford: Oxford University Press.

Höhmann, Daniel. 2019. “When do Female MPs Represent Women's Interests? Electoral Systems and the Legislative Behavior of Women." Political Research Quarterly: OnlineFirst. https://doi.org/10.1177/1065912919859437.

Höhmann, Daniel. 2020. “When Do Men Represent Women's Interests in Parliament? How the Presence of Women in Parliament Affects the Behavior of Male Politicians." Swiss Political Science Review 26 (1): 31-50.

House of Commons Information Office. 2010. "Factsheet P3 (Procedure Series) - Early Day Motions." https://www.parliament.uk/about/how/guides/factsheets/procedure/p03/ (June 8, 2019).

Jones, Peter, ed. 1995. Party, Parliament and Personality: Essays Presented to Hugh Berrington. London: Routledge. 
Kathlene, Lyn. 1994. "Power and Influence in State Legislative Policymaking: The Interaction of Gender and Position in Committee Hearing Debates." American Political Science Review 88 (3): 560-76.

Keele, Luke, Randolph T. Stevenson, and Felix Elwert. 2020. “The Causal Interpretation of Estimated Associations in Regression Models." Political Science Research and Methods 8 (1): 1-13.

Kellermann, Michael. 2012. "Estimating Ideal Points in the British House of Commons Using Early Day Motions." American Journal of Political Science 56 (3): 757-71.

Kellermann, Michael. 2013. "Sponsoring Early Day Motions in the British House of Commons as a Response to Electoral Vulnerability." Political Science Research and Methods 1 (2): 263-80.

Kokkonen, Andrej., and Lena Wängnerud. 2017. “Women's Presence in Politics and Male Politicians Commitment to Gender Equality in Politics: Evidence from 290 Swedish Local Councils.” Journal of Women, Politics \& Policy 38 (2): 199-220.

Krook, Mona L., and Fiona Mackay, eds. 2011. Gender, Politics and Institutions: Towards a Feminists Institutionalism. Basingstoke: Palgrave.

Mansbridge, Jane. 1999. "Should Blacks Represent Blacks and Women Represent Women? A Contingent “Yes".” The Journal of Politics 61 (3): 628-57.

Mansbridge, Jane. 2003. "Rethinking Representation.” American Political Science Review 97 (4): 515-28.

McConnaughy, Corinne M. 2013. The Woman Suffrage Movement in America. New York: Cambridge University Press.

McLean, Ian. 1995. "Backbench Opinion Revisited." In Party, Parliament and Personality: Essays Presented to Hugh Berrington, ed. Peter Jones. London: Routledge, 120-40.

Meserve, Stephan A., Daniel Pemstein, and William T. Bernhard. 2020. "Gender, Incumbency and Party List Nominations." British Journal of Political Science 50 (1): 115. 
Morales, Laura, Thomas Saalfeld, and Maria Sobolewska, eds. forthcoming. Understanding the Patterns of Political Representation of Citizens of Immigrant Origin in Europe. Oxford: Oxford University Press.

Müller, Wolfgang C., and Kaare Strøm. 1999. Policy, Office, or Votes? How Political Parties in Western Europe Make Hard Decisions. Cambridge: Cambridge University Press.

Murray, Rainbow. 2008. "Is the Mere Presence of a Strong Female Candidate Enough to Increase the Substantive Representation of Women?” Parliamentary Affairs 61 (3): 476-89.

Murray, Rainbow. 2014. "Quotas for Men: Reframing Gender Quotas as a Means of Improving Representation for All.” American Political Science Review 108 (3): 520-32.

Murray, Rainbow, Mona L. Krook, and Katherine Oppelo. 2012. "Why Are Gender Quotas Adopted? Party Pragmatism and Parity in France.” Political Research Quarterly 65 (3): 529-43.

Nugent, Mary. 2019. "When Does He Speak for She? Men Representing Women in Parliament.” Dissertation. Rutgers University.

Olofsdotter Stensota, Helena. 2020. "Does Care Experience Affect Policy Interests? Male Legislators, Parental Leave, and Political Priorities in Sweden.” Politics \& Gender 16 (1): 123-144.

Parker, David. 2019. "Looking after Constituency Interests: The Utilisation of MP Expenses and Early Day Motions to Craft Constituency Service Home Styles." Parliamentary Affairs. OnlineFirst. https://doi.org/10.1093/pa/gsz042.

Phillips, Anne. 1995. The Politics of Presence. Oxford: Clarendon Press.

Pitkin, Hanna F. 1967. The Concept of Representation. Berkeley: University of California Press.

Reingold, Beth. 2000. Representing Women: Sex, Gender, and Legislative Behavior in Arizona and California. Chapel Hill: University of North Carolina Press.

Smithson, Michael, and Jay Verkuilen. 2006. "A Better Lemon Squeezer? MaximumLikelihood Regression With Beta-Distributed Dependent Variables." Psychological Methods 11 (1): 54-71. 
Staehr Harder, Mette M. 2019. "Pitkin's Second Way: Freeing Representation Theory from Identity." Representation. OnlineFirst. https://doi.org/10.1080/00344893.2019.1636853.

Teele, Dawn L. 2018. "How the West Was Won: Competition, Mobilization, and Women's Enfranchisement in the United States." Journal of Politics 80 (2): 442-61.

Valdini, Melody E. 2019. The Inclusion Calculation: Why Men Appropriate Women's Representation. Oxford: Oxford University Press.

Wängnerud, Lena. 2009. "Women in Parliaments: Descriptive and Substantive Representation." Annual Review of Political Science 12 (1): 51-69. 


\title{
Research Article
}

Male MPs, Electoral Vulnerability, and the Substantive Representation of Women's Interests

\author{
Daniel Höhmann \\ Mary Nugent \\ (University of Bamberg) \\ (Rutgers University)
}

Appendix 


\section{Appendix A1: Descriptive statistics}

Table A1. Descriptive Statistics

\begin{tabular}{|c|c|c|c|c|c|c|c|c|c|c|}
\hline \multicolumn{6}{|c|}{ Full Data Set } & \multicolumn{5}{|c|}{ Male MPs only } \\
\hline Variables & $\mathrm{N}$ & Mean & $\begin{array}{l}\text { Stand. } \\
\text { Dev. }\end{array}$ & Min & Max & $\mathrm{N}$ & Mean & $\begin{array}{l}\text { Stand. } \\
\text { Dev. }\end{array}$ & Min & Max \\
\hline Share women-specific EDMs & 2618 & 0.02 & 0.04 & 0 & 1 & 2105 & 0.02 & 0.03 & 0 & 0.67 \\
\hline Electoral vulnerability & 2665 & 78.62 & 14.36 & 25.64 & 99.99 & 2146 & 78.18 & 14.52 & 25.64 & 99.99 \\
\hline Population density (district) & 2667 & 18.76 & 23.02 & 0.05 & 146.4 & 2147 & 17.21 & 21.24 & 0.05 & 140.3 \\
\hline $\begin{array}{l}\text { Education (\% level } 4 \text { or } \\
\text { above) }\end{array}$ & 2667 & 21.05 & 8.61 & 7.3 & 57.4 & 2147 & 20.69 & 8.32 & 7.3 & 56.5 \\
\hline Female Challenger & 2600 & 0.25 & 0.43 & 0 & 1 & 2092 & 0.24 & 0.43 & 0 & 1 \\
\hline Government minister & 2667 & 0.06 & 0.24 & 0 & 1 & 2147 & 0.06 & 0.24 & 0 & 1 \\
\hline Frontbench MP & 2667 & 0.39 & 0.49 & 0 & 1 & 2147 & 0.39 & 0.49 & 0 & 1 \\
\hline Age & 2666 & 50.08 & 9.49 & 23 & 84 & 2147 & 50.43 & 9.53 & 25 & 84 \\
\hline Newcomer MP & 2667 & 0.28 & 0.45 & 0 & 1 & 2147 & 0.26 & 0.44 & 0 & 1 \\
\hline Last Term & 2600 & 0.17 & 0.38 & 0 & 1 & 2092 & 0.18 & 0.38 & 0 & 1 \\
\hline Member family committee & 2667 & 0.01 & 0.09 & 0 & 1 & 2147 & 0.01 & 0.07 & 0 & 1 \\
\hline Conservative Party & 2667 & 0.32 & 0.47 & 0 & 1 & 2147 & 0.35 & 0.48 & 0 & 1 \\
\hline Labour Party & 2667 & 0.55 & 0.50 & 0 & 1 & 2147 & 0.51 & 0.50 & 0 & 1 \\
\hline Liberal Democrats & 2667 & 0.08 & 0.28 & 0 & 1 & 2147 & 0.09 & 0.29 & 0 & 1 \\
\hline Share of women in PPG & 2667 & 0.20 & 0.08 & 0.06 & 0.32 & 2147 & 0.19 & 0.08 & 0.06 & 0.32 \\
\hline Polling Data & 2667 & 0.33 & 0.09 & 0.06 & 0.44 & 2147 & 0.33 & 0.09 & 0.06 & 0.44 \\
\hline
\end{tabular}

Note: Data for the parliamentary sessions prior to elections in 2001, 2005, 2010, and 2015. 
This appendix shows the distribution of electoral vulnerability of male MPs between 2001 and 2015.

Figure A2 Histogram of Electoral Vulnerability of male MPs, N=2146

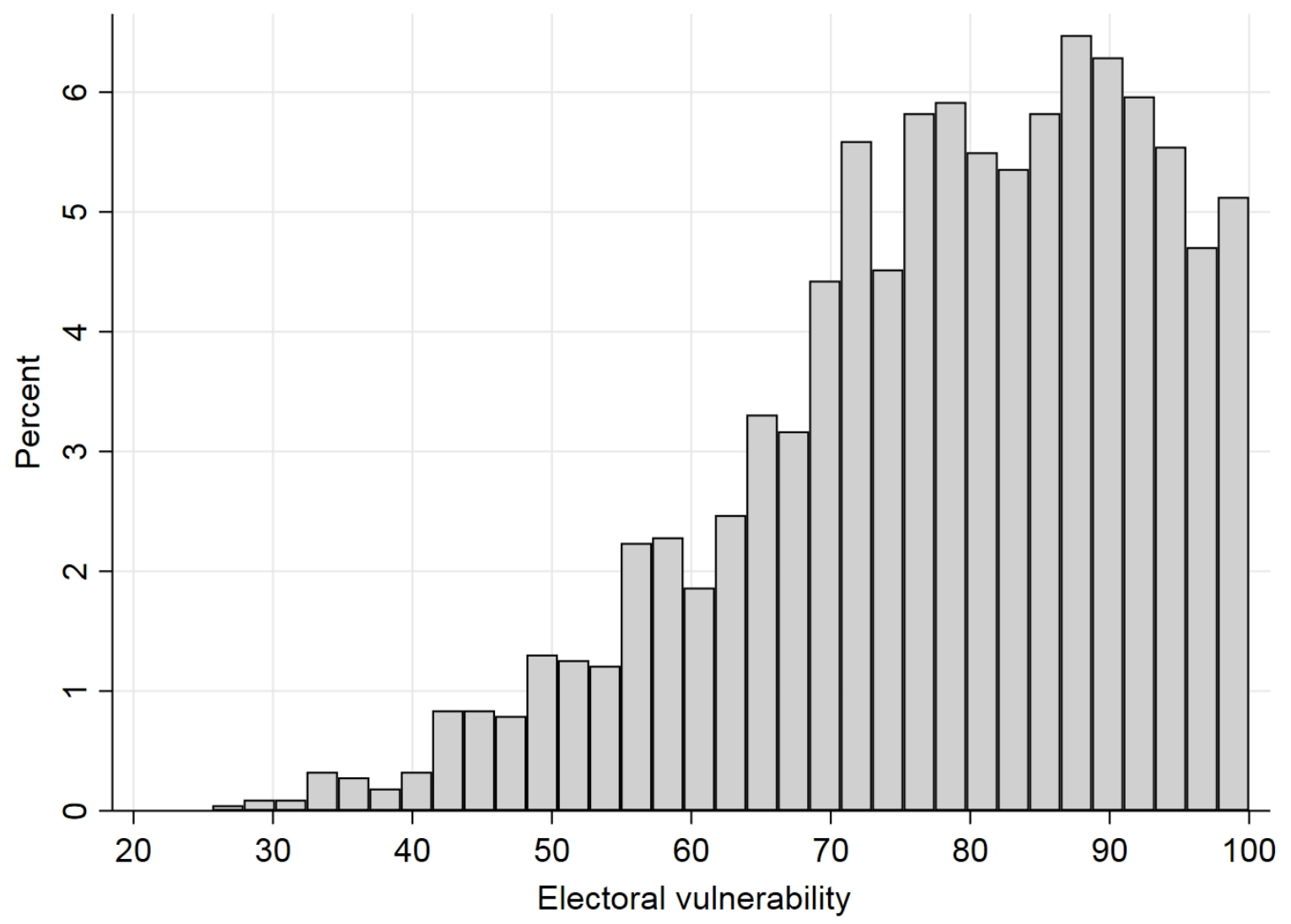




\section{Appendix A3: Separate analyses of signed and proposed women's EDMs}

Appendices A3 and A4 re-estimate the main model of the paper, but use the share of singed women's EDMs and proposed women's EDMs, respectively as the dependent variable. If male MPs primarily represent women's issues to enhance their electoral prospects, they should mainly engage in low-cost activities that are not very time- and labor-intensive. This provides them with the opportunity to present themselves as active advocates for the interests of their female voters, however, they are not willing to make a more credible commitment and to invest a significant amount of time and labor into proposing their own women's EDMs. Accordingly, electoral vulnerability should primarily affect the signing behavior of male MPs, making them more likely to support women-specific EDMs proposed by one of their colleagues. The effect on the introduction of their own motions (which is much more time-consuming than just signing an EDM) should be less pronounced.

The results below confirm this expectation. We find no significant effect of electoral vulnerability on the likelihood to propose women-specific EDMs. In contrast, the effect on the signing behavior of male MPs is statistically significant. 
Table A3a. The effect of electoral vulnerability on the substantive representation of women by male MPs. Signing women's EDMs, 2001-2015.

\begin{tabular}{|c|c|c|}
\hline & $\begin{array}{l}\text { General decision (Logit } \\
\text { Reg.) }\end{array}$ & $\begin{array}{l}\text { Intensity of substantive } \\
\text { representation (Beta Reg.) }\end{array}$ \\
\hline Electoral vulnerability & $\begin{array}{l}0.013 * \cdots \\
(0.004)\end{array}$ & $\begin{array}{l}-0.000 \\
(0.002)\end{array}$ \\
\hline Population density (in district) & $\begin{array}{l}0.003 \\
(0.004)\end{array}$ & $\begin{array}{l}-0.002 \\
(0.001)\end{array}$ \\
\hline Higher Education (share in district) & $\begin{array}{l}-0.001 \\
(0.009)\end{array}$ & $\begin{array}{l}0.012 * \cdots * * \\
(0.003)\end{array}$ \\
\hline Female challenger & $\begin{array}{l}-0.024 \\
(0.122)\end{array}$ & $\begin{array}{l}0.016 \\
(0.052)\end{array}$ \\
\hline Government Minister & $\begin{array}{l}-2.165 * \cdots * * \\
(0.409)\end{array}$ & $\begin{array}{l}0.221 \\
(0.151)\end{array}$ \\
\hline Frontbench MP & $\begin{array}{l}-0.732 * * * \\
(0.138)\end{array}$ & $\begin{array}{l}0.018 \\
(0.059)\end{array}$ \\
\hline Age & $\begin{array}{l}0.038 \text { *⿰冫欠 } \\
(0.008)\end{array}$ & $\begin{array}{l}0.000 \\
(0.003)\end{array}$ \\
\hline Newcomer MP & $\begin{array}{l}0.059 \\
(0.149)\end{array}$ & $\begin{array}{l}0.020 \\
(0.052)\end{array}$ \\
\hline Last term & $\begin{array}{l}-0.331^{*} \\
(0.151)\end{array}$ & $\begin{array}{l}-0.069 \\
(0.052)\end{array}$ \\
\hline Children, Schools and Families Committee & $\begin{array}{l}1.599 * * * \\
(0.619)\end{array}$ & $\begin{array}{l}-0.281 \\
(0.251)\end{array}$ \\
\hline Conservative Party & $\begin{array}{l}-1.668 * \cdots * \\
(0.436)\end{array}$ & $\begin{array}{l}0.068 \\
(0.104)\end{array}$ \\
\hline Labour Party & $\begin{array}{l}-0.343 \\
(0.630)\end{array}$ & $\begin{array}{l}0.003 \\
(0.193)\end{array}$ \\
\hline Liberal Democrats & $\begin{array}{l}0.138 \\
(0.415)\end{array}$ & $\begin{array}{l}-0.168 * \\
(0.081)\end{array}$ \\
\hline Share of women in PPG & $\begin{array}{l}0.480 \\
(2.645)\end{array}$ & $\begin{array}{l}-1.003 \\
(1.236)\end{array}$ \\
\hline Polling results (national) & $\begin{array}{l}-3.779 * * * * \\
(1.129)\end{array}$ & $\begin{array}{l}0.943 * \\
(0.434)\end{array}$ \\
\hline Time trend & $\checkmark$ & $\checkmark$ \\
\hline Constant & $\begin{array}{l}116.468 * \cdots * \\
(34.824)\end{array}$ & $\begin{array}{l}-66.368 * \cdots \cdots \\
(19.986)\end{array}$ \\
\hline $\mathrm{N}$ & 2046 & 790 \\
\hline Log-Pseudolikelihood & -1131.022 & 1868.714 \\
\hline Chi $^{2}$ & $467.24 * * * *$ & $76.89 * * * *$ \\
\hline
\end{tabular}

Notes: Hurdle Regression Model. DV Logit Reg.: Dummy variable coded 1 if share of signed women's EDMs > 0. DV Beta Reg.: Share of signed women's EDMs. Coefficients: Log-Odds. Standard errors (in parentheses) are clustered by MP. Reference category for parties: Other. Significance Levels: * p<.05; *** $\mathrm{p}<.01 ; * * * \mathrm{p}<.001$. 
Table A3b. The effect of electoral vulnerability on the substantive representation of women by male MPs. Proposing women's EDMs, 2001-2015.

\begin{tabular}{|c|c|c|}
\hline Variables & General decision (Logit Reg.) & $\begin{array}{l}\text { Intensity of substantive } \\
\text { representation (Beta Reg.) }\end{array}$ \\
\hline Electoral vulnerability & $\begin{array}{l}0.006 \\
(0.012)\end{array}$ & $\begin{array}{l}0.007 \\
(0.012)\end{array}$ \\
\hline Population density (in district) & $\begin{array}{l}0.006 \\
(0.008)\end{array}$ & $\begin{array}{l}-0.009 * \\
(0.004)\end{array}$ \\
\hline Higher Education (share in district) & $\begin{array}{l}0.013 \\
(0.020)\end{array}$ & $\begin{array}{l}0.010 \\
(0.017)\end{array}$ \\
\hline Female challenger & $\begin{array}{l}0.332 \\
(0.335)\end{array}$ & $\begin{array}{l}0.103 \\
(0.326)\end{array}$ \\
\hline Government Minister & $\begin{array}{l}-0.523 \\
(1.125)\end{array}$ & $\begin{array}{l}1.124 * * * \\
(0.357)\end{array}$ \\
\hline Frontbench MP & $\begin{array}{l}-1.156 * * \\
(0.381)\end{array}$ & $\begin{array}{l}-0.096 \\
(0.385)\end{array}$ \\
\hline Age & $\begin{array}{l}0.010 \\
(0.015)\end{array}$ & $\begin{array}{l}-0.020 \\
(0.026)\end{array}$ \\
\hline Newcomer MP & $\begin{array}{l}-0.067 \\
(0.406)\end{array}$ & $\begin{array}{l}0.746 \\
(0.418)\end{array}$ \\
\hline Last term & $\begin{array}{l}-1.293 * \\
(0.596)\end{array}$ & $\begin{array}{l}0.708^{*} \\
(0.359)\end{array}$ \\
\hline Conservative Party & $\begin{array}{l}-1.647 \\
(1.261)\end{array}$ & $\begin{array}{l}1.430 \\
(0.730)\end{array}$ \\
\hline Labour Party & $\begin{array}{l}-0.512 \\
(1.395)\end{array}$ & $\begin{array}{l}1.484 \\
(1.415)\end{array}$ \\
\hline Liberal Democrats & $\begin{array}{l}0.390 \\
(0.719)\end{array}$ & $\begin{array}{l}1.041 * * \\
(0.404)\end{array}$ \\
\hline Share of women in PPG & $\begin{array}{l}0.116 \\
(7.462)\end{array}$ & $\begin{array}{l}0.784 \\
(9.663)\end{array}$ \\
\hline Polling results (national) & $\begin{array}{l}-1.129 \\
(3.656)\end{array}$ & $\begin{array}{l}-0.343 \\
(3.077)\end{array}$ \\
\hline Time trend & $\checkmark$ & $\checkmark$ \\
\hline Constant & $\begin{array}{l}-21.322 \\
(109.025)\end{array}$ & $\begin{array}{l}47.781 \\
(169.845)\end{array}$ \\
\hline $\mathrm{N}$ & 2039 & 41 \\
\hline Log-Pseudolikelihood & -200.40 & 40.46 \\
\hline $\mathrm{Chi}^{2}$ & $38.99 * * * *$ & $28.80 *$ \\
\hline
\end{tabular}

Notes: Hurdle Regression Model. DV Model 1: Dummy variable coded 1 if share of proposed women's EDMs > 0. DV Model 2: Share of proposed women's EDMs. Coefficients: Log-Odds. Standard errors (in parentheses) are clustered by MP. Reference category for parties: Other. Significance Levels: * $\mathrm{p}<.05 ; * * *$ $\mathrm{p}<.01$. 


\section{Appendix A4: Interaction effect of electoral vulnerability and district characteristics}

The models in Appendix A4 include additional interaction effects to test whether the influence of electoral vulnerability depends on the structural and political characteristics of the electoral district. We theoretically assume that districts with a more progressive population provide higher incentives for male MPs to play the "women card" in order to win additional votes. To measure the progressiveness of districts, we use two different proxies. First, we include the population density (number of inhabitants per hectare) to distinguish between rural and urban districts. As a second proxy, we use education and add the share of the population with higher education (Level 4 or above according to the Regulated Qualifications Framework). Additionally, presenting themselves as being responsive to female voters might be more important if incumbent male MPs are running against a female challenger in their electoral district (i.e. second best candidate in the district is a woman). Thus, male MPs should have stronger incentives to cater to female voters if they are electorally insecure and, at the same time, are running in a progressive district or against a female challenger, respectively.

The results in Table A4a provide evidence that the effect of electoral vulnerability does not depend on the presence of a female challenger in the district. The main effect for electoral vulnerability remains statistically significant and the effect size is essentially the same. The interaction effect between electoral vulnerability and the presence of a female challenger in the district, however, has no significant effect. The results in Table A4b and A4c show that neither the interaction of electoral vulnerability and population density nor the interaction between vulnerability and the share of people with higher education reach conventional levels of statistical significance. Thus, marginal male MPs try to cater to female voters to win additional votes irrespective of the structural and political characteristics of the district. 
Table A4a. The effect of electoral vulnerability and a female challenger on the substantive representation of women by male MPs. Proposing or signing women's EDMs, 2001-2015.

\begin{tabular}{|c|c|c|}
\hline Variables & General decision (Logit Reg.) & $\begin{array}{l}\text { Intensity of substantive } \\
\text { representation (Beta Reg.) }\end{array}$ \\
\hline Electoral vulnerability & $\begin{array}{l}0.013 * * ; \\
(0.005)\end{array}$ & $\begin{array}{l}-0.000 \\
(0.002)\end{array}$ \\
\hline Female challenger & $\begin{array}{l}0.129 \\
(0.647)\end{array}$ & $\begin{array}{l}0.192 \\
(0.209)\end{array}$ \\
\hline Female challenger * Electoral vulnerability & $\begin{array}{l}-0.002 \\
(0.008)\end{array}$ & $\begin{array}{l}-0.002 \\
(0.003)\end{array}$ \\
\hline Population density (in district) & $\begin{array}{l}0.003 \\
(0.003)\end{array}$ & $\begin{array}{l}-0.002 \\
(0.001)\end{array}$ \\
\hline Higher Education (share in district) & $\begin{array}{l}-0.001 \\
(0.009)\end{array}$ & $\begin{array}{l}0.013 * * * * \\
(0.003)\end{array}$ \\
\hline Government Minister & $\begin{array}{l}-2.058 * \cdots * K \\
(0.384)\end{array}$ & $\begin{array}{l}0.213 \\
(0.142)\end{array}$ \\
\hline Frontbench MP & 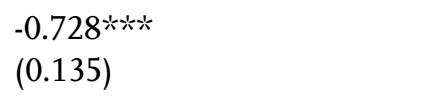 & $\begin{array}{l}0.025 \\
(0.058)\end{array}$ \\
\hline Age & $\begin{array}{l}0.039 * * * * \\
(0.008)\end{array}$ & $\begin{array}{l}0.001 \\
(0.003)\end{array}$ \\
\hline Newcomer MP & $\begin{array}{l}0.098 \\
(0.147)\end{array}$ & $\begin{array}{l}0.058 \\
(0.048)\end{array}$ \\
\hline Last term & $\begin{array}{l}-0.371 * \\
(0.151)\end{array}$ & $\begin{array}{l}-0.064 \\
(0.052)\end{array}$ \\
\hline Children, Schools and Families Committee & $\begin{array}{l}1.548^{*} \\
(0.622)\end{array}$ & $\begin{array}{l}-0.259 \\
(0.174)\end{array}$ \\
\hline Conservative Party & $\begin{array}{l}-1.546^{* \cdots \cdots * k} \\
(0.438)\end{array}$ & $\begin{array}{l}0.082 \\
(0.099)\end{array}$ \\
\hline Labour Party & $\begin{array}{l}-0.139 \\
(0.627)\end{array}$ & $\begin{array}{l}0.039 \\
(0.176)\end{array}$ \\
\hline Liberal Democrats & $\begin{array}{l}0.209 \\
(0.420)\end{array}$ & $\begin{array}{l}-0.177 * \\
(0.080)\end{array}$ \\
\hline Share of women in PPG & $\begin{array}{l}-0.187 \\
(2.607)\end{array}$ & $\begin{array}{l}-0.989 \\
(1.107)\end{array}$ \\
\hline Polling results (national) & $\begin{array}{l}-4.070 * * * * \\
(1.129)\end{array}$ & $\begin{array}{l}0.809 \\
(0.417)\end{array}$ \\
\hline Time trend & $\checkmark$ & $\checkmark$ \\
\hline Constant & $\begin{array}{l}107.044 * * \\
(34.324)\end{array}$ & $\begin{array}{l}-61.260 * * * * \\
(18.212)\end{array}$ \\
\hline $\mathrm{N}$ & 2046 & 805 \\
\hline Log-Pseudolikelihood & -1139.45 & 1959.04 \\
\hline $\mathrm{Chi}^{2}$ & 245.27 *炏 & $76.90 * * * *$ \\
\hline
\end{tabular}

Notes: Hurdle Regression Model. DV Logit Reg.: Dummy variable coded 1 if share of proposed or signed women's EDMs > 0. DV Beta Reg.: Share of signed or proposed women's EDMs. Coefficients: Log-Odds. Standard errors (in parentheses) are clustered by MP. Reference category for parties: Other. Significance Levels: * $\mathrm{p}<.05 ; * * \mathrm{p}<.01 ; * * * \mathrm{p}<.001$ 
Table A4b. The effect of electoral vulnerability and population density (in district) on the substantive representation of women by male MPs. Proposing or signing women's EDMs, 20012015.

\begin{tabular}{|c|c|c|}
\hline & General decision (Logit Reg.) & $\begin{array}{l}\text { Intensity of substantive } \\
\text { representation (Beta Reg.) }\end{array}$ \\
\hline Electoral vulnerability & $\begin{array}{l}0.009 \\
(0.006)\end{array}$ & $\begin{array}{l}-0.001 \\
(0.002)\end{array}$ \\
\hline Population density (in district) & $\begin{array}{l}-0.012 \\
(0.015)\end{array}$ & $\begin{array}{l}-0.002 \\
(0.004)\end{array}$ \\
\hline Electoral vulnerability * Population density & $\begin{array}{l}0.001 \\
(0.001)\end{array}$ & $\begin{array}{l}0.000 \\
(0.000)\end{array}$ \\
\hline Higher Education (share in district) & $\begin{array}{l}-0.001 \\
(0.009)\end{array}$ & $\begin{array}{l}0.013 * * * * \\
(0.003)\end{array}$ \\
\hline Female challenger & $\begin{array}{l}-0.013 \\
(0.121)\end{array}$ & $\begin{array}{l}0.003 \\
(0.047)\end{array}$ \\
\hline Government Minister & $\begin{array}{l}-2.060 * * * * \\
(0.385)\end{array}$ & $\begin{array}{l}0.223 \\
(0.141)\end{array}$ \\
\hline Frontbench MP & $\begin{array}{l}-0.724 * * * * \\
(0.136)\end{array}$ & $\begin{array}{l}0.026 \\
(0.058)\end{array}$ \\
\hline Age & $\begin{array}{l}0.039 * * * * \\
(0.008)\end{array}$ & $\begin{array}{l}0.001 \\
(0.003)\end{array}$ \\
\hline Newcomer MP & $\begin{array}{l}0.095 \\
(0.147)\end{array}$ & $\begin{array}{l}0.056 \\
(0.048)\end{array}$ \\
\hline Last term & $\begin{array}{l}-0.376 * \\
(0.152)\end{array}$ & $\begin{array}{l}-0.063 \\
(0.052)\end{array}$ \\
\hline Children, Schools and Families Committee & $\begin{array}{l}1.539 * \\
(0.607)\end{array}$ & $\begin{array}{l}-0.252 \\
(0.173)\end{array}$ \\
\hline Conservative Party & $\begin{array}{l}-1.548 * * * * \\
(0.441)\end{array}$ & $\begin{array}{l}0.081 \\
(0.100)\end{array}$ \\
\hline Labour Party & $\begin{array}{l}-0.140 \\
(0.628)\end{array}$ & $\begin{array}{l}0.039 \\
(0.177)\end{array}$ \\
\hline Liberal Democrats & $\begin{array}{l}0.204 \\
(0.422)\end{array}$ & $\begin{array}{l}-0.179 * \\
(0.080)\end{array}$ \\
\hline Share of women in PPG & $\begin{array}{l}-0.268 \\
(2.605)\end{array}$ & $\begin{array}{l}-0.987 \\
(1.114)\end{array}$ \\
\hline Polling results (national) & $\begin{array}{l}-4.039 * * * * \\
(1.130)\end{array}$ & $\begin{array}{l}0.807 \\
(0.419)\end{array}$ \\
\hline Time trend & $\checkmark$ & $\checkmark$ \\
\hline Constant & $\begin{array}{l}108.884 * * \\
(34.179)\end{array}$ & $\begin{array}{l}-60.446 * * * \\
(18.166)\end{array}$ \\
\hline $\mathrm{N}$ & 2046 & 805 \\
\hline Log-Pseudolikelihood & -1138.79 & 1958.80 \\
\hline $\mathrm{Chi}^{2}$ & $252.26 * * * *$ & $70.00 * * * *$ \\
\hline
\end{tabular}

Notes: Hurdle Regression Model. DV Logit Reg.: Dummy variable coded 1 if share of proposed or signed women's EDMs > 0. DV Beta Reg.: Share of signed or proposed women's EDMs. Coefficients: Log-Odds. Standard errors (in parentheses) are clustered by MP. Reference category for parties: Other. Significance Levels: * $\mathrm{p}<.05 ; * * \mathrm{p}<.01 ; * * * \mathrm{p}<.001$ 
Table A4c. The effect of electoral vulnerability and education level (in district) on the substantive representation of women by male MPs. Proposing or signing women's EDMs, 2001-2015.

\begin{tabular}{|c|c|c|}
\hline & General decision (Logit Reg.) & $\begin{array}{l}\text { Intensity of substantive } \\
\text { representation (Beta Reg.) }\end{array}$ \\
\hline Electoral vulnerability & $\begin{array}{l}0.001 \\
(0.010)\end{array}$ & $\begin{array}{l}-0.004 \\
(0.003)\end{array}$ \\
\hline Higher Education (share in district) & $\begin{array}{l}-0.056 \\
(0.041)\end{array}$ & $\begin{array}{l}-0.004 \\
(0.014)\end{array}$ \\
\hline Electoral vulnerability * Higher Education & $\begin{array}{l}0.001 \\
(0.000)\end{array}$ & $\begin{array}{l}0.000 \\
(0.000)\end{array}$ \\
\hline Population density (in district) & $\begin{array}{l}0.003 \\
(0.004)\end{array}$ & $\begin{array}{l}-0.002 \\
(0.001)\end{array}$ \\
\hline Female challenger & $\begin{array}{l}-0.018 \\
(0.121)\end{array}$ & $\begin{array}{l}-0.001 \\
(0.047)\end{array}$ \\
\hline Government Minister & $\begin{array}{l}-2.072 * * * \\
(0.383)\end{array}$ & $\begin{array}{l}0.218 \\
(0.138)\end{array}$ \\
\hline Frontbench MP & $\begin{array}{l}-0.723 * * * \\
(0.136)\end{array}$ & $\begin{array}{l}0.024 \\
(0.058)\end{array}$ \\
\hline Age & $\begin{array}{l}0.039 * * * * \\
(0.008)\end{array}$ & $\begin{array}{l}0.000 \\
(0.003)\end{array}$ \\
\hline Newcomer MP & $\begin{array}{l}0.074 \\
(0.148)\end{array}$ & $\begin{array}{l}0.049 \\
(0.047)\end{array}$ \\
\hline Last term & $\begin{array}{l}-0.369 * \\
(0.151)\end{array}$ & $\begin{array}{l}-0.063 \\
(0.052)\end{array}$ \\
\hline Children, Schools and Families Committee & $\begin{array}{l}1.547 * \\
(0.615)\end{array}$ & $\begin{array}{l}-0.265 \\
(0.177)\end{array}$ \\
\hline Conservative Party & $\begin{array}{l}-1.551 * * * * \\
(0.436)\end{array}$ & $\begin{array}{l}0.079 \\
(0.099)\end{array}$ \\
\hline Labour Party & $\begin{array}{l}-0.169 \\
(0.624)\end{array}$ & $\begin{array}{l}0.025 \\
(0.178)\end{array}$ \\
\hline Liberal Democrats & $\begin{array}{l}0.194 \\
(0.418)\end{array}$ & $\begin{array}{l}-0.182 * \\
(0.080)\end{array}$ \\
\hline Share of women in PPG & $\begin{array}{l}-0.174 \\
(2.612)\end{array}$ & $\begin{array}{l}-0.973 \\
(1.110)\end{array}$ \\
\hline Polling results (national) & 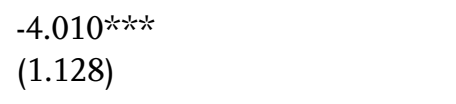 & $\begin{array}{l}0.836^{*} \\
(0.417)\end{array}$ \\
\hline Time trend & $\checkmark$ & $\checkmark$ \\
\hline Constant & $\begin{array}{l}108.865 * * \\
(34.377)\end{array}$ & $\begin{array}{l}-60.141 * * * \text { } \\
(18.203)\end{array}$ \\
\hline $\mathrm{N}$ & 2046 & 805 \\
\hline Log-Pseudolikelihood & -1138.26 & 1959.423 \\
\hline $\mathrm{Chi}^{2}$ & $466.20 * * * *$ & $77.84 * * * *$ \\
\hline
\end{tabular}

Notes: Hurdle Regression Model. DV Logit Reg.: Dummy variable coded 1 if share of proposed or signed women's EDMs > 0. DV Beta Reg.: Share of signed or proposed women's EDMs. Coefficients: Log-Odds. Standard errors (in parentheses) are clustered by MP. Reference category for parties: Other. Significance Levels: * $\mathrm{p}<.05 ; * * \mathrm{p}<.01 ; * * * \mathrm{p}<.001$ 